Modificações e Alternativas aos Testes de Levene e Brown e Forsythe para Igualdade de Variâncias e Médias

Antonia Erilânia de Almeida

DISSERTAÇÃO APRESENTADA

$\mathrm{AO}$

INSTITUTO DE MATEMÁTICA E ESTATÍSTICA

DA

UNIVERSIDADE DE SÃO PAULO

PARA

OBTENÇÃO DO GRAU

$\mathrm{DE}$

MESTRE EM CIÊNCIAS

Área de Concentração: ESTATÍSTICA

Orientadora: Profa. Dra. Silvia Nagib Elian

- São Paulo, agosto de 2006 - 


\title{
Modificações e Alternativas aos \\ Testes de Levene e Brown e Forsythe \\ para Igualdade de Variâncias e Médias
}

\author{
Este exemplar corresponde à redação \\ final da dissertação devidamente corrigida \\ e apresentada por Antonia Erilânia de Almeida \\ e aprovada pela comissão julgadora.
}

São Paulo, 30 de agosto de 2006.

Banca Examinadora:

- Profa. Dra. Silvia Nagib Elian (Presidente)

IME - USP

- Prof. Dr. Heleno Bolfarine

IME - USP

- Prof. Dr. Josemar Rodrigues

UFSCar 
À minha mãe, Maria Vieira (in memorian), às minhas irmãs, Erolândia e Érika, ao meu querido Ney e aos meus amigos. 


\section{Agradecimentos}

À minha inesquecível mãe (in memorian), que me deu a vida, moldou meu caráter, me apoiou com muito amor em todos os momentos e sempre lutou para que o melhor fosse feito.

À minha orientadora Prof ${ }^{\mathrm{a}}$. Dr ${ }^{\mathrm{a}}$. Silvia Nagib Elian, pela dedicada orientação, amizade, compreensão e paciência, sempre. À você meu muito obrigada e meu eterno carinho.

Às minhas irmãs, pelo amor, compreensão, incentivo e amizade.

Ao meu noivo Ney Robson, amigo e companheiro, pelo amor, carinho, compreensão e apoio nos momentos mais difíceis.

À família do Ney, que também é minha, por considerar-me mais uma filha, pelo carinho e por estar sempre disposta a ajudar.

Aos amigos do CRUSP, pelo apoio, carinho e convivência.

Aos amigos do IME-USP e do CCE-USP, pelo companheirismo, pelo apoio e pelas horas de estudo compartilhadas: Noemi, Sandra, Salomé, Karina, Igor, Ronaldo, Fábio, Lídia, Érico, Evandro, Marilda, Rose, Maria Helena e muitos outros.

Ao meu colega Juvêncio, pela importante ajuda no trabalho de programação.

Aos amigos que encontrei na Escola Estadual Francisco Matarazzo Sobrinho, em especial as amigas Valda, Elaine Muniz, Regina e Edna, pelo apoio, incentivo e amizade.

À Rose, minha amiga desde os tempos de colégio, pela preocupação e apoio nas horas difíceis.

Aos professores do Departamento de Estatística do IME-USP, pelos valiosos ensinamentos recebidos ao longo desses últimos anos e aos funcionários, pela ajuda e esclarecimentos prestados.

Ao Prof. Dr. Bryan Manly, pela atenção e pelos artigos enviados por email.

A Deus, por me dar saúde, fé, sabedoria e coragem para concluir mais uma etapa.

Finalmente, a todos que de alguma forma contribuíram para que esse trabalho ocorresse com sucesso. 


\section{Resumo}

Os testes usuais para comparar variâncias e médias, teste de Bartlett e teste $\mathrm{F}$ da análise de variância com um fator, supõem que as amostras sejam provenientes de distribuições normais. Para o teste de igualdade de médias, a suposição de homogeneidade de variâncias também é necessária. Alguns problemas se destacam quando tais suposições básicas são violadas, como tamanho excessivo e baixo poder. Neste trabalho apresentamos inicialmente o Teste de Levene para igualdade de variâncias, que é robusto a não normalidade, e o teste de Brown e Forsythe para igualdade de médias quando existe desigualdade de variâncias. Apresentamos várias modificações do teste de Levene e do teste de Brown e Forsythe, propostas por diferentes autores, e alguns testes aleatorizados que podem ser usados como alternativas. É apresentada ainda uma aplicação do teste aleatorizado para igualdade de médias em problemas de Bioequivalência. Finalizando, aplicamos uma forma do teste modificado de Brown e Forsythe a um conjunto de dados reais. 


\begin{abstract}
The usual tests to compare variances and means, Bartlett's test and test produced by F-statistic from one-way analysis of variance, assume that the sample are from normal distributions. The test for equality of means requires the assumption of homogeneity of variances. There are some problems when these assumptions are not satisfied, like excessive size or low power. In this dissertation, we describe the Levene's test for equality of variance, which is robust under nonnormality, and the Brown and Forsythe's test for equality of means. We also present some modifications of the Levene's test and Brown and Forsythe's test, proposed by different authors, and some tests by randomization that can be used as alternatives. In addiction, we present an application of the randomized test for equality of means in Bioequivalence problems. Finally, we apply one modified form of Brown and Forsythe's test to a real data set.
\end{abstract}




\section{Sumário}

1 Introdução $\ldots \ldots \ldots \ldots \ldots \ldots \ldots \ldots \ldots \ldots \ldots \ldots \ldots \ldots \ldots \ldots \ldots \ldots$

2 Teste de Levene e suas modificações

2.1 Introdução. . . . . . . . . . . . . . . . . . . . . . . . . . 4

2.2 Teste de Levene.............................. . 5

2.3 Modificações do Teste de Levene

2.3.1 Modificações propostas por Brown e Forsythe. ......... 7

2.3.2 Modificações propostas por Hines e Hines. . . . . . . . . . . 15

2.3.3 Modificaç̃es propostas por O'Neill e Mathews.......... 22

\section{Teste de Brown e Forsythe e suas modificações}

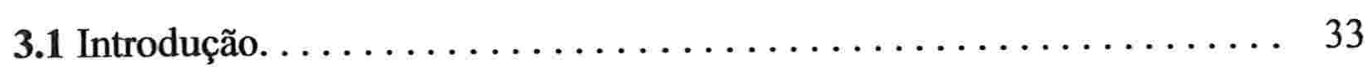

3.2 Teste de Brown e Forsythe. ...................... 35

3.3 Modificações do Teste de Brown e Forsythe

3.3.1 Modificações propostas por Mehrotra. .............. 38

3.3.2 Modificações propostas por Keselman e Wilcox......... 40

\section{Testes Aleatorizados para Igualdade de Médias e de}

\section{Variâncias}

4.1 Introdução. $\ldots \ldots \ldots \ldots \ldots \ldots \ldots \ldots \ldots \ldots \ldots \ldots \ldots \ldots \ldots \ldots \ldots \ldots, 44$

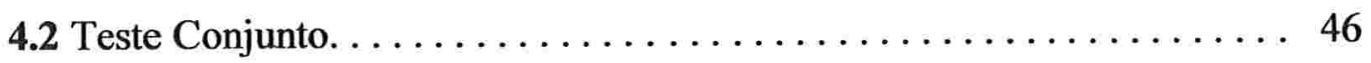

4.3 Teste de Igualdade de Variâncias de Levene Aleatorizado. . . . . . . . . 47

4.4 Teste de Igualdade de Médias Aleatorizado................ 48

4.5 Teste de Igualdade de Médias Aleatorizado com Calibração Boostrap. . . 50

4.6 Teste de Igualdade de Variâncias (Teste de Levene) Aleatorizado

com Calibração Bootstrap.......................... 53

4.7 Estudo de Simulação. ............................... 53 


\section{Aplicações em Bioequivalência}

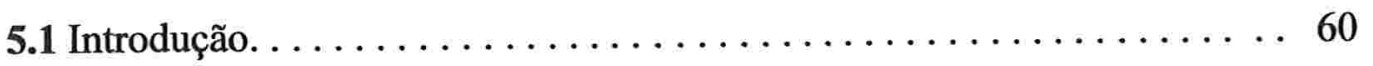

5.2 A Bioequivalência na área farmacêutica. .................. 62

5.3 Testes para Bioequivalência de Médias sob Não Normalidade

e Desigualdade de Variâncias. ........................ 65

5.4 Testes para Bioequivalência de Médias. ................. 68

6 Aplicação do Teste de Brown e Forsythe modificado a um conjunto de dados

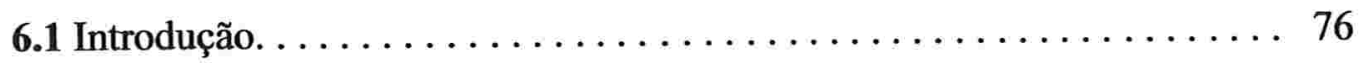

6.2 Implementação do teste. .......................... 80

6.3 Conclusões. . . . . . . . . . . . . . . . . . . . . 83

\section{Apêndice A}

Programa no R e conjunto de dados.

Referências Bibliográficas. 


\section{Capítulo 1}

\section{Introdução}

Os testes de Levene e de Brown e Forsythe têm-se constituído em técnicas úteis para comparação de médias e variâncias quando as suposições básicas dos testes de igualdade de variâncias e de igualdade de médias não são satisfeitas.

Observa-se no entanto que estes testes tradicionais foram sofrendo modificações ao longo do tempo, propostas por diversos autores.

O Teste de Bartlett para homogeneidade de variâncias não é robusto para divergência de normalidade. Visando contornar esse problema, propõe-se o uso do Teste de Levene para a comparação de variâncias de $k$ grupos de observações provenientes de distribuições contínuas e não necessariamente normais. O Teste de Levene é robusto à não-normalidade. No entanto, alguns autores destacam certas deficiências no teste, e apresentam pequenas alterações que podem melhorar sua eficiência.

Por outro lado, o teste $\mathrm{F}$ da análise de variância com um fator para comparar médias de $k$ amostras independentes de populações normais apresenta desvios no nível de significância quando os grupos possuem variâncias populacionais diferentes. Para 
esse problema foram propostas várias soluções, entre elas o teste de Brown e Forsythe. Vários autores apontam alguma inadequação no Teste de Brown e Forsythe e apresentam algumas modificaçõs para o mesmo.

Alguns problemas, como tamanho excessivo ou poder baixo, se destacam quando desejamos comparar médias e variâncias de duas ou mais populações para os casos em que as amostras são provenientes de distribuições não normais. Como proposta para esse problema de comparar médias e variâncias, são apresentados testes aleatorizados para igualdade de médias e de variâncias que podem ser utilizados como alternativas aos testes de Levene e de Brown e Forsythe.

O objetivo principal desse trabalho é apresentar as modificações propostas aos testes de Levene e de Brown e Forsythe e também discutir alguns testes aleatorizados que podem ser usados como alternativas.

Esta dissertação é constituída por seis capítulos. No segundo capítulo é apresentado o Teste de Levene, que testa igualdade de variâncias quando os dados são de distribuições contínuas, mas não necessariamente normais, e algumas de suas modificações. Entre essas modificações está a proposta por Brown e Forsythe (1974a) que considera as distâncias das observações com relação à suas medianas amostrais ao invés das médias amostrais. Usando as medianas amostrais ao invés das médias o teste se torna mais robusto para amostras pequenas e pode ser encontrado no pacote computacional MINITAB 14.

O terceiro capítulo se destina ao estudo do teste de igualdade de médias com amostras independentes de populações normais para variâncias desiguais, Teste de Brown e Forsythe. Também neste capítulo são apresentadas algumas modificações deste teste, propostas por diferentes autores.

No quarto capítulo descrevemos os testes aleatorizados para igualdade de médias e de variâncias propostos por Francis e Manly (2001), Manly e Francis (2002) e Manly (1995).

O quinto capítulo apresenta algumas aplicações dos testes descritos no quarto capítulo ao estudo de Bioequivalência.

O sexto capítulo exibe uma aplicação do Teste de Brown e Forsythe modificado a um conjunto de dados reais. 
Para a execução do teste, foi desenvolvido um programa na linguagem de programação R. O programa calcula a estatística do teste de Brown e Forsythe modificado e o nível de significância, que é estimado via Bootstrap. O programa e o conjunto de dados utilizados no sexto capítulo são apresentados no Apêndice A. 


\section{Capítulo 2}

\section{Teste de Levene e suas modificações}

\subsection{Introdução}

Muitas técnicas estatísticas requerem a suposição de igualdade de variâncias das variáveis de interesse para as populações envolvidas. $O$ teste padrão de homogeneidade de variâncias, teste de Bartlett, é uma ferramenta eficiente somente se as variávies possuem distribuição aproximadamente normal. Quando a suposição de normalidade é violada, o tamanho real do teste (nível de significância atingido) pode ser muito maior do que o nível de significância fixado. Um procedimento que é relativamente insensível a desvios da normalidade é o Teste de Levene. Este teste é robusto, no sentido de que, na ausência de normalidade, seu tamanho real quase coincide com o nível de significância fixado para uma grande variedade de distribuições de probabilidade. 
Levene (1960) propôs uma estatística para testar igualdade de variâncias quando as amostras são de tamanhos iguais, que foi posteriormente generalizada para amostras de tamanhos diferentes. A estatística é obtida a partir de uma Análise de Variância com um fator, sendo que os níveis são as populações e cada observação é substituída pelo desvio absoluto da variável em relação à média do grupo.

O objetivo deste capítulo é apresentar algumas modificações do teste de Levene propostas por diferentes autores. Descreveremos inicialmente o teste de Levene na sua forma original e posteriormente as várias formas modificadas.

\subsection{Teste de Levene}

Suponhamos que $k \geq 2$ amostras aleatórias independentes entre si, $X_{i 1}, \ldots, X_{i n_{i}}$, $i=1, \ldots, k$, sejam tomadas. A amostra $i$ é uma coleção de $n_{i}$ variáveis aleatórias independentes, identicamente distribuídas com distribuição $G_{i}$, média $\mu_{i}$ e variância $\sigma_{i}^{2}$, para $G_{i}, \mu_{i}$ e $\sigma_{i}^{2}$ desconhecidos. A hipótese nula de igualdade de variâncias,

$$
H_{0}: \sigma_{1}^{2}=\sigma_{2}^{2}=\ldots=\sigma_{k}^{2},
$$

é testada ao nível de significância $\alpha$ contra a hipótese alternativa que nem todas as variâncias são as mesmas,

$$
H_{a}: \sigma_{i}^{2} \neq \sigma_{j}^{2} \quad \text { para algum } i \neq j, i, j=1,2, \ldots, k \text {. }
$$

Denotamos os desvios absolutos das variáveis $X_{i j}$ com relação às médias amostrais dos grupos $\bar{X}_{i .}=\frac{1}{n_{i}} \sum_{j=1}^{n_{i}} X_{i j}$ por $Z_{i j}=\left|X_{i j}-\bar{X}_{i}\right|, j=1,2, \ldots, n_{i}, i=1,2, \ldots, k \mathrm{e}$ definimos a estatística,

$$
\mathrm{W}_{0}=\frac{n-k}{k-1} \frac{\sum_{i=1}^{k} n_{i}\left(\bar{Z}_{i .}-\bar{Z}_{. .}\right)^{2}}{\sum_{i=1}^{k} \sum_{j=1}^{n_{i}}\left(Z_{i j}-\bar{Z}_{i .}\right)^{2}}
$$


onde $\bar{Z}_{i .}=\frac{1}{n_{i}} \sum_{j=1}^{n_{i}}\left|X_{i j}-\bar{X}_{i .}\right|, \bar{Z}_{. .}=\frac{1}{n} \sum_{i=1}^{k} \sum_{j=1}^{n_{i}}\left|X_{i j}-\bar{X}_{i .}\right|$ e $n=\sum_{i=1}^{k} n_{i}$.

O Teste de Levene consiste em rejeitar $H_{0}$ a favor de $H_{a}$ se $W_{0}$ excede $F_{k-1, n-k, 1-\alpha}$, o quantil de ordem $(1-\alpha)$ da distribuição $F$ com $k-1$ e $n-k$ graus de liberdade, respectivamente, no numerador e denominador.

Portanto, o teste é uma análise de variância com um fator na variável desvio absoluto $Z_{i j}$. O uso de $Z_{i j}$ ao invés de $Z_{i j}{ }^{2}$ faz com que o critério do teste se torne menos sensível para distribuições $G_{i}$ com caudas pesadas. Mesmo assim, como em geral as variáveis aleatórias $Z_{i j}$ não são normalmente distribuídas nem independentes (verifica-se que $Z_{i j}$ e $Z_{i l}$, para $j \neq l$, têm uma correlação de ordem $n_{i}^{-2}$ ), a distribuição de $W_{0}$ sob a hipótese nula não é $F$ de Snedecor.

Miller (1972), citado em Brown e Forsythe (1974a), destaca que, para amostras muito pequenas, as correlações altas entre desvios no mesmo grupo destroem a validade do teste.

No entanto, para uma variedade de distribuições $G_{i}$, por exemplo, distribuições normais e distribuições simétricas de caudas pesadas tais como a exponencial dupla e a t-Student com quatro graus de liberdade, a níveis de significâncias usuais, $\alpha=0,01,0,05$ ou 0,10 e amostras de tamanho pelo menos 10 , o teste de Levene é robusto. Brown e Forsythe (1974a), num estudo de simulação, verificaram que, neste caso, o quantil de ordem $(1-\alpha)$ da distribuição nula de $W_{0}$, estimado pelo Método de Monte Carlo, é aproximadamente igual a $F_{k-1, n-k, 1-\alpha}$. Verificaram ainda que a falta de robustez devia-se à assimetria das distribuições e não à existência de correlação entre os desvios.

Estes fatos levaram à construção de formas alternativas do teste de Levene. 


\subsection{Modificações do Teste de Levene}

\subsubsection{Modificações propostas por Brown e Forsythe}

Para distribuições $G_{i}$ assimétricas, como a qui-quadrado com quatro graus de liberdade, e distribuições com caudas extremamente pesadas, como a Cauchy, Brown e Forsythe (1974a) observaram que o teste de Levene tende a fornecer muitos resultados significativos, de modo que o tamanho real excede o nível de significância fixado. Por esse motivo, uma modificação do método de Levene é proposta pelos autores. Consiste em alterar a estatística $W_{0}$, substituindo o estimador de posição central $\bar{X}_{i}$. por versões mais robustas.

Formulações alternativas consideradas por Levene substituiam $Z_{i j}$ por $\sqrt{Z_{i j}}$ ou por $\log \left(Z_{i j}\right)$. Desde que num estudo empírico realizado, ambas se mostraram menos poderosas do que a que utilizava $Z_{i j}$, somente os resultados sobre $W_{0}$, a estatística de Levene, são relatados no estudo feito pelos autores.

Substituindo a média $\bar{X}_{i}$ pela mediana do grupo, $M_{i}$, na expressão de $Z_{i j}$, ou seja, $\quad$ utilizando-se $\quad Z_{i j}^{(M)}=\left|X_{i j}-M_{i .}\right|, \quad j=1, \ldots, n_{i}, \quad i=1, \ldots, k, \quad$ define-se $W_{50}=\frac{(n-k) \sum_{i=1}^{k} n_{i}\left(\bar{Z}_{i .}^{(M)}-\bar{Z}^{(M)}\right)^{2}}{(k-1) \sum_{i=1}^{k} \sum_{j=1}^{n_{i}}\left(Z_{i j}{ }^{(M)}-Z_{i .}^{(M)}\right)^{2}}$,

onde

$$
\begin{aligned}
& \bar{Z}_{i .}^{(M)}=\frac{1}{n_{i}} \sum_{j=1}^{n_{i}}\left|X_{i j}-M_{i .}\right|, \\
& \bar{Z}_{. .}^{(M)}=\frac{1}{n} \sum_{i=1}^{k} \sum_{j=1}^{n_{i}}\left|X_{i j}-M_{i}\right| \text { e } n=\sum_{i=1}^{k} n_{i} .
\end{aligned}
$$


Utilizou-se ainda a estatística $W_{10}$, definida a partir de $W_{0}$, substituindo a média $\bar{X}_{i}$ por $\widetilde{X}_{i}$, sendo que $\widetilde{X}_{i}$ é a média aparada a $10 \%$ do i-ésimo grupo. Se $0<\delta<1$, dizemos que $\tilde{X}$ é a média aparada a $100 \delta \%$ se for obtida como a média após a eliminação das $100 \delta \%$ menores observações e das $100 \delta \%$ maiores observações .

Os autores realizaram então o seguinte estudo de simulação:

Geraram números pseudoaleatórios utilizando as distribuições: Normal, pelo método de Box Muller (1958), citado em Brown e Forsythe (1974a), Qui-quadrado com quatro graus de liberdade, como uma distribuição proporcional ao logaritmo do produto de duas variáveis aleatórias com distribuição uniforme, t-Student com quatro graus de liberdade, como a razão de uma variável aleatória com distribuição Normal e a raiz quadrada de uma variável aleatória com distribuição qui-quadrado com quatro graus de liberdade e Cauchy, como razão de duas variáveis aleatórias com distribuição Normal.

A distribuição Qui-quadrado é assimétrica à direita e as distribuições t-Student e Cauchy são simétricas e de caudas pesadas.

Para efetuar a análise, foi gerado um conjunto de 80 observações aleatórias de cada distribuição. Posteriormente, foram formados pares de grupos com amostras de tamanhos $(40,40),(20,40),(10,10)$ e $(10,20)$ selecionados do conjunto de 80 observações e usados no cálculo das estatísticas de teste. As observações na segunda amostra eram transformadas para representar as seguintes razões das variâncias populacionais dos dois grupos: $1: 1,1: 2,1: 4,2: 1$ e 4:1. Todos os testes estatísticos eram executados para os mesmos pares de grupos. Para cada distribuição foram executados 10 blocos de 100 experimentações e para cada bloco eram registrados os números de rejeições quando realizados os testes aos níveis de significância fixados de 5\% e 1\%.

Os resultados da simulação com as distribuições Normal, t-Student com quatro graus de liberdade e qui-quadrado com quatro graus de liberdade, para $\alpha=0,05$, estão resumidos nas Tabelas 2.1.A, 2.1.B e 2.1.C. 
Tabela 2.1.A - Estimativas dos níveis de significância e do poder dos testes (valores em porcentagem) para dados com distribuição Normal

\begin{tabular}{ccccc}
\hline $\mathrm{n}_{1,} \mathrm{n}_{2}$ & $\sigma_{1}{ }^{2} / \sigma_{2}{ }^{2}$ & $\begin{array}{c}\text { Estatística de } \\
\text { Levene }\left(W_{0}\right)\end{array}$ & $\begin{array}{c}\text { Estatística } \\
W_{10}\end{array}$ & $\begin{array}{c}\text { Estatística } \\
W_{50}\end{array}$ \\
\hline 40,40 & $1: 1$ & 6,4 & 6,1 & 5,1 \\
& $2: 1$ & 51,1 & 50,8 & 48,4 \\
& $4: 1$ & 97,1 & 96,9 & 96,7 \\
10,10 & $1: 1$ & 5,5 & 4,9 & 2,9 \\
& $2: 1$ & 15,8 & 14,7 & 9,8 \\
& $4: 1$ & 44,3 & 41,4 & 31,7 \\
20,40 & $1: 1$ & 5,8 & 5,2 & 4,5 \\
& $2: 1$ & 38,8 & 37,5 & 32,9 \\
& $4: 1$ & 88,5 & 88,0 & 85,7 \\
& $1: 2$ & 33,2 & 32,9 & 31,1 \\
& $1: 4$ & 86,3 & 85,3 & 83,9 \\
10,20 & $1: 1$ & 5,7 & 5,2 & 4,0 \\
& $2: 1$ & 21,5 & 20,4 & 15,7 \\
& $4: 1$ & 62,2 & 59,8 & 52,7 \\
& $1: 2$ & 15,8 & 14,8 & 12,1 \\
& $1: 4$ & 49,9 & 48,6 & 43,0 \\
\hline
\end{tabular}

Fonte : Brown e Forsythe (1974a)

Tabela 2.1.B - Estimativas dos níveis de significância e do poder dos testes (valores em porcentagem) para dados com distribuição t-Student com quatro graus de liberdade

\begin{tabular}{|c|c|c|c|c|}
\hline $\mathrm{n}_{1}, \mathrm{n}_{2}$ & $\sigma_{1}^{2}, \sigma_{2}^{2}$ & $\begin{array}{l}\text { Estatística de } \\
\text { Levene }\left(W_{0}\right)\end{array}$ & $\begin{array}{c}\text { Estatística } \\
W_{10}\end{array}$ & $\begin{array}{c}\text { Estatística } \\
W_{50}\end{array}$ \\
\hline \multirow[t]{3}{*}{40,40} & $1: 1$ & 5,0 & 4,8 & 4,4 \\
\hline & $2: 1$ & 36,4 & 34,9 & 33,2 \\
\hline & $4: 1$ & 87,2 & 86,4 & 85,8 \\
\hline \multirow[t]{3}{*}{10,10} & $1: 1$ & 5,9 & 5,3 & 3,5 \\
\hline & $2: 1$ & 12,2 & 10,3 & 7,1 \\
\hline & $4: 1$ & 32,1 & 28,6 & 22,4 \\
\hline \multirow[t]{5}{*}{20,40} & $1: 1$ & 5,0 & 4,7 & 4,4 \\
\hline & $2: 1$ & 27,5 & 25,7 & 22,9 \\
\hline & $4: 1$ & 75,9 & 74,2 & 71,3 \\
\hline & $1: 2$ & 21,4 & 21,1 & 20,2 \\
\hline & $1: 4$ & 66,9 & 65,2 & 63,3 \\
\hline \multirow[t]{5}{*}{10,20} & $1: 1$ & 6,5 & 5,2 & 3,6 \\
\hline & $2: 1$ & 18,4 & 15,9 & 12,4 \\
\hline & $4: 1$ & 50,3 & 47,2 & 42,0 \\
\hline & $1: 2$ & 10,9 & 10,0 & 7,8 \\
\hline & $1: 4$ & 33,5 & 30,6 & 26,7 \\
\hline
\end{tabular}

Fonte : Brown e Forsythe (1974a) 


\begin{tabular}{ccccc}
\multicolumn{5}{c}{ Tabela 2.1.C - Estimativas dos níveis de significância e do } \\
poder dos testes (valores em porcentagem) para dados com \\
\multicolumn{4}{c}{ distribuição Qui-Quadrado com quatro graus de liberdade } \\
\hline $\mathrm{n}_{1,} \mathrm{n}_{2}$ & $\sigma_{1}{ }^{2} / \sigma_{2}{ }^{2}$ & Estatística de & Estatística & Estatística \\
& & Levene $\left(W_{0}\right)$ & $W_{10}$ & $W_{50}$ \\
40,40 & $1: 1$ & 9,7 & 6,6 & 3,6 \\
& $2: 1$ & & 42,1 & 34,8 \\
& $4: 1$ & & 92,6 & 88,4 \\
10,10 & $1: 1$ & 12,9 & 9,9 & 5,6 \\
& $2: 1$ & & & 10,3 \\
& $4: 1$ & & & 23,8 \\
20,40 & $1: 1$ & 10,9 & 7,3 & 4,7 \\
& $2: 1$ & & $(30,2)$ & 24,4 \\
& $4: 1$ & & $(76,0)$ & 71,1 \\
& $1: 2$ & & $(27,9)$ & 22,2 \\
& $1: 4$ & & $(71,3)$ & 65,1 \\
10,20 & & & & \\
& $1: 1$ & 11,8 & 8,7 & 5,2 \\
& $2: 1$ & & & 14,8 \\
& $4: 1$ & & & 40,1 \\
$1: 2$ & & & 9,3 \\
& $1: 4$ & & & 28,1 \\
\hline
\end{tabular}

Fonte : Brown e Forsythe (1974a)

$\mathrm{O}$ caso 1:1 corresponde à igualdade de variâncias da variável resposta nos grupos, ou seja, à situação em que $H_{0}$ é válida. $\mathrm{O}$ valor de $\alpha$, sob $H_{0}$, é estimado quando são utilizadas as estatísticas $W_{0}, W_{10}$ e $W_{50}$. Os testes estatísticos foram executados com as 100 experimentações e anotava-se o número de rejeições. $\mathrm{O}$ procedimento era repetido 10 vezes e posteriormente, calculava-se a média dos números de rejeições obtidos nas 10 repetições. Esperava-se que este valor, estimativa de $\alpha$, se aproximasse de 0,05 .

Os casos 2:1, 4:1, 1:2 e 1:4 representam desigualdade de variâncias da variável resposta nos grupos, ou seja, sob $H_{a}$. O poder do teste foi estimado através de um procedimento similar ao da estimação de $\alpha$.

Para o caso da distribuição normal, foram apresentados somente os resultados ao nível de significância $5 \%$, pois estes eram similares para o nível de significância $1 \%$. Sendo o número de simulações igual a 1000, utilizou-se como estimativa do desvio padrão do estimador de $\alpha$ a quantidade $\sqrt{\frac{\hat{\alpha}(1-\hat{\alpha})}{1000}}$, aproximada por 
$\sqrt{\frac{0,05(1-0,05)}{1000}}=0,7 \%$. Por simplificação, o valor do poder não é exibido para testes cujos tamanhos empíricos são maiores do que $8 \%$ e foram colocados entre parênteses para testes cujos tamanhos estão entre 7 e $8 \%$.

Quando há variâncias iguais nos dois grupos, os resultados para a distribuição Normal (Tabela 2.1.A) indicaram que $W_{50}$ é conservativo para amostras de tamanhos pequenos, ou seja, tende a apresentar nível de significância inferior a $5 \%$.

Os resultados para os demais testes estatísticos não se mostraram inconsistentes com o erro amostral de $0,7 \%$. Verificou-se ainda que o valor do poder dos testes que utilizam essas estatísticas não mudou muito quando existiam diferenças nos tamanhos empíricos dos testes.

Quando a distribuição é de cauda pesada (Tabela 2.1.B), dos três tipos de procedimento de Levene apresentados, o que utiliza $W_{10}$ mostrou-se o mais robusto. Tal procedimento apresentou menor variabilidade nos tamanhos do teste do que $W_{0}$ e atingiu nível de significância mais próximo de $5 \%$ do que $W_{50}$.

A amostra da distribuição de Cauchy enfatizou as saídas precedidas do tamanho fixado. Para os quatro tamanhos de amostras considerados pelos autores, a rejeição foi excessiva para todos os testes, exceto os de estatística $W_{10}$ e $W_{50}$. Adotando-se $W_{10}$, a porcentagem de rejeição de $H_{0}$ resultou entre 2,8 e $5,9 \%$ e para $W_{50}$, de 1,8 a $3,5 \%$. Novamente aqui, o teste baseado em $W_{10}$ apresentou nível de significância mais próximo de $5 \%$ do que o de estatística $W_{50}$.

Os resultados com amostras da distribuição qui-quadrado com quatro graus de liberdade se encontram na Tabela 2.1.C. Somente o teste com estatística $W_{50}$ manteve seu tamanho próximo do nível de significância de 5\%. Os outros divergem dos tamanhos fixados e a taxa de rejeição sob $H_{0}$ mostrou-se maior que 0,05 .

Os resultados dessa simulação indicaram que a igualdade de variâncias em distribuições de caudas pesadas pode ser melhor testada por uma estatística da forma $W_{10}$ e em distribuições assimétricas, por uma estatística similar a $W_{50}$. Portanto, quando desvios de normalidade forem antecipados, a estimativa da média para cada grupo na 
estatística de Levene deve ser substituída por uma estimativa mais robusta de locação central. A perda no poder quando $W_{10}$ é usada ao invés de $W_{0}$ é pequena relativa ao aumento da probabilidade de uma rejeição falsa da hipótese nula causada pela não normalidade.

Carrol e Schneider (1985) apresentam um interessante estudo sobre as estatísticas $W_{0}$ e $W_{50}$, apresentadas anteriormente. Numa primeira etapa, analisam o motivo pelo qual os Testes de Levene utilizando estatística $W_{0}$ e $W_{50}$ têm aproximadamente níveis corretos para distribuições simétricas. Posteriormente, investigam a razão pela qual o Teste de Levene que utiliza a mediana (estatística $W_{50}$ ) tem aproximadamente nível correto para distribuições assimétricas, enquanto o teste de Levene com estatística $W_{0}$ não possui essa propriedade.

Os autores consideraram testes baseados em $\left|\mathrm{X}_{\mathrm{ij}}-\hat{\theta}_{i}\right|$ e em $\mathrm{G}\left(\left|\mathrm{X}_{\mathrm{ij}}-\hat{\theta}_{i}\right|\right)$, onde $\mathrm{G}\left(\right.$. ) é uma função monótona com derivada $\mathrm{g}\left(\right.$. ), $\hat{\theta}_{i}$ é um estimador do parâmetro desconhecido $\theta_{i}$ e analisaram a eficiência dos testes sob hipóteses nulas de variâncias iguais. Neste caso, o modelo seria

$$
\begin{aligned}
& X_{i j}=\theta_{i}+\varepsilon_{i j}, \quad i=1, \ldots, k \text { e } j=1, \ldots, n_{i}, \\
& Z_{i j}=\left|X_{i j}-\theta_{i}\right|, \quad n=\sum_{i=1}^{k} n_{i},
\end{aligned}
$$

com $\theta_{i}$ representando o centro da distribuição dos $X_{i j}$, podendo ser a média populacional, a mediana ou a média aparada a $10 \%$. As variávies aleatórias $\varepsilon_{i j}$ são independentes e identicamente distribuídas, já que a análise foi feita somente sob a hipótese de igualdade de variâncias. Como conseqüência, as conclusões obtidas serão relativas ao nível de significância e não ao poder dos testes.

Admite-se ainda que as estimativas de $\theta_{i}, \hat{\theta}_{i}$, satisfazem à propriedade : $\sqrt{n_{i}}\left(\hat{\theta}_{i}-\theta_{i}\right) \stackrel{D}{\rightarrow} \operatorname{Normal}\left(0, \xi^{2}\right)$, $\left(\sqrt{n_{i}}\left(\hat{\theta}_{i}-\theta_{i}\right)\right.$ converge em distribuição para a distribuição Normal com média 0 e variância $\xi^{2}$ ), com $\xi^{2}<\infty, i=1, \ldots, k$. 
Foi considerada uma classe geral de testes baseados em $R_{i j}=G\left(W_{i j}\right)$, onde $W_{i j}=\left|X_{i j}-\hat{\theta}_{i}\right|$, com estatística de teste dada por

$$
F_{n}\left(\hat{\theta}_{i}\right)=\frac{Q M E\left(\hat{\theta}_{i}\right)}{Q M D\left(\hat{\theta}_{i}\right)}
$$

sendo que $Q M E\left(\hat{\theta}_{i}\right)=\frac{\sum_{i=1}^{k} n_{i}\left(\bar{R}_{i .}-\bar{R}\right)^{2}}{k-1}$,

$Q M D\left(\hat{\theta}_{i}\right)=\frac{\sum_{i=1}^{k} \sum_{j=1}^{n_{i}}\left(R_{i j}-\bar{R}_{i .}\right)^{2}}{n-k}, \bar{R}_{i .}=\frac{\sum_{j=1}^{n_{i}} R_{i j}}{n_{i}}, i=1, \ldots, k$ e $\bar{R} . .=\frac{\sum_{i=1}^{k} \sum_{j=1}^{n_{i}} R_{i j}}{n}$.

Definiu-se ainda a variável aleatória $F_{n}\left(\theta_{i}\right)$ como a estatística $F_{\mathrm{n}}$ calculada em função de $L_{i j}=G\left(Z_{i j}\right)$, com $Z_{i j}=\left|X_{i j}-\theta_{i}\right|$.

Resultados de Bickel (1975) ou Carrol e Ruppert (1982), citados em Carrol e Schneider (1985), podem ser usados para mostrar o seguinte fato.

\section{Teorema 2.1}

Para $F_{n}\left(\hat{\theta}_{i}\right)$ e $F_{n}\left(\theta_{i}\right)$ definidas anteriormente,

$F_{n}\left(\hat{\theta}_{i}\right)-F_{n}\left(\theta_{i}\right)-Q_{n} \stackrel{P}{\rightarrow} 0$

onde

$$
Q_{n}=\frac{\sum_{i=1}^{k}\left\{\gamma^{2} H_{i}^{2}-2 \gamma H_{i} \sqrt{n_{i}}\left(\bar{L}_{i .}-\bar{L}\right)\right\}}{\sigma^{2}(k-1)}, \quad H_{i}=\sqrt{n_{i}}\left\{\left(\hat{\theta}_{i}-\theta_{i}\right)-\sum_{l=1}^{k}\left(\frac{n_{l}}{n}\right)\left(\hat{\theta}_{i}-\theta_{i}\right)\right\},
$$

$\gamma=\int_{0}^{\infty} g(v)\{f(v)-f(-v)\} d v$, sendo que $f$ é a função densidade de $\varepsilon_{i j}=X_{i j}-\theta_{i}$. 
Em particular, se $\hat{\theta}_{i}$ é uma estimativa de $\theta_{i}$, para $G\left(\left|X_{i j}-\hat{\theta}_{i}\right|\right)=\left|X_{i j}-\hat{\theta}_{i}\right|$, de modo que $G(v)=v$, segue que $g(v)=1$ e $\gamma=\int_{0}^{\infty} f(v) d v-\int_{0}^{\infty} f(-v) d v$.

Como $f(-v)$ é a densidade de $-\left(X_{i j}-\theta_{i}\right)$, temos que $\int_{0}^{\infty} f(-v) d v=P\left(-\left(X_{i j}-\theta_{i}\right)>0\right)=P\left(X_{i j}-\theta_{i}<0\right)$

e assim,

$$
\gamma=P\left(X_{i j}-\theta_{i}>0\right)-P\left(X_{i j}-\theta_{i}<0\right) .
$$

A variável aleatória $F_{n}\left(\theta_{i}\right)$ pode ser encarada como uma medida de variabilidade entre as quantidades $G\left(\left|X_{i j}-\theta_{i}\right|\right)$ para os diferentes valores de $\theta_{i}, i=1,2, \ldots, k$. Analogamente, $F_{n}\left(\hat{\theta}_{i}\right)$ pode ser vista como um previsor de $F_{n}\left(\theta_{i}\right)$. Situações nas quais $Q_{n}=0$ que, de acordo com o teorema implicam em $F_{n}\left(\hat{\theta}_{i}\right)-F_{n}\left(\theta_{i}\right)-Q_{n} \stackrel{P}{\rightarrow} 0$, são indicativas de que a estatística do teste de Levene, $F_{n}\left(\hat{\theta}_{i}\right)$, é eficiente na detecção da variabilidade em $G\left(\left|X_{i j}-\theta_{i}\right|\right)$ conforme $i$ varia, $i=1,2, \ldots, k$.

Desta forma, o Teste de Levene terá assintoticamente nível de significância correto somente quando $\gamma=0$, isto é, para $\theta_{i}$ igual à mediana da distribuição de $X_{i j}$. Isso explica porque, para distribuições simétricas, caso em que $\gamma=0$, média ou mediana podem ser utilizadas, sem alterações no nível de significância fixado. Já, para distribuições assimétricas, $\gamma \neq 0$ a menos que $\theta_{i}$ seja a mediana.

Um segundo caso especial interessante ocorre quando tomamos $G(v)=v^{2}$, ou seja, se o teste é baseado em $R_{i j}=\left(X_{i j}-\hat{\theta}_{i}\right)^{2}$. Neste caso, $g(v)=2 v$ e $\gamma=2 E\left(X_{i j}-\theta_{i}\right)$. Assim, para grandes amostras de distribuições assimétricas, o teste teria o nível de significância especificado, somente quando a centralização é na média, situação em que $\gamma=0$. Se $\gamma \neq 0$, o Teorema 2.1 mostra que, para grandes amostras e centralização na mediana, o nível de significância real é diferente do fixado (conclusão obtida por Conover (1981), via simulação). 
Observa-se então que o Teste de Levene terá nível assintótico correto somente quando as estimativas $\hat{\theta}_{i}$ utilizadas estiverem estimando a mediana de cada população. Dessa maneira, para distribuições simétricas, as formas centralizadas na média e mediana serão igualmente eficientes, já que média e mediana amostrais estão estimando a mesma quantidade. Para distribuições assimétricas, o resultado mostrou que, assintoticamente, somente a centralização na mediana é viável e, se utilizada a centralização na média, o teste de Levene terá nível de significância diferente do especificado.

\subsubsection{Modificações propostas por Hines e Hines}

O poder do teste de Levene de homogeneidade de variâncias, que emprega os resíduos calculados usando a mediana populacional, pode ser aumentado com as modificações propostas por Hines e Hines (2000).

Com esse objetivo, os autores redefinem o teste de Levene da seguinte forma:

Sejam $k$ populações com observações $y_{i j}, i=1,2, \ldots, k$ e $j=1,2, \ldots, n_{i}$, com $n_{i}=2 m_{i}$ se $n_{i}$ for par ou $n_{i}=2 m_{i}+1$ se $n_{i}$ for ímpar. Se $y_{i,(1)}, y_{i,(2)}, \ldots, y_{i,\left(n_{i}\right)}$ são as $n_{i}$ observações ordenadas da amostra da i-ésima população, a mediana do grupo será dada por $\tilde{y}_{i}=\frac{\left(y_{i,\left(m_{i}\right)}+y_{i,\left(m_{i}+1\right)}\right)}{2}$ se $n_{i}$ for par ou $\widetilde{y}_{i}=y_{i,\left(m_{i}+1\right)}$ se $n_{i}$ for ímpar. Considere os resíduos $Z_{i j}=y_{i j}-\tilde{y}_{i}$, para $i=1,2, \ldots, k$ e $j=1,2, \ldots, n_{i}$, e realize uma análise de variância sobre os $\left|Z_{i j}\right|$, rejeitando a hipótese de homogeneidade de variâncias se a estatística correspondente produzir valor significante.

Esse teste é intuitivo visto que maior variabilidade tenderá a ser refletida em maiores valores absolutos dos resíduos individuais e diferenças em variabilidades da população causarão diferenças nos valores médios daqueles resíduos. Além disso, algum 
grau de robustez do teste sob não normalidade pode ser esperado, devido à conhecida robustez da análise de variância com um fator.

No entanto, o procedimento pode apresentar falhas, como por exemplo, ignorar a falta de independência dos resíduos envolvidos e não explorar o fato de que médias (ou medianas) e variâncias de variáveis aleatórias são freqüentemente relacionadas em muitas distribuições, tais como Poisson ou Binomial. Os autores determinaram que modificações convenientes (e elementares) no procedimento de Levene convencional, que utiliza a mediana, melhoram substancialmente seu poder. Estas modificações incluem a identificação e remoção dos zeros estruturais (definidos a seguir) e o uso de contrastes relevantes. Os autores discutem cada uma das possibilidades e realizam um estudo de simulação adotando uma ou ambas modificações.

$\mathrm{Na}$ maioria dos casos, relações entre os resíduos os tornam um tanto redundantes do ponto de vista de informação, mas nenhuma ressalva é feita nesse sentido no teste de Levene convencional. Isolar e remover essas redundâncias torna-se uma estratégia simples e efetiva, especialmente quando $n_{i}$ é ímpar.

A modificação proposta por Hines e Hines (2000) é descrita a seguir:

Quando $n_{i}$ for ímpar, sempre haverá um valor $Z_{i j}$ igual a zero, uma vez que a mediana coincide com um dos $y_{i j}$. Esse particular $Z_{i j}$ não é informativo e será denominado zero estrutural.

A presença dos zeros estruturais terá um efeito desfavorável no teste, que será discutido a seguir. Uma possibilidade para resolver o problema é a eliminação do zero estrutural.

Quando $n_{i}$ é par, constrói-se a chamada rotação ortogonal do vetor ordenado $\left(Z_{i,(1)}, Z_{i,(2)}, \ldots, Z_{i,\left(n_{i}\right)}\right)$ substituindo o par de valores $Z_{i,\left(m_{i}\right)}$ e $Z_{i,\left(m_{i}+1\right)}$ pelo par $\frac{Z_{i,\left(m_{i}+1\right)}-Z_{i,\left(m_{i}\right)}}{\sqrt{2}}$ e $\frac{Z_{i,\left(m_{i}+1\right)}+Z_{i,\left(m_{i}\right)}}{\sqrt{2}}$.

Como $Z_{i j}=y_{i j}-\tilde{y}_{i}$ e $n_{i}$ é par, então $\tilde{y}_{i}=\frac{y_{i,\left(m_{i}\right)}+y_{i,\left(m_{i}+1\right)}}{2}$ e assim, $Z_{i,\left(m_{i}\right)}=y_{i,\left(m_{i}\right)}-\frac{y_{i,\left(m_{i}\right)}+y_{i,\left(m_{i}+1\right)}}{2}$ e $Z_{i,\left(m_{i}+1\right)}=y_{i,\left(m_{i}+1\right)}-\frac{y_{i,\left(m_{i}\right)}+y_{i,\left(m_{i}+1\right)}}{2}$. Dessa forma $\mathrm{o}$ 
resíduo rotacionado na posição ordenada $m_{i}$ é dado por:

$$
\begin{aligned}
\frac{\left(Z_{i,\left(m_{i}+1\right)}-Z_{i,\left(m_{i}\right)}\right)}{\sqrt{2}} & =\frac{\left[y_{i,\left(m_{i}+1\right)}-\frac{\left.y_{i,\left(m_{i}\right)}+y_{i,\left(m_{i}+1\right)}\right]-\left[y_{i,\left(m_{i}\right)}-\frac{y_{i,\left(m_{i}\right)}+y_{i,\left(m_{i}+1\right)}}{2}\right]}{\sqrt{2}}\right.}{\sqrt{2}} \\
& =\frac{y_{i,\left(m_{i}+1\right)}-y_{i,\left(m_{i}\right)}}{\sqrt{2}} .
\end{aligned}
$$

Somando e subtraindo $y_{i,\left(m_{i}+1\right)}$ ao numerador dessa expressão e multiplicando numerador e denominador por $\sqrt{2}$, temos

$$
\begin{aligned}
\frac{Z_{i,\left(m_{i}+1\right)}-Z_{i,\left(m_{i}\right)}}{\sqrt{2}} & =\frac{\left(y_{i,\left(m_{i}+1\right)}+y_{i,\left(m_{i}+1\right)}-y_{i,\left(m_{i}\right)}-y_{i,\left(m_{i}+1\right)}\right) \sqrt{2}}{\sqrt{2} \sqrt{2}} \\
& =\sqrt{2} Z_{i,\left(m_{i}+1\right)}
\end{aligned}
$$

e para o resíduo rotacionado na posição ordenada $m_{i}+1$ resulta

$$
\begin{aligned}
\frac{\left(Z_{i,\left(m_{i}+1\right)}+Z_{i,\left(m_{i}\right)}\right)}{\sqrt{2}}= & \frac{\left[y_{i,\left(m_{i}+1\right)}-\frac{\left.y_{i,\left(m_{i}\right)}+y_{i,\left(m_{i}+1\right)}\right]+\left[y_{i,\left(m_{i}\right)}-\frac{y_{i,\left(m_{i}\right)}+y_{i,\left(m_{i}+1\right)}}{2}\right]}{\sqrt{2}}\right.}{2}=0 . \\
& =\frac{\frac{2 y_{i,\left(m_{i}+1\right)}-y_{i,\left(m_{i}\right)}-y_{i,\left(m_{i}+1\right)}+2 y_{i,\left(m_{i}\right)-y_{i,\left(m_{i}\right)-} y_{i,\left(m_{i}+1\right)}}^{2}}{\sqrt{2}}}{2} .
\end{aligned}
$$

Elimina-se então o resíduo rotacionado na posição $m_{i}+1$, pois após a substituição indicada, ele se torna um zero estrutural. Como o resíduo rotacionado na posição $m_{i}$ se tornou $\sqrt{2} Z_{i,\left(m_{i}+1\right)}$, a contribuição do par substituído na soma de quadrados de $\left|Z_{i j}\right|$ não é afetada por essa transformação, embora os correspondentes 
totais o sejam. Esta proposta de alteração, restrita ao caso em que $n_{i}$ é par, não é analisada pelos autores no restante do artigo.

O efeito mais evidente da inclusão de zeros estruturais na tabela de Análise de Variância é um aumento no número de graus de liberdade. Além disso, a inclusão de um valor nulo na coleção de valores geralmente positivos $\left|Z_{i j}\right|$ tende a aumentar a variabilidade e diminuir a média do grupo, gerando um aumento no quadrado médio do erro em detrimento do desempenho do teste. Somente quando os $n_{i}$ são pares e muito pequenos, é possível construir exemplos extremos em que a utilização da rotação ortogonal pode conduzir a aumentos nos quadrados médios dos erros e conseqüente diminuição no poder do teste.

Quando todos os $n_{i}$ são ímpares, verifica-se trivialmente que as somas de $\left|Z_{i j}\right|$ dentro do grupo e total ou a soma de todos os $\left|Z_{i j}\right|^{2}$ não são alteradas com a retirada dos zeros estruturais. No entanto, o número de graus de liberdade e as somas de quadrados são claramente afetados. Em particular, se todos os $n_{i}$ são ímpares e iguais a $n$, é possível mostrar que as razões das estatísticas $\mathrm{F}$ de análise de variância obtidas com e sem os zeros estruturais $\left(\mathrm{F}_{\mathrm{Z}}\right.$ e $\left.\mathrm{F}_{\mathrm{NZ}}\right)$ são relacionadas pela expressão

$$
\frac{\frac{n(k-1)}{k(n-1)^{2}} F_{Z}+M}{\frac{k-1}{k(n-1)} F_{Z}+1}=\frac{\frac{(k-1)}{k(n-2)} F_{N Z}+M}{\frac{k-1}{k(n-2)} F_{N Z}+1}
$$

onde $M=\frac{\left(\sum_{i} \sum_{j}\left|Z_{i j}\right|\right)^{2}}{\left\{k(n-1)\left(\sum_{i} \sum_{j}\left|Z_{i j}\right|^{2}\right)\right\}} \leq 1$. 
Se necessário, essa equação pode ser usada para determinar $\mathrm{F}_{\mathrm{NZ}}$ a partir de uma saída de computador de um teste de Levene convencional, com $k, n, \mathrm{~F}_{\mathrm{Z}}$ e $\mathrm{M}$ conhecidos.

Uma importante conseqüência da equação (2.1) é a seguinte: Suponha que, removidos os zeros estruturais dos valores absolutos dos resíduos restantes, $\mathrm{F}_{\mathrm{NZ}}$ é praticamente infinita devido a uma quase total falta de variabilidade dentro dos grupos. Neste caso, o correspondente (e máximo possível) valor de $\mathrm{F}_{\mathrm{Z}}$ é $\frac{(n-1)^{2}(1-M) k}{(k-1)}$. Desta forma, a inclusão de zeros estruturais nos cálculos presentes na tabela de análise de variância pode limitar severamente o valor da estatística $\mathrm{F}$, até mesmo quando a heterogeneidade de variâncias é extrema. $\mathrm{O}$ efeito é particularmente forte quando $n$ é pequeno, e em casos extremos, pode tornar o teste de Levene convencional, com base na mediana, incapaz de detectar heterogeneidade de variâncias. Este fato está de acordo com o resultado conhecido de que tal teste é bastante conservativo para $n$ pequeno. Exceção ocorre quando todos os $n_{i}{ }^{\prime} s$ são iguais a dois, situação em que o valor da estatística $\mathrm{F}$ do teste de Levene convencional é infinito.

Uma prática comum e efetiva quando realizada uma análise de variância é pré selecionar um ou poucos contrastes que refletem direções em que a hipótese nula de igualdade de médias pode falhar. Formalmente, $\sum_{i=1}^{k} a_{i} \mu_{i}$ é um contraste se $\sum_{i=1}^{k} a_{i}=0$.

O autor defende o uso de contrastes que capturem relações entre o nível do fator e sua média. Escolhas naturais assumiriam dependência linear mas de modo geral, quando desconfia-se da possibilidade de relações não monótonas ou não lineares, devese utilizar contrastes para ambos efeitos, linear e quadrático.

Complementando o estudo, dois conjuntos de simulações foram realizados. No primeiro, a covariável usada no teste de Levene modificado era o nível $i$ de um fator quantitativo e no outro, a mediana $\tilde{y}_{i}$.

Por consistência, o primeiro conjunto de simulações foi similar ao conjunto analisado por Conover et al.(1981). Com isso, foi possível comparar a forma do teste de Levene proposta por Hines e Hines (2000) com a forma do teste de Levene convencional 
com base na mediana e examinar a robustez das modificações determinando proporções de rejeições sob uma série de distribuições, quando a hipótese nula de homogeneidade de variâncias é verdadeira. Assim como na análise feita por Conover et al. (1981), os dados foram gerados a partir das distribuições, Normal, exponencial dupla, qui-quadrado com um e com quatro graus de liberdade, quadrado da exponencial dupla e da quiquadrado (com quatro graus de liberdade), ou padronizações dessas. Desejava-se investigar a eficácia dos métodos quando as variâncias estão relacionadas com a média do fator. Utilizou-se valores médios $\mu_{i}=i$ para $i=1,2, \ldots, k$, e $k=4$ ou 8 , com variâncias $\sigma_{i}{ }^{2}=1$ ( sob a hipótese nula) e ${\sigma_{i}}^{2}=i$ ou $\sigma_{i}{ }^{2}=i^{2}$, no caso de desigualdade de variâncias. Os tamanhos de amostras adotados, $n_{i}=5,10$, ou 20 para todo $i$ ou ainda, $n_{i}=5$ para metade dos grupos e 20 para os demais, foram similares aos usados por Conover et al. (1981).

O segundo conjunto de simulações envolveu $k=4$ ou 8 grupos, com os mesmos tamanhos de amostra que os do primeiro conjunto. Os dados foram gerados pela distribuição de Poisson com média $\mu_{i}$, onde os valores de $\mu_{i}$ eram amostrados de uma distribuição gama. Os valores $\mu_{i}$ eram obtidos através da média amostral de um total de $s$ variáveis aleatórias exponencialmente distribuídas, com média 10 , de modo que os $\mu_{i}$ tinham média 10 e variância $\frac{100}{s}$, para $s=1,2,4, \ldots, 32$ e infinito.

A análise foi realizada em quatro casos, correspondendo à utilização do teste de Levene nas formas clássica e modificada, com e sem contrastes respectivamente. $\mathrm{O}$ erro do tipo I fixado foi de $5 \%$.

Os resultados obtidos para o conjunto completo de simulações estão resumidos a seguir:

1- O primeiro conjunto de simulações confirmou que os níveis de significância observado e nominal geralmente concordam para todas as distribuições consideradas. Exceções ocorreram quando os $n_{i}$ 's eram muito desiguais, no caso de distribuições altamente assimétricas (qui-quadrado e exponencial dupla ao quadrado) quando zeros estruturais foram retirados e o teste não utilizava o contraste linear. Os níveis de 
significância observados para $\mathrm{F}_{\mathrm{NZ}}$ mostraram-se ligeiramente altos, mas raramente ultrapassavam 0,10 .

2- Como esperado, a manutenção de zeros estruturais no teste de Levene convencional com base na mediana resultou em performance conservativa para $n_{i}=5$. Isso não aconteceu quando os zeros estruturais foram excluídos.

3- A eliminação dos zeros estruturais mostrou-se mais vantajosa para amostras de tamanhos pequenos e para número grande de grupos. Nestes casos, a retirada de zeros estruturais tem maior efeito no número de graus de liberdade. Quando os tamanhos de amostras eram muito desiguais, encontrou-se algumas situações em que a exclusão dos zeros estruturais reduziu o poder observado, geralmente para um valor abaixo de $15 \%$.

4- Testes baseados num único contraste se mostraram mais poderosos do que aqueles baseados na análise global, mesmo quando a linearidade não era muito forte.

5- Verifica-se que os benefícios de cada uma das modificações aumentam com o aumento de $k$.

6- Apesar da simplicidade das modificações propostas, o benefício foi grande. Por exemplo, no segundo conjunto de simulações, quando $k=8$ e $n_{i}=5$, o poder, que era igual a $17 \%$ com o teste de Levene convencional com base na mediana, aumentou para quase $40 \%$ quando os zeros estruturais foram retirados e para quase $70 \%$ quando ambas modificações foram usadas.

De acordo com Hines e Hines (2000), para o estatístico aplicado, as melhorias propostas não surpreenderiam pois elas nada mais são que formalizações da prática comum de examinar os resíduos (possivelmente transformados). Com a retirada dos zeros estruturais tem-se uma melhor visualização de variâncias desiguais e de padrões nos gráficos de resíduos em função dos valores ajustados. A principal vantagem das modificações propostas seria o uso de critérios objetivos ao invés de impressões subjetivas. Ainda segundo os autores, o uso de contrastes é uma idéia antiga, mas que, dada sua importância, merece ser relembrada. 


\subsubsection{Modificações propostas por $\mathbf{O}^{\prime}$ Neill e Mathews}

O’Neill e Mathews (2000) propuseram uma forma alternativa do teste de Levene construída com base no procedimento de mínimos quadrados ponderados (Draper e Smith, 1998).

Para dados independentes provenientes de $\mathrm{k}$ grupos deseja-se testar a hipótese nula

$$
H_{01}: \sigma_{i}^{2}=\sigma_{2}^{2}=\ldots=\sigma_{k}^{2}=\sigma^{2}
$$

onde $\sigma_{i}{ }^{2}$ é a variância da variável de interesse para o i-ésimo grupo, contra a hipótese alternativa de que as variâncias não são todas iguais.

Sob normalidade, o teste de Bartlett (1937) é o teste de homogeneidade de variâncias mais usado em análises de variância com um fator. No entanto, sua estatística é sensível à não normalidade e por isso, pacotes estatísticos recentes oferecem testes alternativos, dos quais o teste de Levene é o predominante.

Lembramos que Levene (1960) propôs o seguinte procedimento:

1- Obter os resíduos baseados na média $\left(r_{i j}\right)$ da análise de variância dos dados,

2- Tomar os valores absolutos dos resíduos, $d_{i j}=\left|r_{i j}\right|$,

3- Reanalisar esses valores absolutos usando o mesmo procedimento da análise de variância que gerou os $r_{i j}$.

A estatística F resultante é utilizada em uma das formas do teste de Levene. Para o modelo com um fator, $d_{i j}$ tem valor esperado proporcional a $\sigma_{i}$ e o procedimento de análise de variância descrito testa a hipótese $H_{01}$.

Como o teste $\mathrm{F}$ da análise de variância é robusto à falta de normalidade, o teste de Levene é melhor do que o de Bartlett, pelo menos para dados que não são normalmente distribuídos.

No entanto, vários autores perceberam que esse procedimento, descrito anteriormente, é apropriado somente quando o modelo é balanceado (Keyes e Levy, 
1997, citados em O’Neill e Mathews, 2000). Isto porque se $n_{i}$ é o número de indivíduos no i-ésimo grupo, a média exata para $d_{i j}$, para todo $j$, é

$$
E\left(d_{i j}\right)=\sqrt{\frac{2}{\pi}\left(1-\frac{1}{n_{i}}\right) \sigma_{i}}, \quad i=1, \ldots, k .
$$

Dessa maneira, o teste de Levene, que é uma análise de variância sobre os $d_{i j}$, não testa a hipótese de homogeneidade de variância se o modelo é não balanceado. Para modelos não balanceados, a hipótese nula do teste é

$$
H_{02}: \frac{n_{1}-1}{n_{1}} \sigma_{1}{ }^{2}=\frac{n_{2}-1}{n_{2}} \sigma_{2}{ }^{2}=\ldots=\frac{n_{k}-1}{n_{k}} \sigma_{k}{ }^{2} \text {. }
$$

Para ilustrar isso, a Figura 2.1 apresenta as curvas de poder do teste de Bartlett e do teste de Levene baseado na média, ao nível de significância de $5 \%$, obtidas a partir de 100000 simulações de dados da normal padrão. Foram utilizados quatro grupos com $n_{1}=2, \quad n_{2}=4, \quad n_{3}=6, \quad n_{4}=8$ e dois subconjuntos de variâncias $\left(\sigma_{1}{ }^{2}, \sigma_{2}{ }^{2}, \sigma_{3}{ }^{2}, \sigma_{4}{ }^{2}\right)=\left(1,1,1, \sigma_{4}{ }^{2}\right)$ no primeiro caso e $\left(1,575 ; 1,050 ; 0,945 ; \sigma_{4}{ }^{2}\right)$ no segundo, com $\sigma_{4}{ }^{2}$ variando de 0,1 a 10 . As linhas verticais indicam $H_{01} \mathrm{e} H_{02}$, respectivamente. Está claro no primeiro gráfico que a curva de poder do teste de Bartlett atinge seu mínimo ( $4,4 \%$ e não $5 \%$ ) sob $H_{01},\left(\sigma_{4}{ }^{2}=1\right)$, enquanto que para o teste de Levene, o mínimo é atingido para um valor diferente de $\sigma_{4}{ }^{2}$. Já no segundo caso, seria esperado que a curva de poder do teste de Levene atingisse o mínimo quando $\sigma_{4}{ }^{2}=0,900$, caso em que $H_{02}$ é válida. No entanto, o nível de significância empírico para esse valor de $\sigma_{4}{ }^{2}$ é alto, igual a $14,3 \%$. Além disso, observa-se que o poder do teste de Levene pode ser inferior ao nível de significância. Esta última característica implica que o teste de Levene, baseado na média, é viciado. 


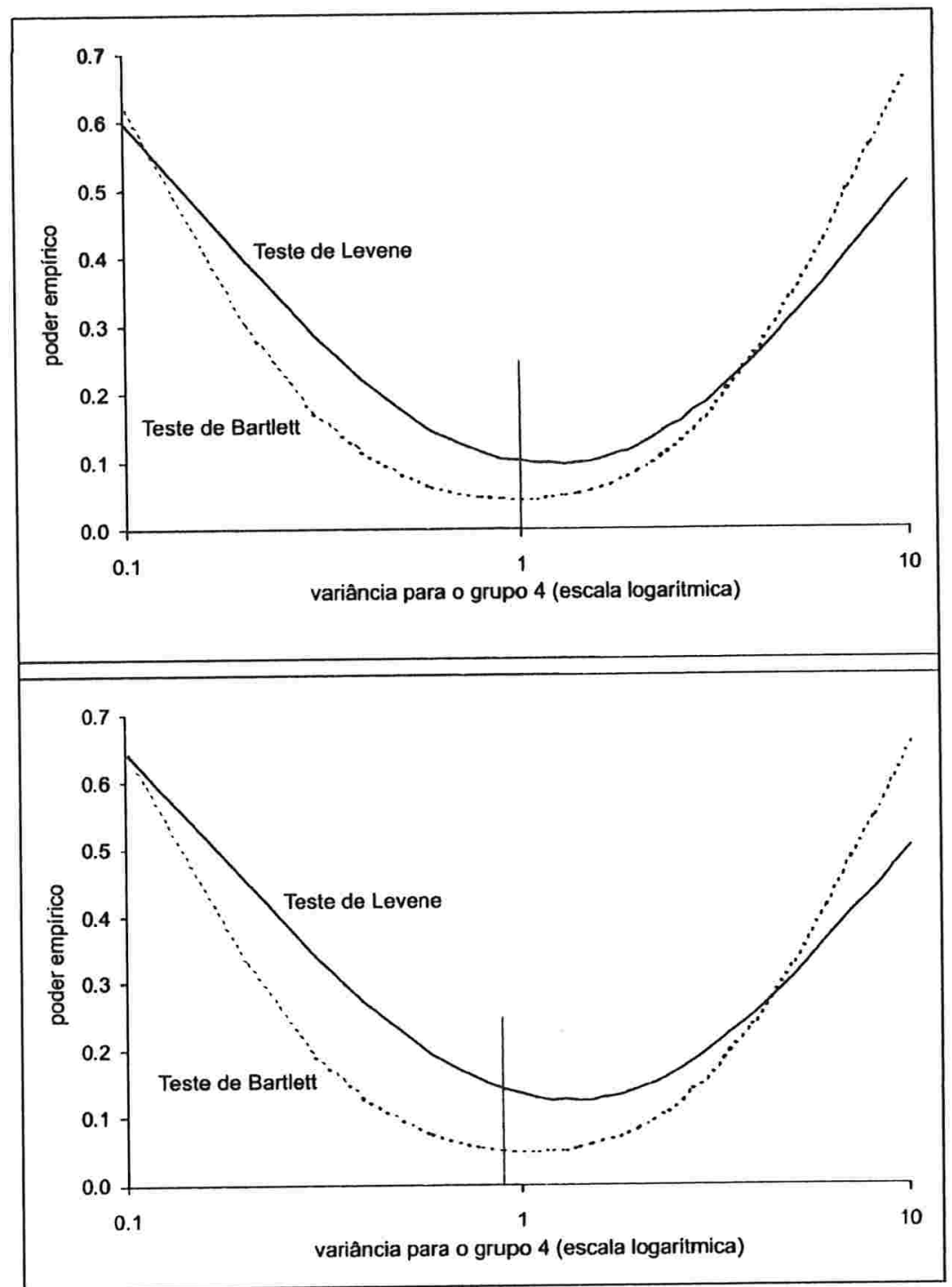

Figura 2.1 - Função Poder dos Testes de Levene e Bartlett Fonte: Figura 1- O'Neill e Mathews (2000)

Desta forma, conclui-se que o teste de Levene não é ótimo para testar homogeneidade de variâncias em modelos não balanceados. Keyes e Levy (1997) sugeriram analisar

$$
u_{i j}=\left(1-\frac{1}{n_{i}}\right)^{-\frac{1}{2}} d_{i j}
$$

ao invés de $d_{i j}$. Esse procedimento não provocaria alterações no teste $\mathrm{F}$ e nos P-valores produzidos pelos pacotes computacionais quando o modelo é balanceado, enquanto que 
para modelos não balanceados, o teste $\mathrm{F}$ agora seria ajustado para testar $H_{01}$ ao invés de $H_{02}$.

O’Neill e Mathews (2000) recomendam um tipo de estatística de teste de Levene totalmente nova, baseada no método de mínimos quadrados generalizados. Esse procedimento teria, entre outras, a vantagem de apresentar nível de significância mais próximo do fixado do que aquele produzido pelo teste de Levene usual.

Sejam $z_{i j}, j=1, \ldots, n_{i}, i=1, \ldots, k$ variáveis aleatórias associadas ao $j$-ésimo elemento do $i$-ésimo grupo, $j=1, \ldots, n_{i}, i=1, \ldots, k$, em um modelo de análise de variância com um fator. Seja $\bar{z}_{i .}$ a $i$-ésima média amostral e $\bar{z}=\sum_{i=1}^{k} \sum_{j=1}^{n_{i}} \frac{z_{i j}}{\sum_{i=1}^{k} n_{i}}$ a média geral. Este modelo linear pode ser escrito na forma matricial como

$$
z=X \beta+\varepsilon,
$$

onde $z^{T}=\left(z_{11}, \ldots, z_{1 n_{1}}, \ldots, z_{k 1}, \ldots, z_{k n_{k}}\right)$, X é a matriz de planejamento formada por zeros $\mathrm{e}$ uns, $\beta^{T}=\left(\mu_{1}, \ldots, \mu_{k}\right)$ e $\varepsilon$ é o correspondente vetor de erros aleatórios.

Se os $z_{i j}$ são independentes com médias $\mu_{i}$ e variância constante $\sigma^{2}$, é utilizado o procedimento de mínimos quadrados ordinários. O estimador de mínimos quadrados de $\beta$ é $\left(X^{\prime} X\right)^{-1} X^{\prime} z$ e a estatística

$$
F=\frac{N-k}{k-1} \frac{\sum_{i=1}^{k} n_{i}\left(\bar{z}_{i .}-\bar{z}\right)^{2}}{\sum_{i=1}^{k} \sum_{j=1}^{n_{i}}\left(z_{i j}-\bar{z}_{i .}\right)^{2}}
$$

onde $N$ é o número total de elementos, $N=\sum_{i=1}^{k} n_{i}=k n$ se $n_{i}=n \forall i$, testa a hipótese : $H_{0}: \mu_{1}=\mu_{2}=\ldots=\mu_{k}$ contra a alternativa de que nem todas as médias são iguais. Dessa forma, o método de mínimos quadrados ordinários é usado quando a matriz de covariância de z é $\sigma^{2} I_{N}$, onde $I_{N}$ é a matriz identidade $N \times N$.

Suponhamos agora que a matriz de covariância de z seja $\sigma^{2} V$, onde $V$ é uma matriz positiva definida de forma conhecida. Esta formulação inclui o caso em que as 
variâncias das observações não são idênticas e também quando as observações são correlacionadas. Nestas condições, utiliza-se o procedimento de mínimos quadrados generalizados. Este procedimento consiste, basicamente, em aplicar uma transformação, que podemos escrever como $V^{-\frac{1}{2}} z$, a qual produz um conjunto de variáveis homocedásticas e não correlacionadas, que podem ser analisadas pelo método de mínimos quadrados ordinários.

O estimador de mínimos quadrados generalizados de $\beta$ é $\left(X^{\prime} V^{-1} X\right)^{-1} X^{\prime} V^{-1} z$ e a soma de quadrados do resíduo fica

$$
S Q D=z^{T}\left(V^{-1}-V^{-1} X\left(X^{T} V^{-1} X\right)^{-1} X^{T} V^{-1}\right) z
$$

A hipótese nula de igualdade de médias é testada através da hipótese linear geral da forma $C \beta=\underset{\sim}{m}$, para $C$ e $\underset{\sim}{m}$ escritas convenientemente (Graybill, 1976).

Em particular, suponhamos que os $z_{i j}$ sejam independentes para elementos pertencentes a diferentes grupos e que no $i$-ésimo grupo, a variância seja constante, igual a $b_{i} \sigma^{2}$ e a covariância entre elementos distintos do grupo seja $c_{i} \sigma^{2}$, com $b_{i}$ e $c_{i}$ conhecidos. Então $V$ pode ser escrita como:

$$
\left.V=\text { Diagonal } \mid\left(b_{1}-c_{1}\right) I_{n_{1}}+c_{1} J_{n_{1}}, \ldots,\left(b_{k}-c_{k}\right) I_{n_{k}}+c_{k} J_{n_{k}}\right\rfloor
$$

onde $J_{n_{i}}$ é uma matriz de "uns" $n_{i} \times n_{i}$. Verifica-se que neste caso a estatística dos mínimos quadrados generalizados para testar $H_{0}=\mu_{1}=\mu_{2}=\ldots=\mu_{k}$ tem a forma

$$
F_{z}=\frac{N-k}{k-1} \frac{\sum_{i=1}^{k} w_{i}\left(\bar{z}_{i .}-\overline{\bar{z}}\right)^{2}}{\sum_{i=1}^{k} w_{i}^{*} \sum_{j=1}^{n_{i}}\left(z_{i j}-\bar{z}_{i .}\right)^{2}},
$$

onde $w_{i}$ e $w_{i}^{*}$ são pesos definidos por

$$
w_{i}=\frac{n_{i}}{b_{i}+\left(n_{i}-1\right) c_{i}}, \quad w_{i}^{*}=\frac{1}{b_{i}-c_{i}}
$$


e $\overline{\bar{z}}$ é a média ponderada de $\bar{z}_{i}$ usando $w_{i}$ como pesos.

Suponha que $b_{i}$ e $c_{i}$ são funções apenas $\operatorname{dos} n_{i}, \operatorname{com} n_{i} c_{i} \rightarrow 0$ quando $n_{i} \rightarrow \infty$. Se além disso, o modelo é balanceado, ou seja, $n_{i}=n$ para todo $i$, sejam $b_{i}=b$ e $c_{i}=c$. Nesse caso, a estatística do teste se tornará

$$
F_{z}=\frac{b-c}{b+(n-1) c} \frac{k(n-1)}{k-1} \frac{n \sum_{i=1}^{k}\left(\bar{z}_{i .}-\bar{z}\right)^{2}}{\sum_{i=1}^{k} \sum_{j=1}^{n}\left(z_{i j}-\bar{z}_{i .}\right)^{2}} .
$$

Essa quantidade é a estatística de mínimos quadrados ordinários dada em (2.2) multiplicada pelo fator $\frac{(b-c)}{b+(n-1) c}$, que tende a 1 quando $n \rightarrow \infty$. Assim, o fator depende somente do número de indivíduos por grupo e não do número de grupos.

Estas considerações são importantes porque verifica-se que, sob $H_{01}$, os valores absolutos dos resíduos baseados na média e na mediana, ou qualquer função deles, têm matrizes de covariância como em (2.3), embora não sejam normalmente distribuídos. Como conseqüência, não é apropriado construir testes com base no procedimento de mínimos quadrados ordinários, como é feito nas formulações atuais do teste de Levene. Por esse motivo, os autores aplicaram uma análise de mínimos quadrados generalizados para os resíduos baseados na média e na mediana, distinguindo as estatísticas F obtidas com subscrito apropriado.

\section{Teste Modificado de Levene Baseado na Média dos Resíduos}

Apresentaremos agora o teste de Levene baseado nos resíduos modificados $u_{i j} \mathrm{e}$ $u_{i j}{ }^{2}$. O teste é obtido a partir do procedimento de mínimos quadrados generalizados, desenvolvido por O’Neill e Mathews (2000).

Suponha que $y_{i j}$ represente o $j$-ésimo indivíduo $\left(j=1, \ldots, n_{i}\right)$ do $i$-ésimo grupo $(i=1, \ldots, k)$ de um modelo com um fator e $\sigma_{i}{ }^{2}$ a $i$-ésima variância populacional. 
Sem perda de generalidade os autores assumiram que $E\left(y_{i j}\right)=0$. Suponha que $\bar{y}_{i}$. represente a média do $i$-ésimo grupo. Assim, os resíduos modificados baseados na média são definidos como

$$
u_{i j}=\sqrt{\frac{n_{i}}{n_{i}-1}}\left|y_{i j}-\bar{y}_{i}\right|
$$

e verifica-se que estas variáveis não têm distribuição normal.

Para o $i$-ésimo grupo, a função densidade de probabilidade de $\left(u_{i 1}, \ldots, u_{i n_{i}}\right)$ é obtida por Fisher (1920), citado em O'Neill e Mathews (2000).

No caso,

$$
\begin{gathered}
E\left(u_{i j}\right)=\sqrt{\frac{2}{\pi}} \sigma_{i}, \quad \operatorname{Var}\left(u_{i j}\right)=\left(1-\frac{2}{\pi}\right) \sigma_{i}^{2} \\
\operatorname{Cov}\left(u_{i j}, u_{i t}\right)=\frac{2}{\pi}\left(\frac{1}{n_{i}-1}\right)\left(\sqrt{n_{i}\left(n_{i}-2\right)}+\operatorname{seno}^{-1} \frac{1}{n_{i}-1}-\left(n_{i}-1\right)\right) \sigma_{i}{ }^{2}, j \neq t, j, t=1,2, \ldots n_{i} .
\end{gathered}
$$

Assim, a estatística de mínimos quadrados generalizados do teste de Levene baseado na média é

$$
F_{u}=\frac{N-k}{k-1} \frac{\sum_{i=1}^{k} w_{i}\left(\bar{u}_{i .}-\overline{\bar{u}}\right)^{2}}{\sum_{i=1}^{k} w_{i}^{*} \sum_{j=1}^{n_{i}}\left(u_{i j}-\bar{u}_{i .}\right)^{2}},
$$

onde $w_{i}$ e $w_{i}^{*}$ são os pesos definidos em (2.4) com

$$
b_{i}=\left(1-\frac{2}{\pi}\right), \quad c_{i}=\frac{2}{\pi}\left(\frac{1}{n_{i}-1}\right)\left(\sqrt{n_{i}\left(n_{i}-2\right)}+\operatorname{seno}^{-1} \frac{1}{n_{i}-1}-\left(n_{i}-1\right)\right)
$$

$\bar{u}_{i .}$ é a i-ésima média de $u_{i j}$ e $\overline{\bar{u}}$ a média ponderada de $\bar{u}_{i .}$, usando pesos $w_{i}$.

Para a variável $v_{i j}=u_{i j}{ }^{2}$, verifica-se que 


$$
\begin{gathered}
E\left(v_{i j}\right)=\sigma_{i}^{2}, \quad \operatorname{Var}\left(v_{i j}\right)=2 \sigma_{i}{ }^{4}, \\
\operatorname{Cov}\left(v_{i j}, v_{i t}\right)=\frac{2 \sigma_{i}{ }^{4}}{\left(n_{i}-1\right)^{2}}, j \neq t, j, t=1,2, \ldots n_{i} .
\end{gathered}
$$

e se esta variável for usada no teste de igualdade de variâncias, a análise de $v_{i j}$ por mínimos quadrados generalizados resulta na estatística $\mathrm{F}$ dada por

$$
F_{v}=\frac{N-k}{k-1} \frac{\sum_{i=1}^{k} \frac{1}{2}\left(n_{i}-1\right)\left(\bar{v}_{i .}-\overline{\bar{v}}\right)^{2}}{\sum_{i=1}^{k} \frac{\left(n_{i}-1\right)^{2}}{2 n_{i}\left(n_{i}-2\right)} \sum_{j=1}^{n_{i}}\left(v_{i j}-\bar{v}_{i}\right)^{2}},
$$

com $\bar{v}_{i .}$ e $\overline{\bar{v}}$ definidos de forma análoga às correspondentes expressões presentes em $F_{u}$.

\section{Teste Modificado de Levene Baseado ma Mediana dos Resíduos}

Apresentaremos a seguir a modificação proposta no teste de Levene baseado nos resíduos relativos à mediana. Novamente aqui, será utilizada a aproximação de mínimos quadrados generalizados.

Suponha que $y_{i j}$ represente o $j$-ésimo indivíduo $\left(j=1, \ldots, n_{i}\right)$ do $i$-ésimo grupo $(i=1, \ldots, k)$ de um modelo de análise de variância com um fator e $\sigma_{i}{ }^{2}$ a $i$-ésima variância populacional. Sem perda de generalidade, O’Neill e Mathews (2000) assumiram que $E\left(y_{i j}\right)=0$.

Suponha ainda que $\tilde{y}_{i}$. represente a mediana do $i$-ésimo grupo. Assim, os resíduos baseados na mediana são definidos como $\widetilde{r}_{i j}=y_{i j}-\tilde{y}_{i \text {. }}$ e seus valores absolutos como $\tilde{d}_{i j}=\left|y_{i j}-\tilde{y}_{i .}\right|$. 
O teste de homogeneidade de variâncias de Levene, que descrevemos na Seção 2.3.1, é uma análise de variância por mínimos quadrados ordinários nos $\widetilde{d}_{i j}$. Essa forma do teste foi sugerida por Brown e Forsythe (1974a) e está disponível no pacote computacional MINITAB. No entanto, assim como no teste baseado nos desvios com relação à média, essa análise de variância não testa a hipótese de homogeneidade de variâncias quando o modelo é não balanceado.

Observa-se que, para um particular conjunto de dados, o teste de Levene baseado na mediana é simplesmente uma análise de variância de

$$
\left\{\tilde{y}_{i .}-y_{i(1)}, \ldots, \tilde{y}_{i .}-y_{i\left(m_{l}\right)}, y_{i\left(m_{i}+1\right)}-\tilde{y}_{i,}, \ldots, y_{i\left(n_{i}\right)}-\tilde{y}_{i .}\right\} \text { para } i=1, \ldots, k,
$$

onde $y_{i(k)}$ representa a $k$-ésima estatística de ordem para o $i$-ésimo grupo, e $m_{i}$ é a posição da mediana no conjunto de dados ordenado. Para $n_{i}$ ímpar, $y_{i\left(m_{i}\right)}-\tilde{y}_{i .}=0$ e para $n_{i}$ par, $\tilde{y}_{i .}-y_{i\left(\frac{n_{i}}{2}\right)}=y_{i\left(\frac{n_{i}+1}{2}\right)}-\widetilde{y}_{i .}$. Assim, os momentos de $\widetilde{d}_{i j}$ envolvem os momentos das estatísticas de ordem. Para variáveis normal padrão, as médias, variâncias e covariâncias das estatísticas de ordem são tabuladas, por exemplo em Owen (1962), citado em O'Neill e Mathews (2000). Alternativamente, podem ser encontradas facilmente por integração numérica e estão disponíveis na área do Publications/Journal, no web site www.cropsci.usyd.edu.au .

Verifica-se que

$$
E\left(\tilde{d}_{i j}\right)=\frac{1}{n_{i}} \sum_{l=1}^{m_{i}} E\left(y_{i\left(n_{i}-l+1\right)}-y_{i(l)}\right)=l_{n_{i}} \sigma_{i}
$$

onde $l_{n_{i}}$ é uma constante dependendo somente do tamanho da amostra $n_{i}$, tal que para todo $m, l_{2 m}=l_{2 m+1}$. Portanto, de maneira análoga à $d_{i j}$, notamos que a análise de variância para os $\tilde{d}_{i j}$ testa a hipótese

$$
H_{03}: l_{n_{1}}{ }^{2} \sigma_{1}{ }^{2}=l_{n_{2}}{ }^{2} \sigma_{2}{ }^{2}=\ldots=l_{n_{k}} \sigma_{k}{ }^{2}
$$

ao invés de $H_{01}$ quando o modelo é não balanceado (a menos que o grau de desbalanceamento seja tal que todo $n_{i}$ coincida com $2 m$ ou $2 m+1$, para algum $m$ ). A 
solução no caso geral seria então utilizar a análise por mínimos quadrados generalizados das variáveis

$$
\widetilde{u}_{i j}=\frac{1}{l_{n_{i}}}\left|y_{i j}-\widetilde{y}_{i .}\right|,
$$

obtendo a estatística que denominaremos $F_{\widetilde{u}}$.

Para determinar as variâncias e covariâncias dos $\tilde{u}_{i j}$, os autores utilizam dois resultados:

a) Para uma amostra da distribuição normal padrão, a soma dos elementos em uma linha ou uma coluna da matriz de covariância das estatísticas de ordem é 1;

b) Para uma amostra de $n_{i}$ observações da distribuição normal padrão,

$$
\sum_{j=1}^{n_{i}} E\left(y_{i j}^{2}\right)=\sum_{l=1}^{n_{i}} E\left(y_{i(l)}^{2}\right)=n_{i} .
$$

Usando esses resultados básicos associados à distribuição normal, temos que para todo $i$ e $j$,

$$
E\left(\tilde{u}_{i j}{ }^{2}\right)=\frac{1}{n_{i}} \sum_{l=1}^{n_{i}} E\left(y_{i(l)}-\tilde{y}_{i .}\right)^{2}=\frac{1}{n_{i}} \sum_{l=1}^{n_{i}} E\left(y_{i(l)}{ }^{2}\right)-\frac{2}{n_{i}} \sum_{l=1}^{n_{i}} E\left(y_{i(l)} \tilde{y}_{i .}\right)+E\left(\tilde{y}_{i .}{ }^{2}\right)=\frac{n_{i}-2}{n_{i}} \sigma_{i}{ }^{2}+\operatorname{Var}\left(\tilde{y}_{i .}\right)
$$

e portanto,

$$
\operatorname{Var}\left(\tilde{u}_{i j}\right)=\frac{1}{l_{n_{i}}^{2}}\left(\frac{n_{i}-2}{n_{i}} \sigma_{i}^{2}+\operatorname{Var}\left(\widetilde{y}_{i}\right)\right)-\sigma_{i}^{2}
$$

O cálculo de $\operatorname{Cov}\left(\tilde{u}_{i j}, \widetilde{u}_{i t}\right)$ está disponível no web site citado anteriormente.

É fundamental destacar que os testes propostos resolvem o problema da desigualdade de variâncias e existência de correlação entre as variáveis $d_{i j}, i=1, \ldots, k$, $j=1, \ldots, n_{i}$ e $\left|d_{i j}\right|, i=1, \ldots, k, \quad j=1, \ldots, n_{i}$. No entanto, a análise de variância do procedimento de mínimos quadrados generalizados também necessita da suposição de normalidade, suposição essa que não é válida nas modificações consideradas. Tal 
problema porém é minimizado devido à maior robustez da Análise de Variância com relação à falta de normalidade do que com relação à desigualdade de variâncias e existência de correlação. 


\section{Capítulo 3}

\section{Teste de Brown e Forsythe e suas modificações}

\subsection{Introdução}

Suponhamos que $X_{i j}$ represente a j-ésima observação da i-ésima amostra correspondente ao i-ésimo grupo, com $j=1,2, \ldots, n_{i}$ e $i=1,2, \ldots, k$, sendo que as $k$ amostras são independentes, as populações normais e as variâncias iguais. A estatística F da análise de variância com um fator para testar a hipótese nula de igualdade de médias $H_{0}=\mu_{1}=\mu_{2}=\ldots=\mu_{k}$, ao nível de significância $\alpha$, contra a hipótese alternativa que nem todas as médias são as mesmas, $H_{a}: \mu_{i} \neq \mu_{g}$ para algum $i \neq g, i, g=1,2, \ldots, k$, é dada por: 


$$
\begin{aligned}
& F=\frac{\sum_{i=1}^{k} n_{i}\left(\bar{X}_{i .}-X_{.}\right)^{2}}{\frac{(k-1)}{\sum_{i=1}^{k}\left(n_{i}-1\right) s_{i}{ }^{2}}}, \\
& \text { onde } n=\sum_{i=1}^{k} n_{i}, \bar{X}_{i .}=\frac{1}{n_{i}} \sum_{j=1}^{n_{i}} X_{i j}, \\
& X_{. .}=\sum_{i} \sum_{j} \frac{X_{i j}}{n}=\sum_{i} \frac{n_{i} \bar{X}_{i .}}{n} \mathrm{e} \\
& s_{i}^{2}=\sum_{j} \frac{\left(X_{i j}-\bar{X}_{i .}\right)^{2}}{n_{i}-1} .
\end{aligned}
$$

Se as variâncias populacionais são iguais, quando há igualdade de médias, ou seja, sob $H_{0}$, essa estatística tem distribuição $\mathrm{F}$ de Snedecor central com $k-1$ e $n-k$ graus de liberdade no numerador e denominador respectivamente.

A estatística $\mathrm{F}$ da análise de variância com um fator produz um teste que é sensível à falta de homogeneidade de variâncias, ou seja, quando os grupos apresentam variâncias populacionais diferentes, o tamanho real do teste não coincide com o tamanho fixado. Neste caso, uma melhor solução seria o teste proposto por Brown e Forsythe (1974b), que leva seu nome e que utiliza a estatística $F^{*}$, uma modificação da estatística F.

O problema de comparar médias de distribuições normais independentes para três ou mais grupos quando há heterocedasticidade é conhecido como problema de Behrens-Fisher generalizado. Várias soluções foram propostas para esse problema, entre elas a de Brown e Forsythe (1974b) que utiliza a estatística $F^{*}$ e será descrita na seção seguinte. 
O objetivo deste capítulo é apresentar o teste de Brown e Forsythe e algumas de suas mais recentes modificações.

\subsection{Teste de Brown e Forsythe}

Suponhamos que $X_{i j}$ represente a j-ésima observação no i-ésimo grupo, com $j=1, \ldots, n_{i}$ e $i=1, \ldots, k$. Os $X_{i j}$ são observações independentes e possuem distribuição Normal com média $\mu_{i}$ e variância $\sigma_{i}{ }^{2}$. Desejamos testar a hipótese nula de igualdade de médias $H_{0}: \mu_{1}=\mu_{2}=\ldots=\mu_{k}$, ao nível de significância $\alpha$, contra a hipótese alternativa que nem todas as médias são iguais, $H_{a}: \mu_{i} \neq \mu_{g}$ para algum $i \neq g, i, g=1,2, \ldots, k$.

A estatística proposta por Brown e Forsythe para testar $H_{0}, F^{*}$, é definida como

$$
F^{*}=\frac{\sum_{i=1}^{k} n_{i}\left(\bar{X}_{i .}-X\right)^{2}}{\sum_{i=1}^{k}\left(1-\frac{n_{i}}{n}\right) s_{i}^{2}} .
$$

Os valores críticos de $F^{*}$ são obtidos da distribuição $\mathrm{F}$ de Snedecor com $k-1$ graus de liberdade no numerador e $f$ no denominador, onde $f$ é implicitamente definido pela aproximação de Satterthwaite (1941), discutida em Brown e Forsythe (1974b):

$$
\frac{1}{f}=\sum_{i=1}^{k} \frac{c_{i}{ }^{2}}{\left(n_{i}-1\right)} \text { e } c_{i}=\frac{\left(1-\frac{n_{i}}{n}\right) s_{i}{ }^{2}}{\sum_{i=1}^{k}\left(1-\frac{n_{i}}{n}\right) s_{i}{ }^{2}}
$$

Através de um estudo de simulação, utilizando diferentes variâncias populacionais e amostras de diversos tamanhos, Brown e Forsythe (1974b) compararam o tamanho e o poder do teste de igualdade de médias populacionais na situação de 
desigualdade de variâncias utilizando as estatísticas: $F$ da Análise de Variância, $F^{*}$, e as propostas por Welch (1951) e James (1951).

A estatística proposta por Welch (1951) é dada por:

$$
W=\frac{\frac{\sum_{i=1}^{k} w_{i}\left(\bar{X}_{i .}-\tilde{X}_{. .}\right)^{2}}{k-1}}{\left[1+\frac{2(k-2)}{\left(k^{2}-1\right)} \sum_{i=1}^{k} \frac{\left(1-\frac{w_{i}}{u}\right)^{2}}{\left(n_{i}-1\right)}\right]},
$$

onde

$$
w_{i}=\frac{n_{i}}{s_{i}{ }^{2}}, \quad u=\sum_{i} w_{i} \quad \text { e } \quad \tilde{X}_{. .}=\sum_{i} \frac{w_{i} \bar{X}_{i}}{u}
$$

Quando as médias populacionais são iguais, $W$ tem aproximadamente distribuição $\mathrm{F}$ de Snedecor, com $k-1$ e $f$ graus de liberdade, sendo que $f$ é definido de modo que

$\frac{1}{f}=\frac{3}{k^{2}-1} \sum_{i=1}^{k} \frac{\left(1-\frac{w_{i}}{u}\right)^{2}}{\left(n_{i}-1\right)}$.

A estatística proposta por James(1951) é da forma:

$$
J=\sum_{i=1}^{k} \frac{w_{i}\left(\bar{X}_{i .}-\tilde{X}_{. .}\right)^{2}}{(k-1)}
$$

Se todas as médias populacionais forem iguais,

$$
P\left\{J>a\left[1+\frac{3 a+(k+1)}{2\left(k^{2}-1\right)} \cdot \sum_{i=1}^{k} \frac{\left(1-\frac{w_{i}}{u}\right)^{2}}{\left(n_{i}-1\right)}\right]\right\}=\alpha
$$


onde $a$ é o percentil de ordem $1-\alpha$ da distribuição Qui-Quadrado com $k-1$ graus de liberdade.

No estudo de simulação realizado, cada condição de análise foi especificada pelos tamanhos da amostra $\left(n_{i}\right)$, médias $\left(\mu_{i}\right)$ e variâncias populacionais $\left(\sigma_{i}{ }^{2}\right)$ para os grupos $(i=1,2, \ldots, k)$. Em cada condição, um conjunto de $n=\sum_{i=1}^{k} n_{i}$ observações de uma distribuição normal com média zero e variânica um foi gerado e associado aos grupos. Esses valores foram multiplicados por $\sigma_{i}$ e somados com $\mu_{i}$ para se obter amostras das populações especificadas. As quatro estatísticas foram calculadas e comparadas com seus percentis de ordem $90 \%, 95 \%$ e $99 \%$ sob $H_{0}$. O procedimento foi repetido 10000 vezes para cada condição usando um diferente valor inicial para o número aleatório gerador da distribuição normal.

Os autores verificaram, através do estudo, que a estatística $F$ da análise de variância apresentou acentuados desvios no tamanho fixado do teste quando as variâncias dos grupos eram desiguais e as outras três estatísticas mostraram pequenas flutuações no tamanho do teste. Para amostras de tamanhos pequenos, verificaram que o teste de hipóteses com estatística $J$ desviava-se mais do tamanho nominal e rejeitava a hipótese nula com maior frequência. $O$ teste de estatística $F^{*}$ variou em tamanho um pouco mais do que o de estatística $W$ e para grupos com mais de 10 observações, a diferença entre os níveis de significância fixado e atingido das duas estatísticas $W$ e $F^{*}$ foi pequena. Quando as variâncias eram iguais, ambas estatísticas $W$ e $F^{*}$ apresentavam poder similiar ao da estatística $F$ da análise de variância.

Observou-se ainda que quando os grupos com médias extremas tinham variâncias pequenas, a estatística $W$ era mais poderosa do que $F^{*}$. Tal fato poderia ser explicado pela diferente ponderação de médias: a estatística $W$ ponderava as médias usando $\frac{n_{i}}{s_{i}{ }^{2}}$ e a estatística $F^{*}, n_{i}$. Dessa forma, médias extremas com variâncias pequenas tenderiam a aumentar $W$ mais do que $F^{*}$, ocorrendo o inverso para médias 
extremas com variâncias grandes. Quando médias extremas vinham acompanhadas de variâncias grandes, o teste de Brown e Forsythe mostrou-se superior.

\subsection{Modificações do Teste de Brown e Forsythe}

Apresentaremos a seguir algumas modificações recentes no teste de Brown e Forsythe propostas por diferentes autores.

\subsubsection{Modificações propostas por Mehrotra}

Mehrotra (1997) aponta uma inadequação na aproximação proposta por Brown e Forsythe (1974b) para a distribuição da estatística de teste $F^{*}$, sob a hipótese nula.

$\mathrm{O}$ autor encontrou a distribuição de $F^{*}$ sob a hipótese nula da seguinte forma:

Inicialmente, identificou $F^{*}$ como uma razão de duas formas quadráticas independentes associadas a um vetor aleatório com distribuição normal multivariada. Sob a hipótese nula de igualdade de médias, as distribuições dessas formas quadráticas foram aproximadas por:

$$
Q_{1}=\sum_{i=1}^{k} n_{i}\left(\bar{X}_{i .}-X_{. .}\right)^{2} \approx a_{1} \chi_{f_{1}}^{2} \quad \text { e } \quad Q_{2}=\sum_{i=1}^{k}\left(1-\frac{n_{i}}{n}\right) s_{i}{ }^{2} \approx a_{2} \chi_{f_{2}}^{2},
$$

onde $\chi_{f}^{2}$ denota uma distribuição qui-quadrado central com $f$ graus de liberdade. Os valores de $a_{1}, a_{2}, f_{1}$ e $f_{2}$ podem ser determinados usando o método de Satterthwaite (1941), ou seja, resolvendo as equações simultâneas $E\left[Q_{i}\right]=a_{i} f_{i}$ e $V\left[Q_{i}\right]=2 a_{i}{ }^{2} f_{i}$, para $i=1,2$. 
Após alguns cálculos, o autor mostrou que $a_{1} f_{1}=a_{2} f_{2}$, com

$$
f_{1}=\frac{\left(\sum_{i=1}^{k} \sigma_{i}{ }^{2}-\frac{\sum_{i=1}^{k} n_{i} \sigma_{i}{ }^{2}}{n}\right)^{2}}{\sum_{i=1}^{k} \sigma_{i}{ }^{4}+\left(\frac{\sum_{i=1}^{k} n_{i} \sigma_{i}{ }^{2}}{n}\right)^{2}-2 \frac{\sum_{i=1}^{k} n_{i} \sigma_{i}{ }^{4}}{n}}
$$

e

$$
f_{2}=\frac{\left[\sum_{i=1}^{k}\left(1-\frac{n_{i}}{n}\right) \sigma_{i}^{2}\right]^{2}}{\sum_{i=1}^{k} \frac{\left(1-\frac{n_{i}}{n}\right)^{2} \sigma_{i}{ }^{4}}{\left(n_{i}-1\right)}}
$$

onde $\sigma_{i}^{2}=E\left(s_{i}^{2}\right)$ é a i-ésima variância populacional.

Na prática os valores de $\sigma_{i}^{2}$, presentes nas fórmulas (3.1) e (3.2) dos graus de liberdade, devem ser substituídos por $s_{i}^{2}$.

Aplicando o Teorema 6.1 dado em Box (1954), citado em Mehrotra (1997), sobre razão de formas quadráticas independentes e sob a hipótese nula, Mehrotra (1997) concluiu que a distribuição de $F^{*}$ poderia ser aproximada por $F^{*} \approx\left(\frac{a_{1} f_{1}}{a_{2} f_{2}}\right) F\left(f_{1}, f_{2}\right)$, onde $F\left(f_{1}, f_{2}\right)$ denota uma distribuição $\mathrm{F}$ central com $f_{1}$ e $f_{2}$ graus de liberdade.

Dessa forma o autor verifica que, como $a_{1} f_{1}=a_{2} f_{2}$, a estatística $F^{*}$ do Teste de Brown e Forsythe, sob $H_{0}$, tem aproximadamente distribuição $F$ com $f_{1}$ e $f_{2}$ graus de liberdade dados por (3.1) e (3.2) respectivamente e não como havia sido proposto por Brown e Forsythe (1974b) (a distribuição de $F^{*}$ era aproximadamente $F\left(k-1, f_{2}\right)$ ).

O número de graus de liberdade do numerador, $f_{1}$ dado em (3.1), somente será igual a $(k-1)$ no caso trivial em que $k=2$ e as variâncias populacionais são iguais. 
Como, em geral, $f_{1}<k-1$, o valor crítico da distribuição $\mathrm{F}$ com $k-1$ e $f_{2}$ graus de liberdade, usado no teste de Brown e Forsythe, tende a ser menor do que deveria. Este fato explicaria porque o teste de Brown e Forsythe apresenta muitas vezes nível de significância real maior do que o nominal.

Assim, segundo Mehrotra (1997), usar $f_{1}$ dado em (3.1) como número de graus de liberdade do numerador na aproximação da distribuição de $F^{*}$, ao invés de $(k-1)$, pode corrigir esta falha no teste de Brown e Forsythe. Resultados empíricos confirmaram o fato, mostrando que o procedimento de Brown e Forsythe modificado, proposto por Mehrotra (1997), de modo geral preservava o tamanho do teste.

\subsubsection{Modificações propostas por Keselman e Wilcox}

Como foi citado anteriormente, Mehrotra (1997) apresentou uma modificação para a estatística do teste de Brown e Forsythe (1974b) de igualdade de médias para amostras independentes de distribuições normais com variâncias heterogêneas. Na estatística do teste modificado, o autor usou uma aproximação dos graus de liberdade do numerador, $f_{1}$, ao invés de usar o número de grupos menos um, $(k-1)$.

Keselman e Wilcox (1999) mostraram que, sob condições semelhantes envolvendo variâncias heterogêneas mas também não normalidade, o teste modificado de Brown e Forsythe apresenta um aumento no erro do tipo I em modelos não balanceados, ou seja, quando os grupos são de tamanhos desiguais. Sendo assim, os autores propõem o uso do teste introduzido por Lix e Keselman (1998), citado em Keselman e Wilcox (1999). O procedimento consiste num teste para igualdade de parâmetros de posição que adota uma estatística de teste utilizando estimadores robustos de tendência central e variabilidade, isto é, médias aparadas e variâncias "Winsorizadas", ao invés dos estimadores usuais. Sugerem ainda que os valores críticos associados a um particular nível de significância sejam obtidos através do método de Bootstrap. 
A hipótese de igualdade de médias, $H_{0}: \mu_{1}=\mu_{2}=\ldots=\mu_{k}$, é substituída pela de igualdade de médias aparadas, $H_{0}: \mu_{a 1}=\mu_{a 2}=\ldots=\mu_{a k}$.

O procedimento proposto pelos autores é o seguinte:

Suponhamos que $n_{i}$ observações independentes $X_{i 1}, \ldots, X_{i n_{i}}$ sejam amostradas da população $i(i=1,2, \ldots, k)$. Assuma que os $X_{i j}{ }^{\prime} s\left(j=1,2, \ldots, n_{i}\right)$ sejam obtidos de uma população normal com média $\mu_{i}$ e variância desconhecida $\sigma_{i}^{2}$, com $\sigma_{i}^{2} \neq \sigma_{i^{\prime}}^{2}$ para algum $i \neq i^{\prime}, i, i^{\prime}=1,2, \ldots, k$.

Sejam $X_{(1) i} \leq X_{(2) i} \leq \ldots \leq X_{\left(n_{i}\right) i}$ as observações ordenadas associadas ao i-ésimo grupo e $J_{i}=\left[\begin{array}{ll}\gamma & n_{i}\end{array}\right]$, onde $\gamma$ representa a proporção de observações aparadas de cada cauda da distribuição. Dessa forma, o tamanho amostral para o i-ésimo grupo é $h_{i}=n_{i}-2 J_{i}$. A i-ésima média amostral aparada é $\bar{X}_{a_{i .}}=\frac{1}{h_{i}} \sum_{j=J_{i}+1}^{n_{i}-J_{i}} X_{(j) i}$.

Define-se ainda a i-ésima média "Winsorizada" como $\bar{X}_{W i .}=\frac{1}{n_{i}} \sum_{j=1}^{n_{i}} Y_{i j}$, onde $Y_{i j}=X_{\left(J_{i}+1\right) i}$ se $X_{i j} \leq X_{\left(J_{i}+1\right) i}$, $Y_{i j}=X_{i j}$ se $X_{\left(J_{i}+1\right) i}<X_{i j}<X_{\left(n_{i}-J_{i}\right) i}$, $Y_{i j}=X_{\left(n_{i}-J_{i}\right) i}$ se $X_{i j} \geq X_{\left(n_{i}-J_{i}\right) i}$.

Observa-se então que, no cálculo da Média Winsorizada, observações inferiores ou iguais à $\left(J_{i}+1\right)$-ésima estatística de ordem são substituídas pela mesma. Analogamente, observações maiores ou iguais à $\left(n_{i}-J_{i}\right)$-ésima estatística de ordem são substituídas por esse valor.

A variância amostral "Winsorizada" para o i-ésimo grupo é definida como $s_{W i}{ }^{2}=\frac{\sum_{j}\left(Y_{i j}-\bar{X}_{W i}\right)^{2}}{\left(n_{i}-1\right)}$. De acordo com Wilcox (1996), citado em Keselman e Wilcox (1999), uma estimativa da variância da média amostral aparada é dado por 
$\widetilde{s}_{W i}{ }^{2}=\frac{\left(n_{i}-1\right) s_{W i}{ }^{2}}{h_{i}\left(h_{i}-1\right)}$. De posse desses estimadores robustos, as médias aparadas do grupo ( $\bar{X}_{a i .}$ 's) substituem as médias amostrais $\left(\bar{X}_{i .}\right.$ 's), os estimadores das variâncias "Winsorizadas" $\left(s_{W i}{ }^{2} \mathrm{~s}\right)$ substituem os estimadores das variâncias usuais $\left(s_{i}{ }^{2} \mathrm{~s}\right) \mathrm{e}$ $\sum_{i=1}^{k} h_{i}$ substitui $n=\sum_{i=1}^{k} n_{i}$, ou seja, $h_{i}$ substitui $n_{i}$, na estatística do teste de Welch e em seus graus de liberdade. Dessa forma, obtém-se a estatística robusta de teste:

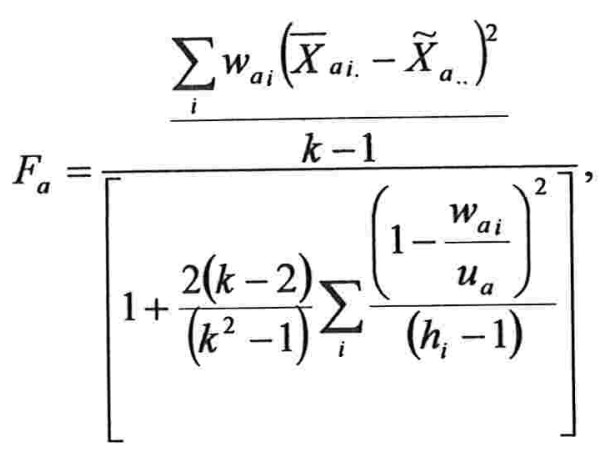

onde $w_{a i}=\frac{h_{i}}{\widetilde{s}_{W i}^{2}}, \tilde{X}_{a . .}=\frac{\sum_{i=1}^{k} w_{a i} \bar{X}_{a i .}}{u_{a}}, u_{a}=\sum_{i=1}^{k} w_{a i}$ e $f_{a}$ é dado por $f_{a}=\frac{k^{2}-1}{3 \sum_{i=1}^{k} \frac{\left(1-\frac{w_{a i}}{u_{a}}\right)^{2}}{h_{i}-1}}$.

Definida a estatística do teste, o valor crítico é estimado através da construção de distribuições empíricas via Bootstrap, da forma descrita a seguir.

Sejam $C_{i j}=X_{i j}-\bar{X}_{a i .}, i=1,2, \ldots, k$ e $j=1,2, \ldots, n_{i}$, os valores das variáveis originais centralizados pela média aparada.

Para o i-ésimo grupo, determina-se a amostra Bootstrap selecionando aleatoriamente, com reposição $n_{i}$ observações dentre as $C_{i j}, j=1,2, \ldots, n_{i}$, gerando as novas observações $X_{i 1}^{*}, \ldots, X_{i i_{i}}^{*}$.

Se $F_{a}^{*}$ é o valor de $F_{a}$ calculado com base em $X_{i 1}^{*}, \ldots, X_{i n_{i}}^{*}, i=1,2, \ldots, k$, repete-se o procedimento B vezes, obtendo-se B valores ${F_{a 1}}^{*}, \ldots, F_{a B}{ }^{*}$. 
O nível de significância estimado $\left(p^{*}\right)$ de uma estatística de teste Bootstrap é a proporção de vezes que esta estatística é maior do que a do teste baseado nos dados originais. Obtido $p^{*}$, se $p^{*} \leq \alpha$, rejeita-se $H_{0}: \mu_{a 1}=\mu_{a 2}=\ldots=\mu_{a k}$.

Wilcox verificou que $\mathrm{B}=599$ proporciona um controle satisfatório no erro do tipo I. 


\section{Capítulo 4}

\section{Testes Aleatorizados para Igualdade de Médias e de Variâncias}

\subsection{Introdução}

A tarefa aparentemente simples de comparar médias e variâncias de duas ou mais populações e de verificar se elas são significantemente diferentes é na verdade bastante difícil quando as amostras são provenientes de distribuições "muito distantes" da normal.

De acordo com Manly e Francis (2002), há três problemas potenciais:

1- Se não existe desigualdade nas variâncias entre as populações, os testes para comparar as médias podem ter propriedades pobres ( tamanho excessivo ou poder baixo) devido à não normalidade; 
2- Se existem diferenças nas variâncias mas não nas médias, os testes de igualdade de médias podem ter tamanhos excessivos devido à sensibilidade à desigualdade de variâncias; e

3- Testes para comparar variâncias mesmo quando não afetados por diferenças nas médias, podem ter propriedades pobres como conseqüência da não normalidade.

Um teste aleatorizado é um particular teste de permutação que é baseado em aleatorização e é realizado da seguinte maneira:

Uma estatística de teste é calculada para os dados experimentais (medidas ou observações), os dados são permutados (divididos e reorganizados) repetidamente de acordo com o procedimento de escolha aleatória e a estatística de teste é calculada para cada um dos resultados das permutações dos dados. Essas permutações dos dados, incluindo aquela representando os resultados obtidos inicialmente, constituem o conjunto referência para determinar o nível de significância. A proporção de permutações dos dados, no conjunto referência, com valores da estatística de teste maiores ou iguais (ou, para certas estatísticas de teste, menores ou iguais) ao valor obtido experimentalmente é o nível descritivo (ou p-valor). Definir a significância com base na distribuição de estatísticas de teste geradas por permutar os dados é característica de todos os testes de permutação.

Um teste de permutação é chamado teste aleatorizado quando a permutação dos dados é feita através de escolhas aleatórias.

A hipótese nula para um teste aleatorizado é de que a distribuição de probabilidades da variável para cada unidade experimental é a mesma qualquer que seja a associação dos tratamentos. Assim, sob a hipótese nula, a escolha de unidades experimentais para os tratamentos teria sido feita de forma aleatória.

Neste capítulo, descreveremos os testes aleatorizados propostos por Francis e Manly (2001), Manly e Francis (2002) e Manly (1995), que podem ser utilizados como alternativas aos testes de Levene e Brown Forsythe apresentados nos capítulos anteriores. 


\subsection{Teste Conjunto}

Manly e Francis (2002) apresentam como proposta para o problema de comparar médias e variâncias, um teste aleatorizado conjunto, cuja hipótese nula é a de que as amostras comparadas provem da mesma distribuição. Os autores propõem o uso da estatística da razão de verossimilhança para testar se as amostras são provenientes de uma mesma distribuição normal. Se $X_{i j}, i=1,2, \ldots, k, j=1,2, \ldots, n_{i}$ correspondem às $k$ amostras aleatórias das $k$ populações, a estatística de teste é calculada como:

$$
\begin{aligned}
& T_{0}=\sum_{i=1}^{k} n_{i} \log _{e}\left(\frac{V_{T}}{V_{i}}\right), \\
& \text { onde } \\
& V_{i}=\sum_{j=1}^{n_{i}} \frac{\left(X_{i j}-\bar{X}_{i}\right)^{2}}{n_{i}}
\end{aligned}
$$

é o estimador de máxima verossimilhança da variância da i-ésima população, $\bar{X}_{i}$ é a média da i-ésima amostra e

$$
V_{T}=\sum_{i=1}^{k} \sum_{j=1}^{n_{l}} \frac{\left(X_{i j}-\bar{X}\right)^{2}}{n}
$$

é o estimador de máxima verossimilhança da variância comum, $\bar{X}$ é a média amostral geral e $n=n_{1}+n_{2}+\ldots+n_{k}$ é o número total de observações.

A estatística $T_{0}$ é sensível tanto a diferenças entre médias como a diferenças entre variâncias amostrais. $\mathrm{O}$ fato de as amostras serem provenientes de uma distribuição normal é irrelevante se a significância de um valor observado é obtida por aleatorização. 
Dessa forma $T_{0}$ é considerado significante ao nível $100 \alpha \%$ quando exceder o quantil de ordem $100(1-\alpha) \%$ do conjunto consistindo do próprio $T_{0}$ e de M-1 valores de $T_{0}$ calculados após realocação aleatória dos dados observados às amostras.

Se $T_{0}$ for calculado para um conjunto de dados e for encontrado um resultado não significante com o teste aleatorizado, é razoável concluir que não há qualquer evidência para diferenças entre as distribuições, em termos de médias ou variâncias. Se $T_{0}$ for significante, então há evidências de diferenças. Para identificar se as diferenças são nas médias, variâncias ou ambas, é necessário algum teste adicional. Os autores constroem testes separados para igualdade de médias e igualdade de variâncias, que serão apresentados nas próximas seções.

\subsection{Teste de Igualdade de Variâncias de Levene Aleatorizado}

O Teste de Levene aleatorizado, proposto por Francis e Manly (2001), é simplesmente uma forma aleatorizada do teste de Levene. Inicialmente, o teste de Levene convencional baseado na mediana é aplicado e o valor da estatística $\mathrm{F}$ obtido, $\mathrm{F}_{1}$, é registrado. Em seguida:

a) os dados originais são transformados através da subtração das medianas amostrais,

b) os dados transformados são aleatoriamente reorganizados para as amostras,

c) o teste de Levene é aplicado para os dados transformados e reorganizados e um novo valor da estatística $\mathrm{F}$ resultante, $\mathrm{F}_{2}$, é guardado,

d) os passos b) e c) são repetidos muitas vezes para gerar $F_{3}, F_{4}, \ldots, F_{n}$ para algum $n$ grande. $\mathrm{O}$ nível descritivo do teste é a porcentagem de valores $\mathrm{F}_{1}, \mathrm{~F}_{2}, \ldots, \mathrm{F}_{\mathrm{n}}$ que são maiores ou iguais a $F_{1}$. 


\subsection{Teste de Igualdade de Médias Aleatorizado}

Manly (1995) destaca que testes aleatorizados para igualdade de médias quase sempre são muito sensíveis à desigualdade de variâncias. Como conseqüência, o nível de significância atingido pode ser muito diferente do fixado.

Devido a esse problema, o autor constrói um teste de igualdade de médias aleatorizado que prevê uma possível desigualdade de variâncias.

Consideremos o problema de testar $H_{0}: \mu_{1}=\mu_{2}=\ldots=\mu_{k}$, com base na amostra aleatória $X_{i j}, \mathrm{i}=1,2, \ldots, \mathrm{k}, \mathrm{j}=1,2, \ldots, \mathrm{n}_{\mathrm{i}}$, sendo que $E\left(X_{i j}\right)=\mu_{i}$ e $\operatorname{Var}\left(X_{i j}\right)=\sigma_{i}{ }^{2}$.

A idéia básica do procedimento é transformar as variáveis $X_{i j}, i=1,2, \ldots, k$, $j=1,2, \ldots, n_{i}$ em variáveis $U_{i j}$, com mesma média que $X_{i j}$ e variância constante, igual a 1.

Esta construção é equivalente a admitir que $X_{i j}=A_{i}+B_{i} U_{i j}$, para escolhas convenientes de $A_{i}$ e $B_{i}$.

A análise é feita sob $H_{0}$, de modo que $E\left(X_{i j}\right)=\mu$, para todo $i$. Além disso, por construção, temos que $E\left(U_{i j}\right)=\mu, i=1,2, \ldots, k, j=1,2, \ldots, n_{i}$.

Como conseqüência,

$$
E\left(X_{i j}\right)=A_{i}+B_{i} E\left(U_{i j}\right)=A_{i}+B_{i} \mu=\mu
$$

e assim

$$
A_{i}=\mu\left(1-B_{i}\right), X_{i j}=\mu+B_{i}\left(U_{i j}-\mu\right) \text { e } U_{i j}=\mu+\frac{X_{i j}-\mu}{B_{i}} .
$$

As quantidades $\mu$ e $B_{i}$ são desconhecidas e devem ser estimadas. Como é assumido que $\operatorname{Var}\left(U_{i j}\right)=1$, então $\operatorname{Var}\left(X_{i j}\right)=B_{i}{ }^{2}$, de modo que $B_{i}{ }^{2}$ é estimado por

$$
\hat{B}_{i}^{2}=\sum_{j=1}^{n_{i}} \frac{\left(X_{i j}-\bar{X}_{i}\right)^{2}}{n_{i}-1}, i=1,2, \ldots, k .
$$


Adicionalmente, estima-se a média comum $\mu$ por $\hat{\mu}=\frac{\sum_{i=1}^{k} \frac{n_{i} \bar{X}_{i}}{\hat{B}_{i}}}{\sum_{i=1}^{k} \frac{n_{i}}{\hat{B}_{i}}}$. É fácil verificar que $\hat{\mu}$ assim definido é o estimador de mínimos quadrados ponderados de $\mu$, sendo portanto o estimador linear não viciado de variância mínima para esse parâmetro, quando admite-se que $\hat{B}_{i}$ é o verdadeiro valor de $B_{i}$.

Com base nesses elementos, o procedimento fica:

1- Aplica-se o teste de igualdade de médias com estatística $\mathrm{F}$ às variáveis originais $X_{i j}$. Seja $F_{1}$ o valor da estatística de teste.

2- As equações

$\hat{\mu}=\frac{\sum_{i=1}^{k} \frac{n_{i} \bar{X}_{i}}{\hat{B}_{i}}}{\sum_{i=1}^{k} \frac{n_{i}}{\hat{B}_{i}}}$

e

$\hat{B}_{i}=\sqrt{\frac{\sum_{j=1}^{n_{i}}\left(X_{i j}-\hat{\mu}\right)^{2}}{n_{i}}}, i=1,2, \ldots, k$

são resolvidas iterativamente, partindo-se de $\hat{B}_{i}=1 \mathrm{e}$ aplicando-se sucessivamente (a), (b), (a), (b), ,..

De acordo com Manly (1995), este procedimento sempre convergiu em simulações e para dados reais.

3- Calcula-se os valores de $U_{i j}$,

$U_{i j}=\hat{\mu}+\frac{\left(X_{i j}-\hat{\mu}\right)}{\hat{B}_{i}}$

4- Os valores dos $U_{i j}$ são realocados aleatoriamente às amostras, correspondendo ao conjunto aleatorizado de dados transformados. (Observamos que aqui a alocação é feita 
sob igualdade de variâncias). $\mathrm{O}$ correspondente conjunto de dados não transformado é tal que $X_{i j}=\hat{\mu}+\hat{B}_{i}\left(U_{i j}-\hat{\mu}\right)$.

É feita a análise de variâncias para essa alocação dos $X_{i j}$, determinando-se assim o valor da estatística $\mathrm{F}$ do teste aleatorizado para a situação em que existe desigualdade de variâncias.

5- $O$ passo 4 é repetido M-1 vezes, gerando $F_{2}, F_{3}, \ldots, F_{M}$. O valor $F_{1}$, obtido no passo 1 , é considerado significante ao nível $100 \alpha \%$ se exceder os $100(1-\alpha) \%$ menores valores dentre os $F_{1}, F_{2}, \ldots, F_{M}$.

Portanto, aplicando-se esse procedimento assumiu-se que sob $H_{0}$ as observações foram geradas por um mecanismo que associou aleatoriamente os valores dos $U_{i j}$ às $k$ amostras. Como os $U_{i j}$ têm variância constante, o problema da desigualdade de variâncias, durante a aleatorização, não existiria.

\subsection{Teste de Igualdade de Médias Aleatorizado com Calibração Bootstrap}

Francis e Manly (2001) descrevem dois procedimentos de calibração Bootstrap: um para testes de igualdade de médias e o outro para testes de igualdade de variâncias. Ambos têm o mesmo propósito. Deseja-se inicialmente determinar se o tamanho real do teste aleatorizado difere do seu tamanho nominal para posteriormente, se necessário, calibrar o teste a fim de que os tamanhos nominal e real coincidam.

O procedimento de calibração é mais complicado para testes de médias do que de variâncias devido ao fato de que os testes de médias são sensíveis à diferenças nas variâncias populacionais, enquanto os testes de variâncias são inafetados por diferenças nas médias populacionais. No primeiro caso, o procedimento poderia ser aplicado para qualquer teste de diferença de médias. Já o segundo seria utilizado para qualquer teste de igualdade de variâncias que fosse inafetado por diferenças nas médias populacionais. 
Francis e Manly (2001) mostram como um teste aleatorizado pode ser melhorado utilizando-se dados que passaram pelo procedimento de Bootstrap.

Os autores começam descrevendo o procedimento mais complicado (para testar igualdade de médias) e posteriormente mostram como pode ser simplificado para testes de igualdade de variâncias.

Assuma que deseja-se comparar $k$ médias com base nos valores de $k$ amostras, que a i-ésima amostra seja de tamanho $n_{i}$, consistindo de valores $X_{i j}$, para cada $j=1,2, \ldots, n_{i}$, com média $\overline{X_{i}}$ e variância $\hat{V}_{i}=\frac{\sum_{j}\left(X_{i j}-\overline{X_{i}}\right)^{2}}{\left(n_{i}-1\right)}$. Suponha adicionalmente que as amostras estejam ordenadas de tal forma que a amostra 1 seja tão grande quanto possível.

O método de Calibração via Bootstrap proposto consiste em "reamostrar" os dados originais de modo a obter novos conjuntos de dados com mesmas médias que o conjunto original mas variâncias iguais à da distribuição gerada no procedimento Bootstrap.

Os passos envolvidos no procedimento são os seguintes:

a) O teste de igualdade de médias usual é realizado a um nível de significância $\alpha$. Rejeita-se a hipótese de igualdade de médias neste teste, que é não calibrado, se seu nível descritivo, $p_{0}$, for menor ou igual a $\alpha$.

b) As observações na amostra 1 são usadas como uma distribuição Bootstrap para serem reamostradas com reposição representando a distribuição original desconhecida. Essa distribuição tem média $\mu=\overline{X_{1}}$ e variância $\sigma^{2}=\hat{V}_{1} \frac{n_{1}-1}{n_{1}}$.

c) A distribuição Bootstrap é amostrada para produzir amostras Bootstrap de tamanhos $n_{1}, n_{2}, \ldots, n_{k}$ e suas variâncias amostrais são calculadas. Essas variâncias são denotadas por $\hat{V}_{B_{i}}$, para $i=1,2, \ldots, k$. 
d) A razão $R_{i}=\frac{\hat{V}_{B_{i}}}{\sigma^{2}}$ é encarada como aproximadamente um valor aleatório da distribuição da razão entre a variância amostral e a verdadeira variância para uma amostra de tamanho $n_{i}$ da distribuição original. Igualando $R_{i}$ a $\frac{\hat{V}_{i}}{V_{i}}$ onde $V_{i}$ é a verdadeira variância da distribuição da qual cada amostra $i$ foi selecionada, então considera-se $V_{B_{i}}=\frac{\hat{V}_{i}}{R_{i}}=\frac{\hat{V}_{i} \sigma^{2}}{\hat{V}_{B_{i}}}$ como um plausível valor para $V_{i}$.

e) A distribuição Bootstrap é amostrada novamente para gerar amostras Bootstrap de tamanhos $n_{1}, n_{2}, \ldots, n_{k}$, e essas amostras são ajustadas de tal forma que a variância para a i-ésima amostra seja igual a $V_{B_{i}}$, mas os valores esperados sejam inalterados. Isto é, se cada elemento da nova amostra Bootstrap é $X^{\prime}{ }_{i j}$, então a amostra Bootstrap ajustada tem como ij-ésimo elemento $\overline{X_{1}}+\left(X^{\prime}{ }_{i j}-\overline{X_{1}}\right) \sqrt{\frac{\hat{V}_{i}}{\hat{V}_{B i}}}$. Deste modo, a média de $X_{i j}$ independe de $i$ mas a variância depende.

f) O teste de interesse que compara as médias amostrais é realizado com base na nova amostra Bootstrap ajustada, e o nível descritivo $p_{1}$ é determinado.

g) Os passos c) a f) são repetidos $\mathrm{N}$ vezes, com $\mathrm{N}$ grande, para gerar uma distribuição Bootstrap de p-valores, $p_{1}, p_{2}, \ldots, p_{N}$.

h) A proporção $p_{B k}$ de resultados significantes ( $\mathrm{p}$-valores menores ou iguais a $\alpha$ ) dos $\mathrm{N}$ testes é determinado. Se esse valor é significantemente diferente de $\alpha$ ao nível $5 \%$, isto é, está fora do intervalo $\alpha \pm 1,96 \sqrt{\frac{\alpha(1-\alpha)}{N}}$, há evidências de que o teste não atinge o nível de significância $\alpha$ especificado. Nesse caso, executase o passo i) .

i) Os $N$ p-valores obtidos no passo g) são ordenados dos menores para os maiores e o maior valor $p_{c}$ que é excedido por pelo menos uma fração $(1-\alpha)$ desses p- 
valores é determinado. Se $p_{c}$ é próximo de $\alpha$, há indicação de que o teste considerado tem o tamanho correto. Valores de $p_{c}$ muito menores do que $\alpha$ sugerem que o teste fornece mais resultados significantes do que o desejável. Por outro lado, se $p_{c}$ é muito maior do que $\alpha$, supõe-se que o teste dá poucos resultados significantes. A calibração do teste para o conjunto de dados original consiste em considerar um resultado significante se $p_{0}$ é menor ou igual a $p_{c}$.

A última etapa do passo i) consiste na calibração proposta; compara-se $p_{0}$ com $p_{c}$ ao invés de comparar com $\alpha$.

Finalizando, os autores comentam que a utilização de uma única amostra para gerar as subamostras do procedimento Bootstrap pode parecer pouco razoável. No entanto, nos estudos realizados, verificou-se que o uso de apenas uma amostra fornece uma melhor representação da distribuição original para os dados.

\subsection{Teste de Igualdade de Variâncias (Teste de Levene) Aleatorizado com Calibração Bootstrap}

O procedimento de calibração para o teste de igualdade de variâncias é o mesmo que para o teste de igualdade de médias, exceto que os passos d) e e) são omitidos, e o teste no passo f) é realizado sobre as amostras Bootstrap geradas no passo c). Por outro lado, se o objetivo é calibrar um teste de igualdade de variâncias, que é sensível a diferenças de médias, outras modificações são necessárias.

\subsection{Estudo de Simulação}

Considerando os três problemas potenciais apresentados na Seção 4.1, Manly e Francis (2002) propuseram um esquema de teste em dois estágios, conforme descrevemos nas seções anteriores. Inicialmente, realiza-se um teste aleatório exato para determinar se há evidência de desigualdade das distribuições que estão sendo comparadas. Este teste garante o tamanho correto para dados de qualquer distribuição. 
Se for obtido um resultado não significativo, o processo de teste pára e conclui-se que não há evidência de diferenças (nas médias e variâncias).

Caso seja obtido um resultado significativo, realiza-se um teste aleatorizado robusto aproximado para igualdade de médias juntamente com um procedimento Bootstrap que indicará se o teste de igualdade de médias é confiável. Um teste robusto para igualdade de variâncias também é realizado.

Há cinco possíveis resultados para o esquema proposto pelos autores (Tabela 4.1).

Tabela 4.1 - Possíveis Resultados do Esquema de Teste proposto por Manly e Francis (2002)

\begin{tabular}{cccc}
\hline $\begin{array}{c}\text { Teste para qualquer } \\
\text { diferença, } T_{0}\end{array}$ & Teste de Médias, $T_{M}$ & Teste de Variâncias, $T_{V}$ & Conclusão \\
\hline Não Significante & Desnecessário & Desnecessário & $\begin{array}{c}\text { Não há evidência de } \\
\text { diferenças de médias e } \\
\text { variâncias }\end{array}$ \\
Significante & Significante e Confiável & Significante & $\begin{array}{c}\text { Evidência para diferença } \\
\text { de médias e variâncias } \\
\text { Evidência para diferença } \\
\text { de médias mas não de } \\
\text { variâncias }\end{array}$ \\
Significante & Significante e Confiável & Não Significante & Não Significante ou Não \\
Confiável & Significante & $\begin{array}{c}\text { Evidência para diferença } \\
\text { de variâncias mas não de } \\
\text { médias }\end{array}$ \\
& Não Significante ou Não & Não Significante & $\begin{array}{c}\text { Evidência para diferença } \\
\text { de médias e/ou de } \\
\text { variâncias }\end{array}$ \\
\hline
\end{tabular}

Fonte: Manly e Francis (2002)

Esse esquema de teste foi avaliado através de simulação e apresentou boas propriedades no sentido de controlar a probabilidade de concluir que um particular tipo de diferença existe (de médias ou variâncias), quando não existe.

Para investigar as propriedade dos testes individuais e do esquema de teste cujos possíveis resultados foram apresentados na Tabela 4.1, foi realizado, pelos autores, um estudo de simulação com dados gerados de três distribuições com diferentes valores de médias e desvios padrão e duas ou quatro amostras $(\mathrm{k}=2$ e $\mathrm{k}=4)$. Para $\mathrm{k}=2$, um planejamento fatorial foi empregado, com os níveis dos fatores tais que:

A: as três distribuições eram da família Johnson de distribuições (Johnson, 1949), citado em Manly e Francis (2002), com valores de assimetria e curtose de $(0,0 ; 30,0),(0,0 ; 3,0)$ 
e $(5,2 ; 40,3)$. Tais distribuições foram denominadas 1,2 e 3 respectivamente. A distribuição 2 era normal e as outras duas, distribuições com maior assimetria ou maior curtose.

B: os tamanhos das amostras eram $(12,4),(8,8),(36,12)$ e $(24,24)$;

C: as médias populacionais associadas aos grupos, na mesma ordem dos tamanhos amostrais, eram $(0,2),(0,1),(0,0),(1,0)$ e $(2,0) ;$ e

D: os correspondentes desvios padrão populacionais, eram $(1,0 ; 0,2),(1,0 ; 0,4),(1,0$; $1,0),(1,0 ; 2,5)$ e $(1,0 ; 5,0)$.

Para cada das uma das $3 \times 4 \times 5 \times 5=300$ combinações das condições especificadas em A, B, C e D, 100 conjuntos de dados independentes foram gerados. O teste global e os individuais foram aplicados para cada conjunto. Foram usadas 99 aleatorizações, para os testes aleatorizados. Para determinar a confiabilidade do teste de igualdade de médias foram utilizadas 500 reamostras via procedimento Bootstrap. Todos os testes de hipóteses tinham nível de significância de 5\%.

Para o experimento com quatro amostras, as distribuições de probabilidades eram as mesmas do estudo com duas amostras, mas os itens B , C e D foram alterados para:

B: os tamanhos das amostras eram $(8,6,4,2),(5,5,5,5),(24,18,12,6),(15,15,15,15)$;

$\mathrm{C}$ : as médias populacionais eram $(0,0 ; 1,0 ; 2,0 ; 3,0),(0,0 ; 0,5 ; 1,0 ; 1,5),(0,0 ; 0,0 ; 0,0$; $0,0),(1,5 ; 1,0 ; 0,0 ; 0,0)$ e $(3,0 ; 2,0 ; 1,0 ; 0,0)$ e

D: os desvios padrão eram $(1,0 ; 0,6 ; 0,3 ; 0,2),(1,0 ; 0,8 ; 0,6 ; 0,5),(1,0 ; 1,0 ; 1,0 ; 1,0)$, $(1,0 ; 1,3 ; 1,6 ; 2,0)$ e $(1,0 ; 1,8 ; 3,0 ; 5,4)$.

Essas condições são similares às usadas por Francis e Manly (2001). Neste trabalho, os autores consideravam cinco distribuições do tipo Johnson, das quais três foram repetidas aqui, justamente aquelas em que os testes apresentaram melhor desempenho.

Feita a simulação, os autores verificaram que o tamanho do teste é bem controlado para $T_{0}$ e para $T_{M}$ ( teste de igualdade de médias) quando não há diferenças de variâncias. Para $\alpha$ fixado em 0,05 e sob igualdade de médias, a porcentagem de resultados significantes na realização de 100 testes variou entre 0 e $10 \%$ em $95 \%$ do estudo. 
Quando há somente diferenças de médias seria razoável esperar que sempre o teste $T_{M}$ fosse mais poderoso do que o teste $T_{0}$. No entanto, com bastante freqüência $T_{0}$ apresentou mais resultados significantes do que $T_{M}$ e para $\mathrm{k}=4$ mostrou-se em geral mais poderoso para a $1^{\mathrm{a}}$. e $3^{\mathrm{a}}$. distribuição analisada.

$\mathrm{Na}$ existência de diferenças somente entre variâncias, seria esperado que $T_{0}$ fornecesse resultados mais significantes do que $T_{M}$, para o qual foi fixado um nível de $5 \%$. De fato, $T_{0}$ apresentou mais resultados significantes, neste caso, mas nota-se que há uma quantidade muito maior de resultados significantes com relação a $T_{M}$ quando utiliza-se duas amostras e a distribuição 3. Isso mostra como $T_{M}$ é pouco confiável sob a distribuição 3.

Quando não há diferenças de médias e variâncias, o tamanho de $T_{V}$ (Teste de igualdade de variâncias) é razoavelmente bem controlado. Houve um caso em que $T_{V}$ foi significante $14 \%$ das vezes com $\mathrm{k}=4$ na distribuição 3 , mas isso parece ser uma rara anomalia.

Havendo somente diferenças de médias, $T_{0}$ apresentou mais resultados significantes do que $T_{V}$, com $T_{V}$ apresentando uma variação de $1 \%$ a $9 \%$ de resultados significantes na maioria das vezes. Quando há somente diferenças de variâncias, $T_{0}$ sempre forneceu mais resultados significantes do que $T_{V}$. O mesmo ocorreu quando houve diferenças de médias e variâncias.

Desta forma, o teste $T_{0}$ mostrou-se tão eficiente quanto o teste $T_{M}$ para detectar diferenças de médias e melhor do que o teste $T_{V}$ para detectar desigualdades de variâncias. Por outro lado, é razoável usar o teste $T_{0}$ como procedimento inicial para decidir se igualdade de médias e de variâncias devem ser testadas separadamente.

A Tabela 4.2 apresenta os resultados dos experimentos de simulação para avaliar o esquema de teste da Tabela 4.1: porcentagem de vezes que o esquema de teste conduz a cada um dos cinco possíveis resultados, com referência à situação verdadeira, para diferenças de média $(\mathrm{M})$ e variância $(\mathrm{V})$, distribuição amostrada e o número de amostras. Também mostra a porcentagem de vezes que são encontradas evidências para diferenças 
de médias (coluna Todas M que é a soma das porcentagens da coluna $\mathrm{M}$ e V e da coluna Somente Média) e analogamente as porcentagens para variâncias (coluna Todas V).

Tabela 4.2 - Resultados das Simulações (valores em porcentagem)

\begin{tabular}{|c|c|c|c|c|c|c|c|c|c|}
\hline \multirow{2}{*}{\multicolumn{2}{|c|}{$\begin{array}{c}\text { Diferenças } \\
\text { Verdadeiras }\end{array}$}} & \multirow[b]{3}{*}{$\begin{array}{l}\text { Distribuição } \\
\text { Amostrada }\end{array}$} & \multicolumn{7}{|c|}{ Resultados do Esquema de Teste } \\
\hline & & & \multirow[b]{2}{*}{ Nenhuma } & & & & & & \\
\hline Média & Variância & & & $\begin{array}{c}\mathrm{Me} \\
\mathrm{V}\end{array}$ & $\begin{array}{l}\text { Somente } \\
\text { Média }\end{array}$ & $\begin{array}{l}\text { Somente } \\
\text { Variância }\end{array}$ & $\begin{array}{c}\text { Alguma } \\
\text { Diferença }\end{array}$ & $\begin{array}{c}\text { Todas } \\
\text { M }\end{array}$ & $\begin{array}{c}\text { Todas } \\
\mathrm{V}\end{array}$ \\
\hline & & & \multicolumn{7}{|c|}{ Simulações com Duas Amostras } \\
\hline \multirow[t]{3}{*}{ Não } & Não & 1 & 95,5 & 0,0 & 0,8 & 2,3 & 1,5 & 0,8 & 2,3 \\
\hline & & 2 & 96,5 & 0,3 & 1,0 & 1,3 & 1,0 & 1,3 & 1,5 \\
\hline & & 3 & 94,0 & 0,0 & 0,0 & 4,0 & 2,0 & 0,0 & 4,0 \\
\hline \multirow[t]{3}{*}{ Sim } & Não & 1 & 26,1 & 0,8 & 47,0 & 3,6 & 22,6 & 47,8 & 4,4 \\
\hline & & 2 & 28,6 & 2,2 & 53,6 & 1,6 & 13,9 & 55,8 & 3,8 \\
\hline & & 3 & 24,2 & 0,2 & 23,6 & 4,8 & 47,3 & 23,8 & 5,0 \\
\hline \multirow[t]{3}{*}{ Não } & Sim & 1 & 39,9 & 0,4 & 0,3 & 52,9 & 6,4 & 0,7 & 53,4 \\
\hline & & 2 & 23,6 & 0,5 & 0,7 & 68,0 & 7,2 & 1,2 & 68,5 \\
\hline & & 3 & 52,8 & 0,3 & 3,8 & 23,4 & 19,8 & 4,1 & 23,6 \\
\hline \multirow[t]{4}{*}{$\operatorname{Sim}$} & $\operatorname{Sim}$ & 1 & 12,4 & 4,2 & 10,6 & 54,9 & 17,9 & 14,8 & 59,1 \\
\hline & & 2 & 10,3 & 7,0 & 7,0 & 64,7 & 11,1 & 13,9 & 71,7 \\
\hline & & 3 & 20,6 & 0,7 & 11,1 & 26,0 & 41,6 & 11,8 & 26,7 \\
\hline & & & \multicolumn{7}{|c|}{ Simulações com Quatro Amostras } \\
\hline \multirow[t]{3}{*}{ Não } & Não & 1 & 95,3 & 0,5 & 0,0 & 1,0 & 3,3 & 0,5 & 1,5 \\
\hline & & 2 & 93,0 & 0,3 & 2,3 & 1,5 & 3,0 & 2,5 & 1,8 \\
\hline & & 3 & 96,5 & 0,0 & 0,3 & 2,0 & 1,3 & 0,3 & 2,0 \\
\hline \multirow[t]{3}{*}{$\operatorname{Sim}$} & Não & 1 & 21,8 & 2,5 & 48,0 & 2,3 & 25,5 & 50,5 & 4,8 \\
\hline & & 2 & 28,1 & 2,0 & 52,4 & 2,1 & 15,5 & 54,4 & 4,1 \\
\hline & & 3 & 8,2 & 1,2 & 32,6 & 5,3 & 52,8 & 33,8 & 6,4 \\
\hline \multirow[t]{3}{*}{ Não } & Sim & 1 & 66,4 & 0,5 & 0,5 & 25,4 & 7,3 & 1,0 & 25,9 \\
\hline & & 2 & 56,8 & 1,1 & 0,8 & 33,8 & 7,6 & 1,9 & 34,9 \\
\hline & & 3 & 66,5 & 0,0 & 2,0 & 10,1 & 21,4 & 2,0 & 10,1 \\
\hline \multirow[t]{3}{*}{$\mathrm{Sim}$} & Sim & 1 & 18,4 & 9,3 & 25,4 & 21,3 & 25,5 & 34,7 & 30,7 \\
\hline & & 2 & 20,6 & 15,6 & 20,3 & 25,7 & 17,9 & 35,9 & 41,3 \\
\hline & & 3 & 13,1 & 1,5 & 23,8 & 11,3 & 50,3 & 25,3 & 12,8 \\
\hline
\end{tabular}

Fonte: Manly e Francis (2002) 
Apenas a probabilidade do erro do tipo I foi controlada pelo esquema de teste. Quando não houve diferenças de médias, evidências para tais diferenças foram obtidas $4,1 \%$ das vezes ou menos para todas as condições consideradas (ver coluna 6: Todas $M$, da tabela de resultados). Similarmente quando não houve diferenças de variâncias, evidências para tais diferenças foram obtidas $6,4 \%$ das vezes ou menos(ver coluna 7 : Todas V).

Quando havia diferença de médias mas não de variâncias, evidências para a diferença de médias foram encontradas em 50\% das análises para distribuições 1 e 2 . Para a distribuição 3, foram encontrada evidências em $24 \%$ das vezes no estudo com duas amostras (ver coluna Todas M) e em 34\% das vezes com 4 amostras (ver coluna Todas M) . Essas baixas porcentagens foram largamente compensadas por aumentos nas porcentagens de casos onde evidências para diferenças de distribuições foram detectadas sem identificação se de médias ou variâncias (coluna 5: Alguma Diferença).

Na presença de diferenças de médias e variâncias, a evidência de diferenças de médias foi obscurecida por uma maior evidência de diferenças de variâncias (porcentagens da coluna Todas M são menores do que da coluna Todas V na maioria dos casos).

Se havia desigualdade de variâncias mas não de médias, tal fato foi detectado na maioria das vezes nas distribuições 1 e 2 no caso de duas amostras e com metade dessa frequência para quatro amostras. Para a distribuição 3, houve menor poder para detectar as diferenças de variâncias e um aumento na porcentagem de vezes onde uma diferença foi detectada, mas não seria atribuída à médias ou variâncias (coluna 5). Resultados similares foram observados quando ocorreram diferenças de médias e variâncias.

Os resultados da simulação realizada por Manly e Francis (2002) sugerem que o esquema de teste proposto é robusto e conservativo. O erro do tipo I é sempre controlado mas à custa de produzir muitos casos onde existe evidência de uma diferença e não se sabe se essa diferença é em termos de médias, variâncias ou ambas. Devido à natureza conservativa do esquema, os autores não recomendam usá-lo em todos os casos em que deseja-se comparar médias e variâncias.

Ainda de acordo com os autores, a robustez e a característica conservadora do esquema é atingida em parte pelo procedimento Bootstrap usado para decidir se o teste 
$T_{M}$ é confiável, o que forneceria muitos falsos positivos com dados de distribuições para as quais o teste $T_{M}$ é realmente confiável. Por outro lado, para dados com desvios moderados da distribuição normal, seria aconselhável usar o teste $T_{M}$ e o teste $T_{V}$ separadamente, com o teste $T_{M}$ calibrado por Bootstrap $\left(T_{M C}\right)$ como uma medida de segurança extra .

Para decidir se os dados são provenientes de distribuições com moderado ou grande afastamento da distribuição normal, Francis e Manly (2001) propuseram a medida

$$
\chi=\frac{\beta_{1}+1}{\left(\beta_{2}-\beta_{1}-1\right)^{\frac{1}{2}}},
$$

onde $\sqrt{\beta_{1}}$ e $\beta_{2}$ são as medidas de assimetria e curtose, e mostraram que o desempenho de $T_{M}$ e $T_{M C}$ se reduz conforme $\chi$ aumenta. Entretanto, os autores verificaram que essa medida pode ser pobremente estimada através de amostras pequenas (o mesmo ocorrendo com a assimetria e curtose). Na impossibilidade de decidir quão extremas são as distribuições com base em pequenas amostras, sugere-se a utilização do esquema de teste proposto.

Uma suposição fundamental desse estudo (e também para quaisquer outros estudos similares) é que as populações das quais as amostras foram retiradas podem diferir apenas em suas médias e variâncias. Em particular, os autores assumiram que elas não diferiam em suas assimetrias e curtoses.

No próximo capítulo estudaremos uma aplicação em bioequivalência dos testes apresentados e discutiremos como realizar testes unilaterais para bioequivalência quando os dados são de distribuições não normais com variâncias que podem ser desiguais. 


\section{Capítulo 5}

\section{Aplicações em Bioequivalência}

\subsection{Introdução}

Neste capítulo apresentaremos algumas aplicações dos testes descritos no Capítulo 4 ao estudo de bioequivalência.

Um teste para bioequivalência sobre uma variável de interesse é às vezes usado para determinar se um local que foi afetado no passado é suficientemente similar a um outro local. Por exemplo, o teste pode ser usado para comparar a porcentagem média coberta de vegetação em uma área anteriormente usada para exploração de minas $\mathrm{e}$ depois recuperada com a média da mesma variável de uma área vizinha que nunca foi minada. O estudo da bioequivalência necessita de uma metodologia própria de testes de hipóteses. Isto porque, conforme veremos futuramente, um resultado significante em um teste de bioequivalência indica que os locais são similares, enquanto um resultado não 
significante conduz à conclusão de não haver evidência para considerar os locais similares.

Manly (2004) discute como realizar testes unilaterais para bioequivalência quando os dados são de distribuições não normais, com variâncias que podem ser desiguais. Para ilustrar os métodos propostos, o autor usa exemplos que envolvem a medida dos níveis de arsênio em uma região de munição de um campo do exército e a vegetação que cobre um local minado recuperado.

Segundo o autor, um problema comum na ciência ambiental é a comparação entre um local sob controle e um local "tratado" que pode estar danificado, para decidir se os dois são similares em termos da distribuição de alguma medida de saúde ambiental. Nessa área, o uso de um teste de significância padrão tem dois problemas. Primeiro, é absurdo supor que o local tratado e o sob controle terão exatamente a mesma média para a variável em estudo, mesmo na ausência de qualquer dano no local tratado. Neste caso, tomadas amostras grandes de cada local, haverá uma alta probabilidade de se detectar diferenças, independentemente da extensão na qual o local tratado esteja danificado. Além disso, quando o teste para uma diferença entre os dois locais não apresentar resultados significantes, isso não significará necessariamente que uma diferença importante não exista. Uma explicação alternativa seria que o tamanho da amostra não foi suficientemente grande para detectar a diferença. Essas considerações sugerem que a questão de interesse pode não ser se há uma diferença significante entre os locais, mas sim se a diferença é de importância prática. Uma forma de abordar esse tipo de problema é usando o conceito de bioequivalência .

$\mathrm{Na}$ área farmacêutica, uma nova droga pode ser bioequivalente a uma droga padrão se sua potência é, por exemplo, mais do que $80 \%$ da potência da droga padrão. Da mesma forma, um local tratado pode ser considerado bioequivalente a outro sob controle em termos da biomassa (peso total da matéria viva em uma área determinada) da vegetação se a média da biomassa por unidade de área no local tratado, $\mu_{t}$, é mais do que $80 \%$ da média no local sob controle, $\mu_{c}$. Nesse caso, a bioequivalência pode ser examinada testando a hipótese nula $H_{0}: \mu_{t} \leq 0,8 \mu_{c}$ contra a hipótese alternativa 
$H_{1}: \mu_{t}>0,8 \mu_{c}$. Um resultado significante fornece evidências de bioequivalência, já um resultado não significante sugere que o local tratado pode estar prejudicado.

Testes bilaterais de bioequivalência também são possíveis, mas o autor não os considera pois assume que a variável estudada é uma medida de saúde ambiental ( com valores altos sendo desejados) ou de danos ambientais (com baixos valores sendo desejados).

Nem todas as situações analisadas envolvem organismos biológicos, motivo pelo qual os testes deveriam ser denominados de equivalência. No entanto, o termo bioequivalência foi mantido devido às implicações biológicas dos possíveis resultados.

\subsection{A Bioequivalência na Área Farmacêutica}

Duas diferentes drogas ou formulações de uma mesma droga são chamadas bioequivalentes se elas são absorvidas pelo sangue e se tornam disponíveis no mesmo ritmo e concentração.

$\mathrm{Na}$ área farmacêutica, o teste de bioequivalência consiste em verificar se o medicamento genérico apresenta a mesma biodisponibilidade no organismo que o respectivo medicamento de referência. $\mathrm{O}$ medicamento de referência é aquele que já passou por pesquisa clínica para comprovar sua eficácia e segurança antes do registro junto ao Ministério da Saúde, através da ANVISA- Agência Nacional de Vigilância Sanitária. A biodisponibilidade relaciona-se à quantidade absorvida e à velocidade do processo de absorção do fármaco ou princípio ativo (substância existente na formulação do medicamento, responsável pelo seu efeito terapêutico). Quando dois medicamentos apresentam a mesma biodisponibilidade no organismo, sua eficácia clínica é considerada comparável. A bioequivalência, na grande maioria dos casos, assegura que o medicamento genérico é equivalente terapêutico do medicamento de referência, ou seja, que apresenta a mesma eficácia clínica e a mesma segurança em relação ao medicamento de referência.

Conforme Del Pino (1993), a bioequivalência é usualmente estudada através da administração de doses e medição da concentração da droga no sangue ou urina em 
vários instantes depois de sua administração. Esses dados são utilizados para verificar se as drogas são absorvidas na mesma proporção. A urina não é muito utilizada pois é menos influenciada por motivo de absorção. Dessa forma, é mais proveitoso observar respostas às concentrações da droga no sangue.

A comparação dos efeitos terapêuticos de formulações diferentes é feita determinando-se as concentrações da droga no sangue num período de tempo através da construção de curvas de concentração da droga no sangue, levando em conta que duas formulações de uma droga que produzam curvas de concentração sanguínea equivalentes devem ter efeitos terapêuticos equivalentes.

As curvas de concentração são construídas da seguinte maneira: uma dose da formulação é administrada a um indivíduo e no decorrer de um intervalo de tempo são retiradas várias amostras de sangue, onde são medidas as concentrações da droga seqüencialmente, que constituem nossa variável resposta. Essas curvas representam o comportamento da concentração da droga no sistema circulatório em função do tempo. Na curva de concentração sanguínea de cada indivíduo que participa do experimento são observadas as variáveis Cmáx, Tmáx e ASC e os efeitos terapêuticos avaliados com base nelas. São definidas como:

Cmáx - pico de concentração máxima - concentração mais elevada observada no experimento;

Tmáx - tempo do pico de concentração máxima - tempo necessário para que ocorra o pico de concentração máxima a partir do início do experimento;

ASC - área sob a curva de concentração sanguínea - representa a quantidade da droga absorvida após a administração de dose única, isto é, a quantidade da droga potencialmente ativa presente no organismo durante um determinado intervalo de tempo.

Em ensaios de bioequivalência, na comparação de duas formulações com o mesmo princípio ativo, uma é considerada padrão, e portanto com efeito conhecido, enquanto que a outra consiste de uma formulação teste (ou formulação nova). O objetivo do experimento é avaliar se a formulação nova é bioequivalente à padrão.

Do ponto de vista estatístico é necessário verificar a exigência da agência reguladora de alimentos e drogas dos Estados Unidos, Food and Drug Administration (FDA), de aceitar a bioequivalência da formulação nova $(\mathrm{N})$ com a formulação padrão 
(P), se a razão $\frac{\mu_{N}}{\mu_{P}}$, em valor absoluto difere de 1 em no máximo 0,20 (diferença máxima de importância terapêutica), de maneira que a bioequivalência é aceita se $0,80 \leq \frac{\mu_{N}}{\mu_{P}} \leq 1,20$, onde $\mu_{N}$ e $\mu_{P}$ são os valores esperados ou médios da quantidade de droga absorvida para as formulações nova e padrão respectivamente. Para a variável Cmáx, os Estados Unidos utilizam como limites superior e inferior, respectivamente 1,25 e 0,80 e a Europa usa 1,43 e $0,70=1 / 1,43$.

Matematicamente, as hipóteses de interesse são:

$$
H_{0}: \frac{\mu_{N}}{\mu_{P}} \leq \delta_{I} \text { ou } H_{0}: \frac{\mu_{N}}{\mu_{P}} \geq \delta_{S}
$$

contra

$$
H_{a}: \delta_{I} \leq \frac{\mu_{N}}{\mu_{P}} \leq \delta_{S}
$$

e o erro do tipo I consistiria em concluir que as drogas são bioequivalentes, quando na verdade não são.

Bueno (2005) apresenta uma ampla discussão sobre bioequivalência de medicamentos genéricos e similares no Brasil. Segundo a autora, o mercado farmacêutico brasileiro transformou-se radicalmente devido às Políticas de Saúde como a publicação das diretrizes sobre a Política Nacional de Medicamentos, a criação da Agência Nacional de Vigilância Sanitária, a promulgação da Lei de Medicamentos Genéricos, bem como a publicação das resoluções que estabelecem os critérios técnicos para seu registro. Através das Políticas de Saúde, foram introduzidos vários conceitos no mercado farmacêutico, entre eles, equivalência farmacêutica e terapêutica, biodisponibilidade e bioequivalência. Tais conceitos constituem as bases ciêntíficas para a implantação dos medicamentos genéricos, aliados à certificação de Boas Práticas de Fabricação e Controle, e são considerados um marco na legislação de medicamentos no Brasil.

Segundo Bueno (2005), depois de cinco anos de implantação, os medicamentos genéricos representam aproximadamente $10 \%$ do mercado farmacêutico brasileiro em unidades. A redução mínima do preço do genérico em relação ao medicamento de 
referência é de $35 \%$, observando-se um maior impacto no tratamento de doenças crônicas. A redução de preço ocorre devido ao fato do fabricante de medicamentos genéricos não necessitar investir nos estudos clínicos para comprovação da eficácia e segurança e em propaganda da marca do medicamento. A segurança e eficácia são garantidas pela comprovação da equivalência terapêutica.

De acordo com a autora, a regulamentação técnica sobre o registro de medicamentos genéricos no Brasil foi fundamentada em legislações de países com ampla experiência na implementação e utilização de medicamentos genéricos, tais como Canadá, Estados Unidos e países da Comunidade Européia. Esses países são considerados como detentores de sistemas avançados de Vigilância Sanitária, cujos mercados farmacêuticos evoluíram nos últimos anos, contemplando as inovações e as alternativas genéricas.

Conforme pesquisa realizada por Bueno (2005), o Brasil foi o primeiro país da América do Sul a implantar o registro de medicamentos genéricos tendo como prérequisitos os testes de equivalência farmacêutica e bioequivalência, e tem sido considerado como modelo para outros países da região.

\subsection{Testes para Bioequivalência de Médias sob Não Normalidade e Desigualdade de Variâncias}

Segundo Manly (2004), um problema que surge com bastante freqüência no estudo de bioequivalência é que a variável de interesse pode não ser normalmente distribuída e as variâncias podem ser diferentes nos dois grupos. Os métodos usuais para realizar o teste são de validade questionável. Para o exemplo da comparação dos níveis de arsênio, a Tabela 5.1 mostra o logaritmo das concentrações de arsênio medidas em 32 regiões de um campo do exército (o local tratado) e 6 regiões vizinhas (os locais sob controle), como parte de um estudo para avaliar se é necessário remediar o local tratado. Aqui, a suposição de que a variável é normalmente distribuída pode ser razoável, embora haja um valor muito baixo no local tratado. Observa-se que a variância amostral é mais alta no local tratado do que no controle. 
Tabela 5.1 - Logaritmo Natural das Concentrações de Arsênio (mg/Kg) .

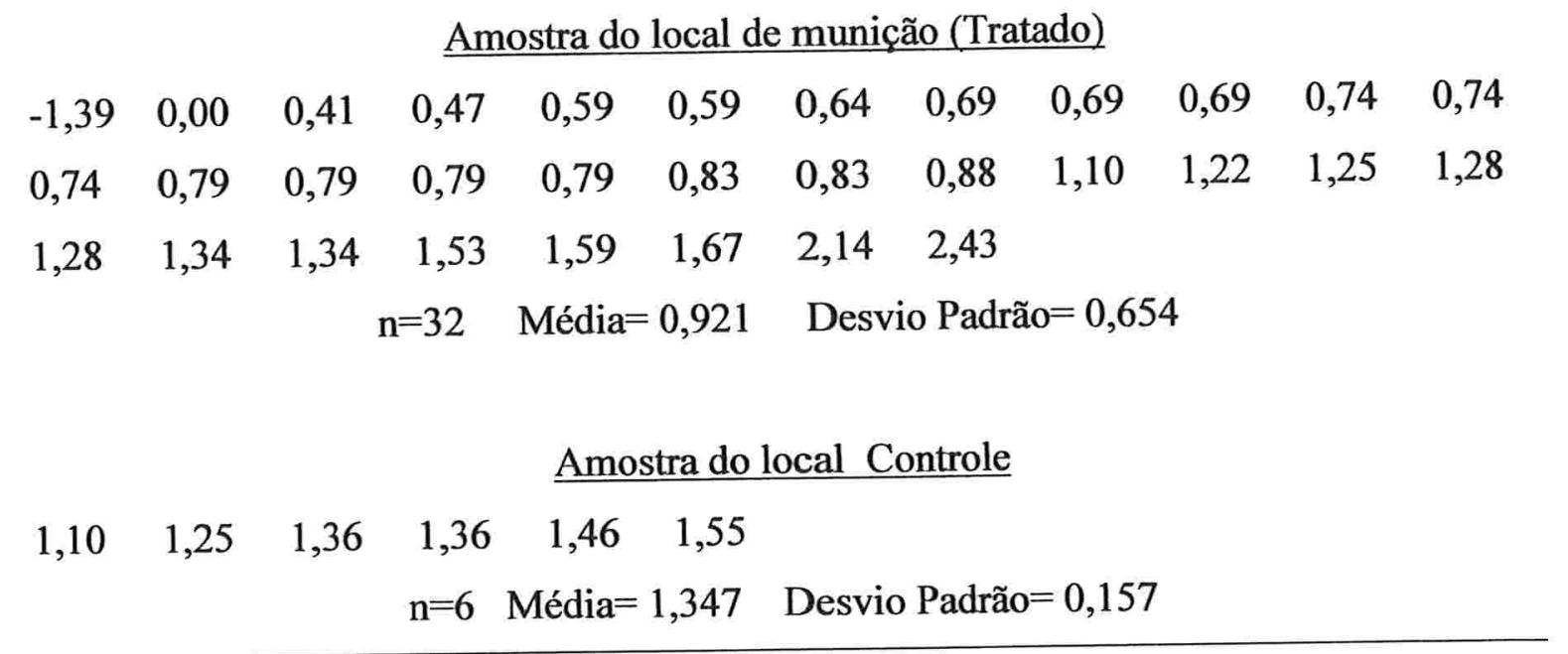

Fonte: Manly (2004)

Um questão que é levantada nesse exemplo é a de que o local tratado tem uma média mais baixa do que o local de controle, mas ao mesmo tempo tem níveis de arsênio muito mais altos. Isso sugere a possibilidade de que os dois locais sejam considerados bioequivalentes com respeito aos níveis médios, mas não em termos dos indesejáveis níveis altos de arsênio.

Como um segundo exemplo, Manly (2004) considera os dados apresentados na Tabela 5.2. Como parte da condição do programa regulatório de Wyoming, exige-se dos operadores de mina um vínculo antes de obter a licença para exploração. Quando a exploração da mina é completada, esse vínculo termina e os operadores devem demonstrar que a área minada foi recuperada de modo a se tornar similar em termos de variáveis de vegetação a uma outra área que nunca foi minada. Uma das variáveis de vegetação usadas é a produção de forragem em gramas por metro quadrado $\left(\mathrm{g} / \mathrm{m}^{2}\right)$. A Tabela 5.2 mostra os valores coletados para essa variável na mina de Wyoming em 1995. 
Tabela 5.2 - Produção de Vegetação $\left(\mathrm{g} / \mathrm{m}^{2}\right)$ medida de um local da mina de Wyoming recuperada e de uma área de controle vizinha .

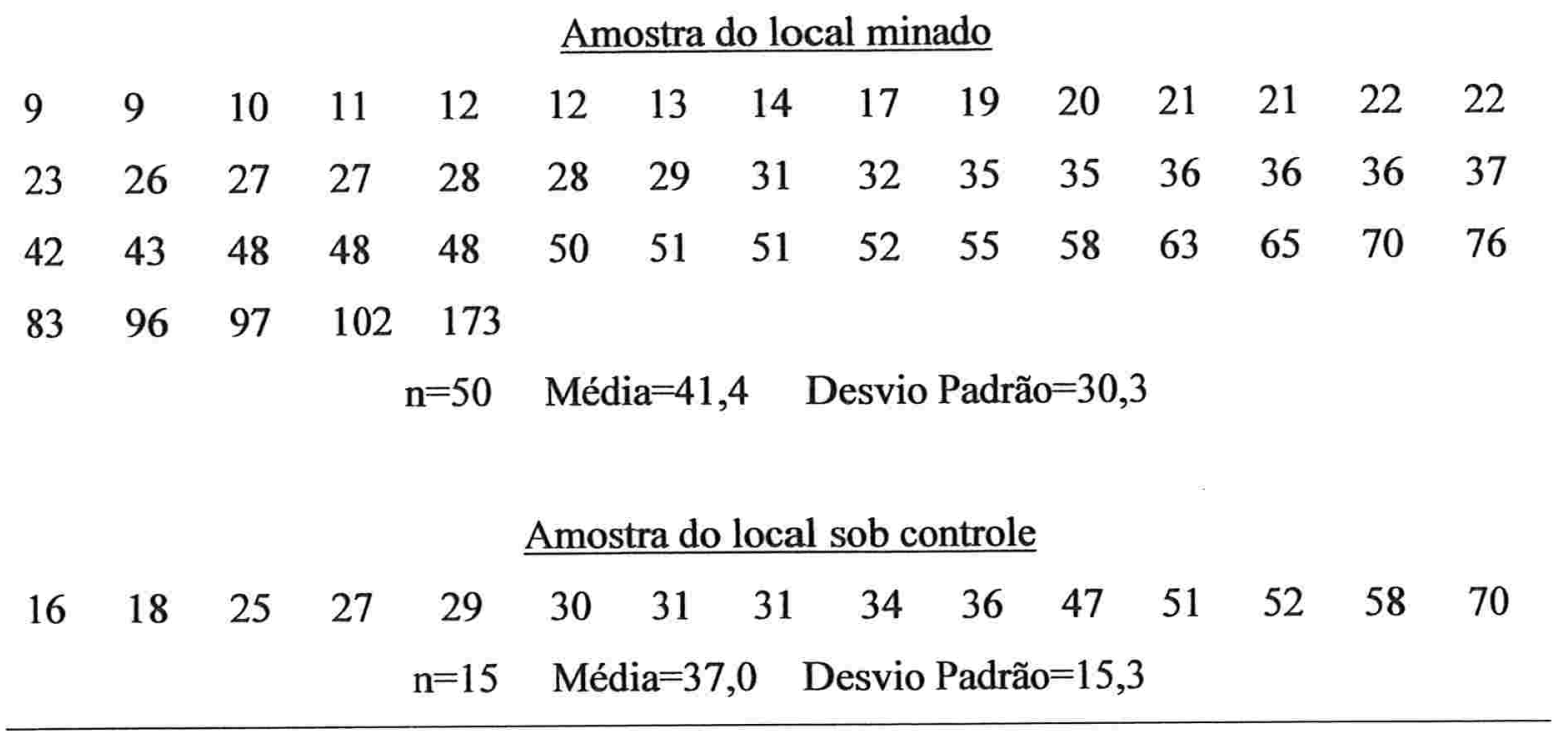

Fonte: Manly (2004)

Esse exemplo difere do anterior pois agora altos valores da variável são desejáveis. No entanto, ambos exemplos são similares no sentido de apresentarem mais valores extremos indesejáveis na amostra do local tratado do que na do local sob controle. Novamente aqui, há evidências de extremos para a produção de forragem do local minado, que também são sugestivos de não normalidade.

Exemplos como esses levantam a questão de como testar bioequivalência com amostras que podem ser provenientes de distribuições não normais e com variâncias diferentes para os locais tratado e de controle. Manly (2004) analisa essa questão, primeiro verificando se os valores médios para o local tratado e de controle são bioequivalentes e depois se as distribuições são bioequivalentes em termos dos valores indesejáveis para a variável considerada. 


\subsection{Testes para Bioequivalência de Médias}

$\mathrm{Na}$ formulação do teste de bioequivalência de médias, muitas vezes, é conveniente usar a transformação logaritmo. Por exemplo, no caso da análise da biomassa da vegetação as hipóteses são

$$
H_{0}: \mu_{t} \leq 0,8 \mu_{c}
$$

contra

$$
H_{a}: \mu_{t}>0,8 \mu_{c},
$$

sendo $H_{a}$ a hipótese de existência de bioequivalência.

Aplicando logaritmos temos

$$
H_{0}: \log \left(\mu_{t}\right) \leq \log (0,8)+\log \left(\mu_{c}\right) \text {. }
$$

Dessa forma, em termos práticos, realizar o teste para bioequivalência equivale a verificar se o logaritmo da média da variável para o local tratado é significantemente maior do que a correspondente média do local controlado mais $\log (0,8)$. Isso é equivalente a adicionar $\log (0,8)$ a todas as observações das amostras do local sob controle e testar se a média do local tratado é significantemente maior do que a média modificada do local sob controle.

Se altos valores da variável são desejáveis, a hipótese de bioequivalência do local tratado com relação ao local sob controle estipula que a média do local tratado seja significantemente maior do que a média do local sob controle menos alguma quantidade positiva $\Delta$. Freqüentemente, é usado o logaritmo, conforme discutido. Se valores baixos da variável são os de interesse, o autor sugere trocar o sinal dos valores da variável em ambas as amostras e aplicar as hipóteses já discutidas.

Segundo Manly (2004) sob normalidade e igualdade de variâncias, um teste t padrão pode ser usado para verificar se a média do local tratado é significantemente maior do que a média amostral do local sob controle depois da amostra ter sido modificada através da subtração de $\Delta$ a cada valor. A estatística do teste é então dada por 


$$
t_{1}=\frac{(\bar{y}-\bar{x})}{\left\{s \sqrt{\left(\frac{1}{m}+\frac{1}{n}\right)}\right\}}
$$

onde $\bar{y}$ é a média da amostra do local tratado, $\bar{x}$ é a média da amostra do local sob controle modificada, $\mathrm{s}$ é a estimativa combinada usual do desvio padrão de ambas as amostras, $\mathrm{m}$ é o tamanho da amostra do local tratado e $\mathrm{n}$ é o tamanho da amostra do local sob controle. Se $t_{1}$ é maior que o quantil de ordem $1-\alpha$ da distribuição $t$ de Student com $m+n-2$ graus de liberdade, então existe evidência para bioequivalência, ao nível de significância $\alpha$.

Sob normalidade, mas se as variâncias são desiguais, uma possibilidade é usar o teste t modificado, por exemplo, o teste de Welch apresentado no Capítulo 3. Esse teste tem como estatística, para esse exemplo de comparar a média do local tratado com a do local sob controle, $t_{2}$ dada por:

$$
t_{2}=\frac{(\bar{y}-\bar{x})}{\sqrt{\left(\frac{s_{y}^{2}}{m}+\frac{s_{x}^{2}}{n}\right)}}
$$

onde $s_{y}$ e $s_{x}$ são os desvios padrão usuais da amostra para os locais tratado e sob controle, respectivamente. São obtidas evidências para bioequivalência se $t_{2}$ é maior que o quantil de ordem $1-\alpha$ da distribuição $t$ de Student com $v=\frac{\left(w_{y}+w_{x}\right)^{2}}{\left\{\frac{w_{y}{ }^{2}}{m-1}+\frac{w_{x}{ }^{2}}{n-1}\right\}}$ graus de liberdade, onde $w_{y}=\frac{s_{y}{ }^{2}}{m} \mathrm{e} w_{x}=\frac{s_{x}{ }^{2}}{n}$ (Bussab e Morettin, 2006).

Havendo igualdade de variâncias mas não normalidade, um teste aleatorizado é apropriado. Poderia ser feito comparando os valores observados de $d=\bar{y}-\bar{x}$ com a distribuição obtida para $d$ quando os $m+n$ valores dos dados são aleatoriamente 
realocados para a amostra do local tratado de tamanho $m$ e a amostra do local sob controle de tamanho $n$. Supondo que $d_{0}$ seja o valor observado de $d$ e $d_{i}$ é o valor de $d$ para o i-ésimo conjunto de dados aleatorizado, o $p$-valor do teste é igual à proporção de valores $d_{0}, d_{1}, \ldots, d_{N}$ que são maiores ou iguais a $d_{0}$.

Na presença de não normalidade e desigualdade de variâncias, Manly e Francis (2002) mostraram que pode não existir um teste confiável para diferença de médias. Em particular, no contexto de testes para bioequivalência de médias, pode ocorrer uma quantidade excessiva de resultados significantes sugerindo bioequivalência quando isso verdadeiramente não existe. Além disso, tal problema pode ocorrer qualquer que seja o procedimento de teste adotado. Os autores apresentaram uma solução através do esquema de teste descrito no Capítulo 4 . O procedimento inicialmente verificava se dois ou mais grupos diferiam com respeito a médias ou variâncias usando testes de aleatorização robustos . Uma posterior avaliação da confiabilidade do teste aleatorizado para diferença de médias era feita através de procedimento Bootstrap.

$\mathrm{O}$ esquema proposto consistia num teste bilateral para diferença de médias usando a estatística F da análise de variância. Manly (2004) modificou o procedimento para um teste unilateral, escolhendo como estatística de teste $t_{1}$ ou $t_{2}$, definidas anteriormente e $p$-valor baseado no número de configurações dos dados aleatorizados que é igual ou excede a estatística de teste observada.

Como um primeiro exemplo do uso desses testes, o autor considerou os dados da produção de vegetação, presentes na Tabela 5.2. O local minado era tido como recuperado se sua produção fosse maior do que $90 \%$ da produção do local sob controle. A hipótese nula para este teste é $H_{0}: \mu_{t} \leq 0,9 \mu_{c}$, ou $H_{0}: \log \left(\mu_{t}\right) \leq \log (0,9)+\log \left(\mu_{c}\right)$. Tomando os logaritmos naturais para todas as observações e adicionando $\log (0,9)=-0,105$ a cada uma das 15 medidas do grupo controle, obteve-se média amostral $\bar{x}=3,43$, com um desvio padrão amostral de $s_{x}=0,42$. Para as 50 observações do local tratado, obteve-se $\bar{y}=3,50 \mathrm{com}$ um desvio padrão amostral de $s_{y}=0,68$. 
Utilizando esses resultados, a estatística da expressão (5.1) resulta em $t_{1}=0,38$ com 63 graus de liberdade, que é não significante $(p=0,354)$. O valor obtido da estatística de Welch é $t_{2}=0,49$, com 38,6 graus de liberdade, que também é não significante $(p=0,315)$.

Aplicando-se um teste aleatorizado com 10.000 aleatorizações, a probabilidade de uma diferença de médias $\bar{y}-\bar{x}$ ser tão grande ou maior que a observada $(0,07)$ é $p=0,351$.

Finalmente o esquema de teste de Manly e Francis (2002) foi utilizado. O procedimento teve início com o teste aleatorizado conjunto para diferença entre médias e variâncias da variável de interesse nos dois locais, descrito na Seção 4.2. Devido ao intensivo cálculo envolvido com esse esquema, 2.000 aleatorizações foram usadas e obteve-se um resultado aproximadamente significante $(p=0,088)$. Embora esse teste tenha sido não significante para os padrões usuais, realizou-se o teste para diferença de médias. Cada uma das estatísticas $t_{1}$ e $t_{2}$ pode ser usada para esse propósito, mas $t_{2}$ é mais conveniente por levar em conta a aparente diferença de variâncias para os dois locais. Com 2.000 aleatorizações, $t_{2}$ não foi significante $(p=0,321)$. Portanto, para esse conjunto de dados, os quatro testes aplicados não mostraram evidência de bioequivalência.

Como um segundo exemplo, Manly (2004) considerou os dados de arsênio da Tabela 5.1. Considerou o local de munição (local testado) bioequivalente ao local sob controle se a média do local testado fosse menor que $25 \%$ a mais que a média do local sob controle. Portanto a hipótese nula para o teste de bioequivalência é $H_{0}: \mu_{t} \geq 1,25 \mu_{c}$ ou $H_{0}: \log \left(\mu_{t}\right) \geq \log (1,25)+\log \left(\mu_{c}\right)$ e a hipótese alternativa $H_{a}: \mu_{t}<1,25 \mu_{c}$ corresponderia à existência de bioequivalência.

Os dados da Tabela 5.1 já são os logaritmos naturais das concentrações de arsênio. Adicionando $\log (1,25)=0,223$ para cada uma das 6 medidas de controle resulta nas observações ajustadas, tendo uma média de $\bar{x}=1,570$ e um desvio padrão amostral de $s_{x}=0,157$. Para as 32 observações do local tratado, obteve-se $\bar{y}=0,921$ com um 
desvio padrão amostral de $s_{y}=0,654$. Como baixos níveis de arsênio são desejáveis, o interesse está em verificar se $\bar{y}-\bar{x}$ é significantemente baixo.

Através do teste $t$ usual da equação 5.1 obteve-se $t_{1}=-2,39$, que é significante ( $p=0,011)$. O teste de Welch resultou em $t_{2}=-4,90$, com 33,4 graus de liberdade, que é significantemente baixo $(p<0,001)$. Com 10.000 aleatorizações dos dados no teste aleatorizado verificou-se que o valor $\bar{y}-\bar{x}=-0,649$ é significante ao nível $p=0,006$.

Aplicando-se o esquema de teste apresentado na Seção 4.7, com 2.000 aleatorizações, o resultado se mostrou bastante significante $(p=0,005)$ para o teste aleatorizado. Numa posterior análise, baseado em 1.000 conjunto de dados Bootstrap, o autor verificou a confiabilidade do teste.

Dessa forma, os quatro testes aplicados aos dados de arsênio forneceram evidência de bioequivalência. Segundo o autor, é provável que os testes $t$ e o aleatorizado sejam afetados pela não normalidade e desigualdade de variâncias. Já, o esquema de teste de Manly e Francis (2002), que forneceu nível descritivo de 0,1\%, deve ser mais confiável que os demais.

As diferenças aparentes nas distribuições do arsênio para os dois locais sugerem que eles não são bioequivalentes com respeito a altos níveis de arsênio. Em particular, embora a média do local sob controle seja mais alta do que a média do outro local, as quatro concentrações mais altas de arsênio ocorrem no local tratado. Num caso como esse, pode ser apropriado assegurar que o local de munição é similar ao local sob controle para os valores altos indesejáveis da variável medida, ao invés de apenas comparar os valores médios. Um caminho simples para fazer isso seria se limitar à comparação somente de valores grandes. Por exemplo, pode ser razoável com os dados de arsênio excluir todos os valores menores do que a mediana para o local de munição e testar se há bioequivalência somente para os dados restantes. Evidência para bioequivalência indica que a distribuição dos valores altos é comparável para os dois locais. Por outro lado, se não há evidência para bioequivalência, pode ser devido a valores altos no local de munição.

O teste aleatorizado descrito anteriormente pode ser modificado para comparar as amostras somente com respeito às altas concentrações de arsênio. Conforme feito 
anteriormente, adiciona-se 0,223 aos logaritmos das concentrações do local sob controle. Valores acima da mediana do local de munição são removidos e as médias da variável para o local sob controle e local de munição são calculadas para os dados restantes. Finalmente, o teste aleatorizado de igualdade de médias é executado.

A mediana do local de munição é 0,79 e há 19 observações maiores ou iguais a 0,79 com uma média de 1,26. As demais observações do local de munição foram descartadas. As seis observações da amostra do local sob controle, após a adição de 0,223 , excedem 0,79 e a média dos valores transformados da amostra do local sob controle é 1,57. Dessa forma, a diferença de médias (local de munição menos local sob controle) é -0,31. Após 5.000 aleatorizações dos 25 valores de dados para as amostras com tamanhos de 19 e 6, a probabilidade de obter um valor abaixo disso é 0,066 . Conseqüentemente, a evidência para a bioequivalência dos locais em termos das altas concentrações de arsênio não é muito clara. Isso contraria a forte evidência para bioequivalência de médias, obtido com todos os dados, para os quatro testes realizados.

Segundo Manly (2004), quando se deseja valores baixos para as variáveis medidas é preciso encontrar o valor excedido por P\% das observações modificadas do local sob controle e o excedido por P\% daquelas do local tratado. As observações conservadas serão as maiores ou iguais ao mínimo desses dois valores críticos. Uma razoável escolha de $\mathrm{P}$ é 50, que assegura que há suficientes observações em ambas amostras para a realização do teste aleatorizado, a menos que um ou ambos tamanhos amostrais sejam muito pequenos. Por outro lado, se valores grandes da variável medida são desejáveis, então o mesmo procedimento pode ser aplicado com os valores críticos correspondendo ao que excede as $\mathrm{P} \%$ menores observações nas duas amostras, o maior desses dois valores determinaria que observações usar.

Para avaliar o comportamento dos testes descritos, Manly (2004) realizou um estudo de simulação.

Foram gerados dados de três distribuições, variando-se médias e variâncias e utilizando-se amostras de tamanhos 10, 20 e 40, correspondendo a tamanhos de amostra respectivamente pequeno, médio e grande. Uma das distribuições simuladas era normal e as outras duas eram assimétricas à direita e à esquerda. 
Em cada uma das situações, executava-se os testes: $t$ usual, de Welch, aleatorizado e os testes de bioequivalência de Manly e Francis usual e para baixos valores indesejáveis.

Houve similaridade nos resultados obtidos nos testes $t$ usual, aleatorizado e de Welch e por esse motivo, a comparação restringiu-se aos testes de Welch, de bioequivalência de Manly e Francis usual e para baixos valores indesejáveis.

$\mathrm{O}$ teste de Welch funcionou bem para dados normalmente distribuídos com poucos resultados significantes na ausência de bioequivalência, aproximadamente $5 \%$ de resultados significativos com bioequivalência moderada, e bom poder para detectar bioequivalência clara. No entanto, este teste funcionou pobremente para a distribuição assimétrica a esquerda, com $23,6 \%$ resultados significantes em um caso onde isso deveria ter sido $5 \%$.

O teste de Manly e Francis (2002) tem a propriedade esperada de ser muito conservativo, com menos do que $5 \%$ de resultados significantes quando há bioequivalência marginal de média e baixo poder para detectar bioequivalência clara comparado ao teste de Welch.

O teste para a bioequivalência para valores indesejáveis baixos funcionou extremamente bem para a distribuição normal em termos de apresentar resultados significantes quando havia bioequivalência e resultados não significantes na ausência dela. No entanto, esse comportamento não se repetiu para a distribuição assimétrica à esquerda com amostras de tamanhos pequenos.

Globalmente, segundo o autor, parece razoável concluir que se não há preocupação sobre normalidade, mas pode haver variâncias desiguais, o teste de Welch (1951) deve ser usado para testar bioequivalência de médias. Se há dúvidas sobre a igualdade de variâncias e normalidade então é mais seguro usar o método de Manly e Francis (2002), aceitando que poderá ter baixo poder para amostras de tamanhos pequenos.

Quando se aplicou o teste de Manly e Francis (2002) para valores indesejáveis altos ou baixos, obteve-se muitos resultados satisfatórios quando as variâncias são claramente desiguais, para dados de distribuição normal ou não normal, desde que a assimetria nas distribuições esteja na direção dos valores desejáveis da variável. Se a 
assimetria está na direção dos valores indesejáveis da variável, essa aproximação ainda é razoável. No entanto, grandes tamanhos de amostra seriam necessários. 


\section{Capítulo 6}

\section{Aplicação do Teste de Brown e Forsythe modificado a um conjunto de dados}

\subsection{Introdução}

Nesse capítulo, apresentaremos uma aplicação do Teste de Brown e Forsythe com as modificaçõe propostas por Keselman e Wilcox (1999), apresentado na Seção 3.3.2, a um conjunto de dados fornecido pelo Centro de Estatística Aplicada- CEA-USP. Os dados que utilizaremos para realizar o teste foram retirados do conjunto de dados utilizado na elaboração do Relatório de Análise Estatística sobre o projeto: "Tipos Psicológicos Associados a Variáveis Estratégicas em Empreendedores de Pequena e Micro Empresa", Elian e Santos (2003). 
Segundo este trabalho, no Brasil, as micros e pequenas empresas, que representam $98 \%$ do total, exercem um papel significante na economia brasileira. Estudos realizados mostram que essas empresas são responsáveis por 35 milhões de empregados e $20 \%$ do produto interno bruto total. Da mesma forma que 1,5 milhões de empresas do estado de São Paulo estão iniciando as suas atividades, em contrapartida, 1 milhão estão decretando falência. Uma das prováveis razões pela qual as empresas fracassam é a inexistência de um planejamento.

O estudo realizado baseou-se em questionários aplicados a 115 empreendedores de micro (0 a 9 empregados) e pequenas empresas ( 10 a 99 empregados).

Várias variáveis foram obtidas através do questionário, porém trabalharemos apenas com a variável Variação Percentual do Faturamento bruto (VALFAT): Variação Percentual do faturamento bruto no período de 2000 a 2002, considerando como base o ano de 1999 e com a variável EMPRETEC: Participou alguma vez do curso de treinamento oferecido pelo SEBRAE (Serviço Brasileiro de Apoio às micros e pequenas Empresas): Sim ou Não.

Nosso objetivo é comparar a média da variável Variação percentual do faturamento bruto das empresas que fizeram o curso de treinamento EMPRETEC (VALFAT com EMPRETEC) com a média da variável Variação percentual do faturamento bruto das empresas que não realizaram o curso de treinamento EMPRETEC (VALFAT sem EMPRETEC).

Foram calculadas as medidas descritivas para as variáveis VALFAT com EMPRETEC e VALFAT sem EMPRETEC, presentes na Tabela 6.1.

Tabela 6.1 - Medidas Descritivas para a Variação Percentual de Faturamento Bruto com EMPRETEC e Variação de Faturamento Bruto sem EMPRETEC

\begin{tabular}{lcc}
\hline & $\begin{array}{c}\text { VALFAT } \\
\text { com EMPRETEC }\end{array}$ & $\begin{array}{c}\text { VALFAT } \\
\text { sem EMPRETEC }\end{array}$ \\
\hline Média & 162,4 & 125,1 \\
Desvio Padrão & 100,4 & 70,6 \\
Mediana & 138,0 & 127,0 \\
$\mathbf{1}^{\mathbf{0}}$ Quartil & 109,0 & 72,8 \\
$\mathbf{3}^{\mathbf{0}}$ Quartil & 187,0 & 160,0 \\
Mínimo & 0 & 0 \\
Máximo & 600 & 328 \\
Tamanho da amostra & 59 & 46 \\
\hline
\end{tabular}


Observamos que 50\% dos menores valores de VALFAT com EMPRETEC estão entre 0 e 138,0 e que o máximo dessa variável é um valor muito acima dos demais. Para a variável VALFAT sem EMPRETEC 50\% dos menores valores estão entre 0 e 127,0.

Analisando a Figura 6.1, Boxplot das duas variáveis, podemos notar que ambas apresentam valores discrepantes e há evidências de assimetria nos dois grupos.

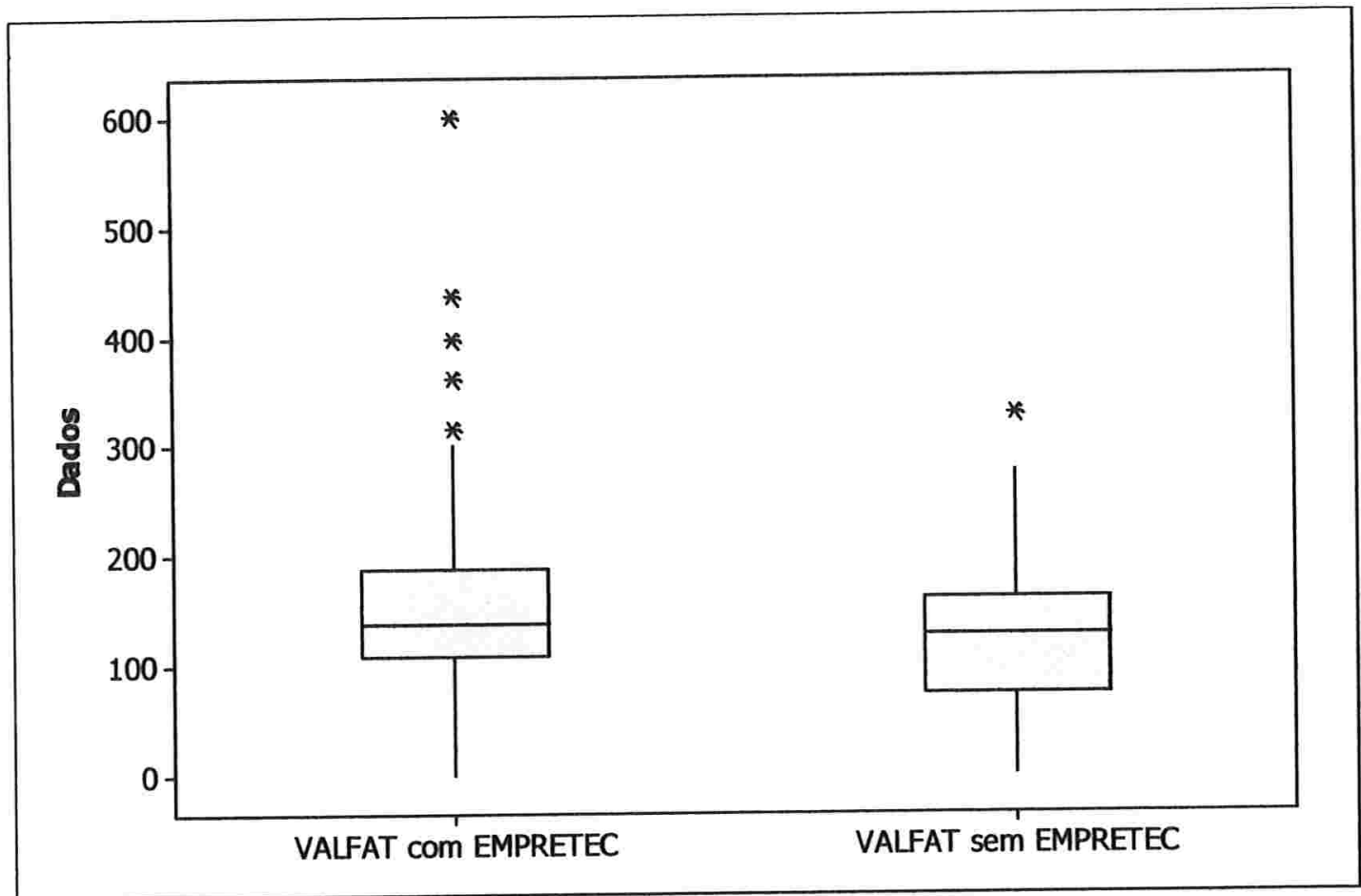

Figura 6.1 Boxplot para a Variação Percentual de Faturamento Bruto com EMPRETEC e Variação de Faturamento Bruto sem EMPRETEC

Obsevando o histograma das variávis VALFAT com EMPRETEC e VALFAT sem EMPRETEC, Figuras 6.2 e 6.3, respectivamente, notamos que os dados não são normalmente distribuídos. A partir da Tabela 6.1, observa-se uma grande diferença entre os desvios padrão nos dois grupos, sugerindo desigualdade das variâncias populacionais. 


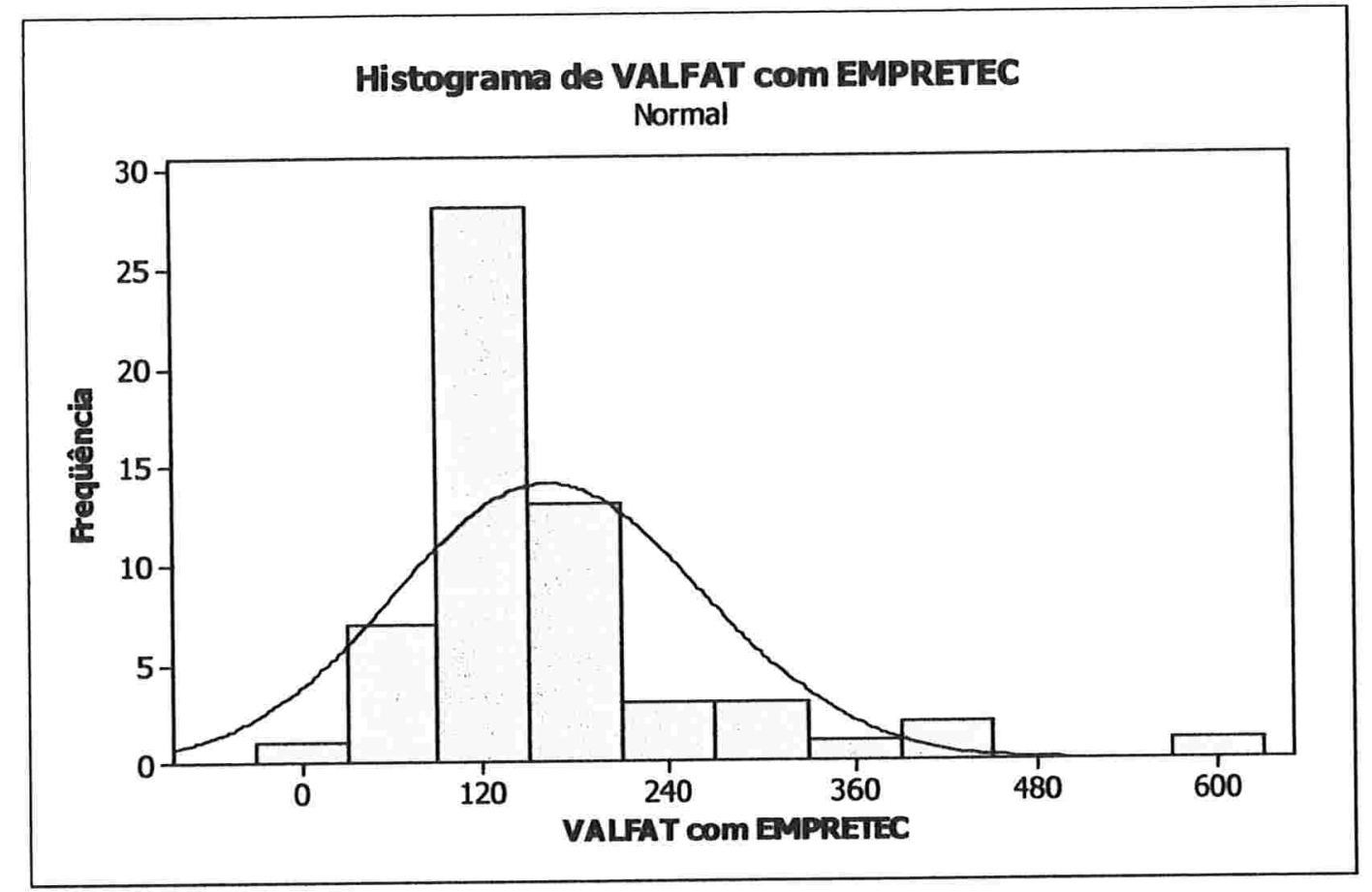

Figura 6.2 Histograma para a Variação Percentual de Faturamento Bruto com EMPRETEC

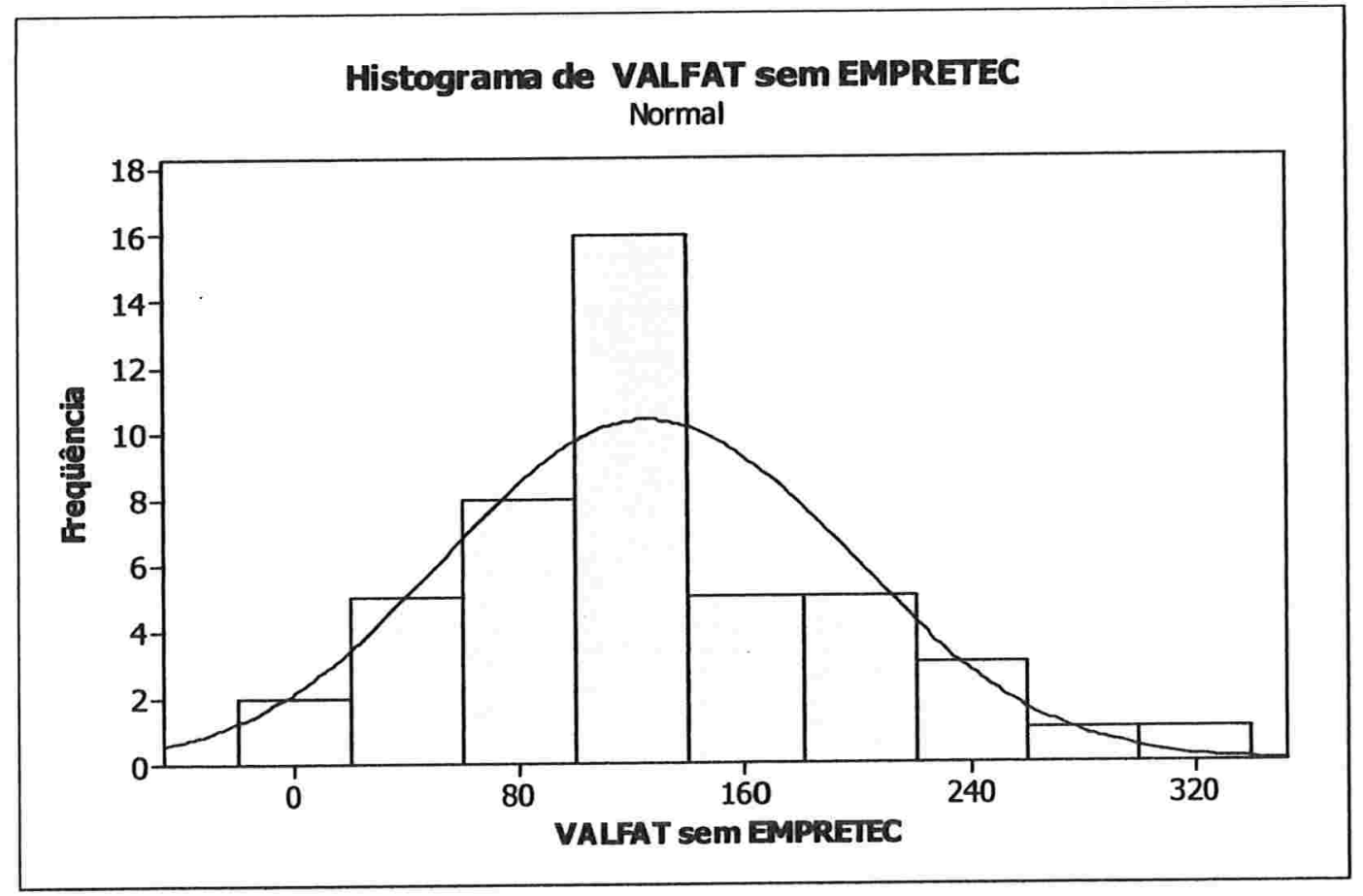

Figura 6.3 Histograma para a Variação Percentual de Faturamento Bruto sem EMPRETEC 


\subsection{Implementação do teste}

Através da forma modificada do teste de Brown e Forsythe descrita na Seção 3.3.2, desejamos testar a hipótese nula de igualdade de médias

$$
H_{0}: \mu_{1}=\mu_{2}
$$

contra a hipótese alternativa

$$
H_{a}: \mu_{1} \neq \mu_{2}
$$

onde

$\mu_{1}$ :Média da variação percentual do faturamento bruto das empresas que fazem o curso de treinamento EMPRETEC e

$\mu_{2}$ : Média da variação percentual do faturamento bruto das empresas que não fazem o curso de treinamento EMPRETEC.

Dispomos de duas amostras independentes $\left(n_{1}=59, n_{2}=46, s_{1}{ }^{2}=10.080,16 \mathrm{e}\right.$ $s_{2}{ }^{2}=4.984,36$ ) com evidências de populações não normais e variâncias desiguais.

De acordo com o teste proposto, a hipótese de igualdade de médias, $H_{0}: \mu_{1}=\mu_{2}$, é substituída pela de igualdade de médias aparadas, $H_{0}: \mu_{a 1}=\mu_{a 2}$.

Nosso objetivo é aplicar o teste de Brown e Forsythe modificado para testar as hipóteses descritas. Para isso, foi elaborado um programa no software R que se encontra no Apêndice A.

O teste foi realizado para aparos de $30 \%, 20 \%, 10 \%, 5 \%, 1 \%$ e $0 \%$. O aparo de $30 \%$ corresponde à situação em que retira-se $30 \%$ das observações de cada cauda da distribuição. Por outro lado, o aparo de $0 \%$ significa a não retirada de observações.

A estatística do teste, $F_{a}$, foi calculada e o valor crítico foi estimado através da construção de distribuições empíricas via Bootstrap, conforme descrito na Seção 3.3.2. O procedimento de reamostragem via Bootstrap foi repetido B vezes e a estatística $F_{a}$ foi calculada para cada uma das B reamostras. 
Foi calculado o nível de significância estimado $\left(p^{*}\right)$ de uma estatística de teste Bootstrap, ou seja, a proporção de vezes que a estatística calculada nas reamostras Bootstrap era maior do que a estatística do teste baseado nos dados originais, $F_{a}$.

Para aparos de $30 \%, 20 \%$ e $10 \%$ usamos $B=100,250,599$ e 1000 . Para os demais aparos utilizamos $\mathrm{B}=599$, pois não foram observadas alterações relacionadas à quantidade de reamostras nos aparos de $30 \%, 20 \%$ e $10 \%$ e Wilcox verificou que B=599 proporcionava um controle satisfatório no erro do tipo I. O valor de $p^{*}$ foi obtido e a decisão tomada (se $p^{*} \leq \alpha$, rejeitamos a hipótese nula de igualdade de médias aparadas).

A Tabela 6.2 exibe os resutados obtidos e a correspondente decisão a um nível de significância de $5 \%$.

Tabela 6.2 - Resultados obtidos na realização do teste de Brown e Forsythe modificado.

\begin{tabular}{|c|c|c|c|}
\hline & Estatística $F_{a}$ & p-valor & Decisão a $\alpha=0,05$ \\
\hline \multicolumn{4}{|l|}{ Aparos de $30 \%$} \\
\hline $\mathrm{B}=100$ & 46,0994 & 0,200 & Não rejeita $H_{0}$ \\
\hline$B=250$ & 46,0994 & 0,156 & Não rejeita $H_{0}$ \\
\hline$B=599$ & 46,0994 & 0,145 & Não rejeita $H_{0}$ \\
\hline$B=1000$ & 46,0994 & 0,165 & Não rejeita $H_{0}$ \\
\hline \multicolumn{4}{|l|}{ Aparos de $20 \%$} \\
\hline$B=100$ & 76,7002 & 0,100 & Não rejeita $H_{0}$ \\
\hline$B=250$ & 76,7002 & 0,128 & Não rejeita $H_{0}$ \\
\hline$B=599$ & 76,7002 & 0,132 & Não rejeita $H_{0}$ \\
\hline$B=1000$ & 76,7002 & 0,130 & Não rejeita $H_{0}$ \\
\hline \multicolumn{4}{|l|}{ Aparos de $10 \%$} \\
\hline $\mathrm{B}=100$ & 137,4755 & 0,070 & Não rejeita $H_{0}$ \\
\hline $\mathrm{B}=250$ & 137,4755 & 0,076 & Não rejeita $H_{0}$ \\
\hline$B=599$ & 137,4755 & 0,075 & Não rejeita $H_{0}$ \\
\hline$B=1000$ & 137,4755 & 0,071 & Não rejeita $H_{0}$ \\
\hline \multicolumn{4}{|l|}{ Aparos de 5\% } \\
\hline $\mathrm{B}=599$ & 201,4128 & 0,038 & Rejeita $H_{0}$ \\
\hline \multicolumn{4}{|l|}{ Aparos de $1 \%$} \\
\hline $\mathrm{B}=599$ & 264,4095 & 0,023 & Rejeita $H_{0}$ \\
\hline \multicolumn{4}{|l|}{ Aparos de $0 \%$} \\
\hline$B=599$ & 264,4095 & 0,025 & Rejeita $H_{0}$ \\
\hline
\end{tabular}


Observa-se que quanto maior a porcentagem de aparo, maior é o p-valor, nos levando à aceitação da hipótese nula. Para aparos de 5\% e 1\%, rejeitamos a hipótese nula de igualdade de médias aparadas. Da mesma forma, rejeitamos $H_{0}$ quando não há aparos, ou seja, a porcentagem de aparos, $\gamma$, é $0 \%$.

Esse comportamento faz sentido pois as medianas dos dois grupos são próximas, mas as médias são muito distintas, devido provavelmente à presença dos valores discrepantes observados no Boxplot da Figura 6.1. Uma alta porcentagem de aparos teria o efeito de excluir tais pontos discrepantes, tornando a média aparada próxima da mediana e levando portanto à aceitação da hipótese nula.

Com o objetivo de comparação, foram realizados os testes com as estatísticas $F^{*}$, W (Welch) e $t$.

\section{Teste utilizando a estatística $F^{*}$}

O valor da estatística $F^{*}$ depende das seguintes quantidades:

- Tamanho da primeira amostra: $n_{1}=59$;

- Tamanho da segunda amostra: $n_{2}=46$;

- Variância amostral em cada grupo: $S_{1}{ }^{2}=10.080,16$ e $S_{2}{ }^{2}=4.984,36$;

- Média amostral em cada grupo: $\bar{X}_{1 .}=162,40$ e $\bar{X}_{2 .}=125,10$;

- Média geral : $\bar{X}_{. .}=146,03$ e $n=n_{1}+n_{2}=105$.

Posteriormente obtivemos $F^{*}=4,98$ e os graus de liberdade, conforme Seção 3.2. Os valores críticos de $F^{*}$ são obtidos da tabela da distribuição $\mathrm{F}$ de Snedecor com $(k-1=2-1=1)$ e $(f=102)$ graus de liberdade no numerador e denominador respectivamente. A região crítica obtida ao nível de significância de 0,05 é $R C=\left\{F^{*}>3,92\right\}$. Como $F^{*}=4,98$ pertence à região crítica, rejeitamos a hipótese nula de igualdade de médias a um nível de significância de $5 \%$. 


\section{Teste utilizando a estatística de Welch, W}

A estatística W, apresentada na Seção 3.2, foi calculada. O valor da estatística de Welch obtido, $W=4,98$, coincidiu com o apresentado para estatística $F^{*}$. Tal fato pode ter ocorrido devido ao uso de amostras de tamanhos grandes. Como, sob $H_{0}, W$ tem distribuição F de Snedecor com 1 e 102 graus de liberdade, a região crítica do teste é a mesma apresentada para o teste de estatística $F^{*}$ e decidimos pela rejeição da hipótese nula de igualdade de médias.

\section{Teste t para duas amostras}

Realizamos 0 teste $\mathrm{t}$ usual para igualdade de médias para amostras independentes, distribuições normais, com variâncias desconhecidas e desiguais. Obtivemos a estatística $t=2,23$. Sob $H_{0}, t$ tem distribuição $t$ de Student com 102 graus de liberdade. Assim, a região crítica do teste é dada por $R C=\{t / t<-1,98$ ou $t>1,98\}$. Como $t=2,23$ pertence à região crítica, rejeitamos a hipótese nula a um nível de significância de 5\%.

\subsection{Conclusões}

Pudemos verificar que quando realizados os testes de estatísticas $F^{*}, W$ e $t$, a hipótese de igualdade de médias foi rejeitada a um nível de signifiância de $5 \%$, ou seja, conclui-se que a média populacional da variável variação percentual do faturamento bruto para empresas que fazem o curso de treinamento EMPRETEC difere da correspondente média das empresas que não fazem o curso de treinamento EMPRETEC.

Em contrapartida, o teste de Brown e Forsythe modificado, que utiliza uma estatística robusta, rejeita a hipótese nula de igualdade de médias a um nível de significância de 5\% somente para aparos iguais ou inferiores a 5\%. Já para aparos de $10 \%, 20 \%$ e $30 \%$, a decisão é pela não rejeição da hipótese nula. 


\section{Apêndice A}

\section{Programa no $\mathbf{R}$ e conjunto de dados}

O teste de Brown e Forsythe modificado foi programado utilizando o software R, versão 2.2.1 (Gentleman e Ihaka, 1997).

Os dados utilizados (RAE-CEA-03P27) encontram-se na Tabela A.1.

Tabela A.1- Conjunto de dados.

\begin{tabular}{lcccccccccc}
\hline VALFAT com & 259 & 41 & 398 & 95 & 120 & 127 & 53 & 172 & 192 & 110 \\
EMPRETEC & 151 & 176 & 0 & 437 & 165 & 127 & 144 & 600 & 136 & 130 \\
& 82 & 84 & 163 & 111 & 110 & 187 & 102 & 139 & 147 & 120 \\
& 100 & 216 & 362 & 191 & 125 & 127 & 104 & 120 & 109 & 273 \\
& 157 & 125 & 141 & 198 & 77 & 138 & 170 & 145 & 62 & 315 \\
& 152 & 206 & 97 & 85 & 129 & 300 & 140 & 245 & 92 & \\
& & & & & & & & & & \\
VALFAT sem & 180 & 138 & 0 & 166 & 110 & 276 & 40 & 133 & 42 & 60 \\
EMPRETEC & 133 & 0 & 110 & 89 & 108 & 201 & 154 & 133 & 96 & 151 \\
& 158 & 68 & 73 & 72 & 133 & 100 & 38 & 257 & 24 & 129 \\
& 70 & 85 & 184 & 203 & 27 & 125 & 100 & 137 & 148 & 225 \\
& 100 & 180 & 110 & 328 & 230 & 130 & & & & \\
\hline
\end{tabular}


O programa lê o conjunto de dados, calcula a estatística robusta $F_{a}$ e estima o valor crítico de $F_{a}$ através de distribuições empíricas via Bootstrap.

Inicialmente os dados são lidos e é indicada a proporção de observações aparadas em cada cauda da distribuição. Em seguida é criada uma função para calcular a estatística robusta $F_{a}$.

Também são definidas e calculadas várias medidas necessárias ao cálculo dessa estatística, conforme segue:

1- Determina-se o tamanho das amostras;

2- As observações são ordenadas, em cada grupo;

3- São definidas e calculadas as médias amostrais e médias aparadas para cada grupo, (no programa a porcentagem de aparos é denotada por g);

4- Calcula-se o número de observações descartadas;

5- É calculado o novo tamanho amostral (após os aparos);

6- São definidas e calculadas as médias "winzorizadas" dos grupos;

7- São definidas e calculadas as variâncias "winzorizadas" dos grupos;

8- São definidos e calculados os pesos utilizados no cálculo da estatística $F_{a}$;

9- Calcula-se o numerador de $F_{a}$, o denominador e em seguida a estatística robusta $F_{a}$;

10- São construídas as distribuições empíricas via Bootstrap;

11-A estatística $F_{a}$ é calculada para as novas B observações ;

12-Determina-se o nível de significância estimado da estatística de teste Bootstrap, que é a proporção de vezes que esta estatística é maior do que a do teste baseado nos dados originais.

13-O programa retorna o valor da estatística $F_{a}(\operatorname{print}(T))$ e o nível de significância estimado (print $(p))$.

O programa encontra-se a seguir:

$\mathrm{k}<-2$ \#\#\# Número de populações

$\mathrm{x} 1<-$

c(259,41,398,95,120,127,53,172,192,110,151,176,0,437,165,127,144,600,136,130,82, 


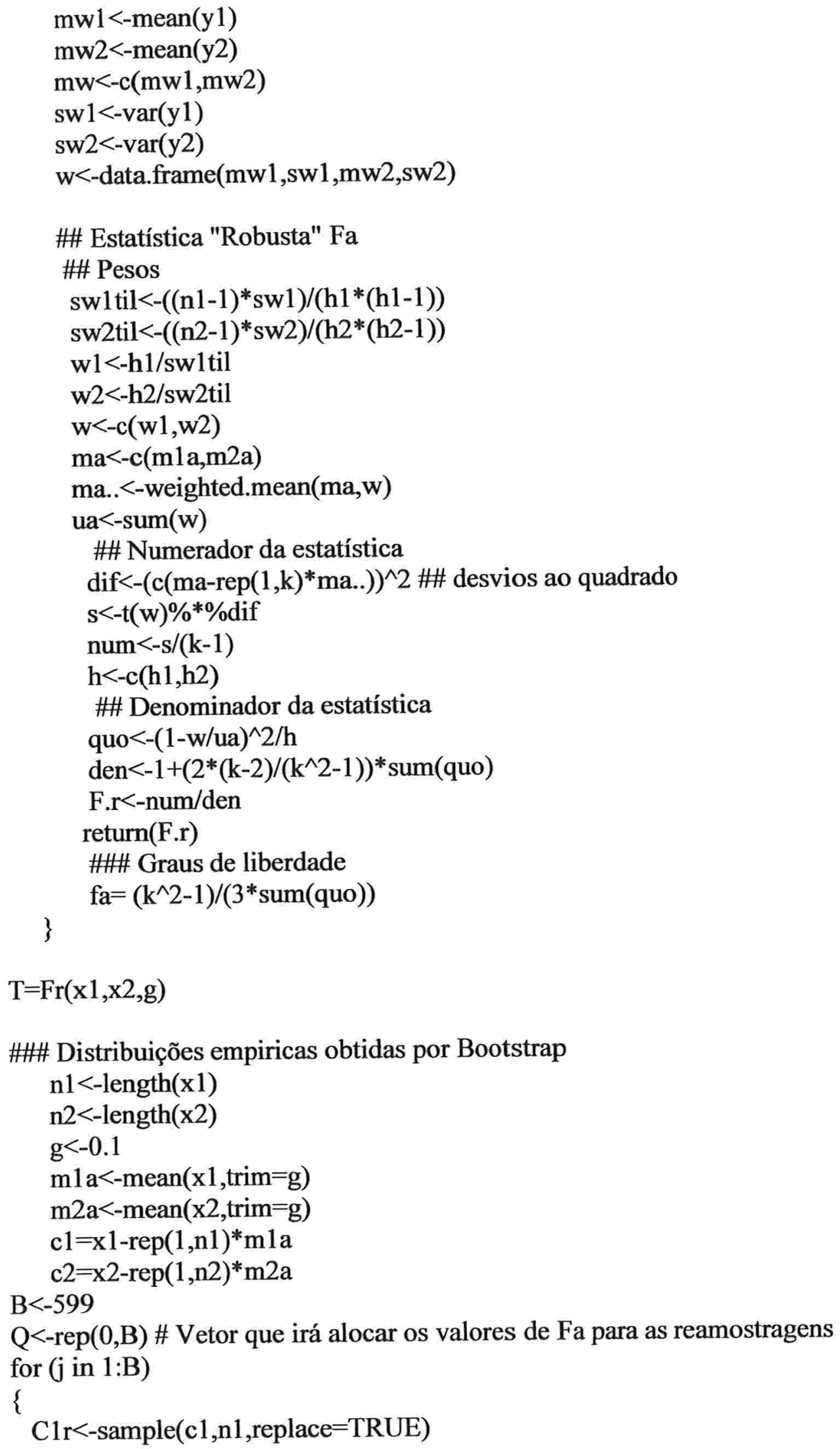

\#\#\# Distribuições empiricas obtidas por Bootstrap 
$\mathrm{C} 2 \mathrm{r}<$-sample(c2,n2,replace $=$ TRUE $)$

$\mathrm{Q}[\mathrm{j}]<-$ as.numeric $(\mathrm{Fr}(\mathrm{C} 1 \mathrm{r}, \mathrm{C} 2 \mathrm{r}, \mathrm{g}))$

\}

a<-length $(\mathrm{Q}[\mathrm{Q}>$ as.numeric $(\operatorname{Fr}(\mathrm{x} 1, \mathrm{x} 2, \mathrm{~g}))])$

$\mathrm{p}<-\mathrm{a} / \mathrm{B}$

print(p)

$\operatorname{print}(\mathrm{T})$ 


\section{Referências Bibliográficas}

Bartlett, M. S. (1937). Properties of sufficiency and statistical tests, Proc. Roy. Statist. Soc. Ser. A 160, 268-282.

Bickel, P. J. (1975). One-step Haber estimates in the linear model, J. Am. Statist. Assoc. $70,428-434$.

Box and Muller, M. E. (1958). A Note on the Generation of Normal Deviates, Annals of Mathematical Statistics, 29, No. 2, 610-11.

Box, G. E. P. (1954). Some theorems on quadratic forms applied in the study of analysis of variance problems, I. Effect of inequality of variance in the one-way classification. Annals of Mathematical Statistics, 25, 290-403.

Brown, M. B. and Forsythe, A. B. (1974a). Robust tests for the equality of variances, Journal of the American Statistical Association, 69, 364-367.

Brown, M. B. and Forsythe, A. B. (1974b). The small sample behavior of some statistics which test the equality of several means, Technometrics, 16, 129-132.

Bueno, M. M. (2005). Implantação, evolução, aspectos técnicos e perspectivas da regulamentação técnica de biodisponibilidade relativa e bioequivalência de medicamentos genéricos e similares no Brasil, Dissertação de Mestrado, FCF-USP, $193 p$.

Bussab, W. O. e Morettin, P. A. (2006). Estatística Básica, 5a. ed. São Paulo. Saraiva.

Carrol, R. J. And D. Ruppert (1982). Robust estimation in heteroscedastic linear models, Ann. Statist. 10, 429-441.

Carrol, R. J. And Schneider, H. (1985). A note on Levene's test for equality of variances, Statistics and Probability Letters, 3, 191-194.

Conover, W. J., Johnson, M. E., and Johnson, M. M.(1981). A comparative study of tests for homogeneity of variances, with applications to the outer continental shelf bidding data. Technometrics 23, 351-361.

Del Pino, L. C. H.(1993). Estudos de Bioequivalência: Abordagem clássica e Bayesiana. Dissertação de Mestrado, IME-USP, 135p. 
Draper, N. R. and Smith, H. (1998). Applied Regression Analysis, Third Edition. New York: John Wiley \& Sons. 706p.

Elian, S. N., Santos, L. D. (2003). Relatório de análise estatística sobre o projeto: "Tipos psicológicos associados a variáveis estratégicas em empreendedores de pequena e micro empresa". São Paulo, IME-USP. (RAE-CEA-03P27).

Fisher, R. A. (1920). A mathematical examination of the methods of detrmining the accuracy of an observation by the mean error, and by the mean square error, Monthly Not. Roy. Astron. Soc., 80, 758-770.

Francis, R. I. C. C. and Manly, B. F. J. (2001). Bootstrap calibration to improve the reliability of tests to compare means and variances, Environmetrics, 12, 713-729.

Gentleman, R. and Thaka, R. (1997). The R language. In L. Billard e N. Fisher (eds), Proceedings of the 28th Symposium on the Interface, The Interface Foundation of North America.

Graybill, F. A. (1976). Theory and Application of the Linear Model. Duxburry Press, Belmont, California, Wadsworth Publishing Company Inc.

Hines, W. G. S. And O'Hara Hines, R.J. (2000). Increased power with modified forms of the Levene (Med) test for heterogeneity of variance, Biometrics, 56, 451-454.

James, G. S. (1951) Tests of linear hypotheses in univariate and multivariate analysis when the ratios of the population variances are unknown. Biometrika, 38, 19-43.

Johnson, N. L. (1949) Systems of frequency curves generated by methods of translation, Biometrika, 36, 149-176.

Keselman, H. J. and Wilcox, R. R. (1999) The 'improved' Brown and Forsythe test for mean equality: some things can't be fixed, Communications in Statistics Simulation, 28, 687-698.

Keyes, T. K. and Levy, M. S. (1997) Analysis of Levene's test under design imbalance, J. Educ. And Behav. Statist., 22, 227-236.

Levene, H. (1960) Robust test for equality of variances, In Contributions to Probability and Statisticas: Essays in Honor of Harold Hotteling, I. Olkin et al., eds. Stanford University Press, Stanford, Calif., pp. 278-292. (Includes a Monte Carlo study of power functions). 
Lix, L. M. and Keselman, H. J. (1998) "To trim or not to trim: Tests of mean equality under heteroscedasticity and non normality," Educational and Psychological Measurement, 58, 409-429 (Errata-58, 853).

Manly, B. F. J. (1995) Randomization tests to compare means with unequal variation, Sankhyã, B57, 200-222.

Manly, B. F. J. (2004) One-sided tests of bioequivalence with nonnormal distributions and unequal variances, Journal of Agricultural, Biological and Environmental Statistics (in press)

Manly, B. F. J. and Francis, R. I. C. C. (2002) Testing for mean and variance differences with samples from distributions that may be non-normal with unequal variances, Journal of Statistical Computation and Simulation, 72, 633-646.

Mehrotra, D. V. (1997) Improving the Brown-Forsythe solution to the generalized Behrens-Fisher problem, Communications in Statistics - Simulation an Computation, 26(3), 1139-1145.

Miller, R. G., Jr., (1972) Appeared in "Letters to the Editor", Technometrics, 14, No. 2, 507.

O'Neill,M. E. and Ky Mathews (2000) A weighted least squares approach to Levene's test of homogeneity of variance, Austral. \& New Zealand J. Statist., 42 (1), 81-100.

Owen, D. B. (1962) Handbook of Statistical Tables, Addison-Wesley Publishing Co. Inc.

Sattherthwaite, F. E.(1941) Synthesis of variance. Psychometrika 6, 309-316.

Welch, B. L. (1951) On the comparison of several mean values: an alternative approach. Biometrika, 38, 330-336.

Wilcox, R. R. (1996) Statistics for the social sciences. New York: Academic Press. 